\title{
Student Performance in Higher Education: Ability, Class Attendance, Mobility and the Bologna Process
}

\author{
Dissertation \\ zur Erlangung des Doktorgrades \\ der Wirtschaftswissenschaftlichen Fakultät \\ der Georg-August-Universität Göttingen
}

vorgelegt von

Katharina Lerche geb. Suntheim

aus Gelnhausen

Göttingen, 2016 
Erstgutachter: Prof. Dr. Robert Schwager

Zweitgutachter: Prof. Ingo Geishecker, Ph.D.

Drittprüferin: Prof. Dr. Susan Seeber

Tag der mündlichen Prüfung: 2. November 2016 


\section{Acknowledgements}

At last, the work is done! I would like to thank my first supervisor, Robert Schwager, for his trust in my skills and my work as well as for his support and advice. I learned many things during my time as a doctoral student and am grateful for the opportunity to develop myself further, both academically and personally. In addition, I would like to thank Ingo Geishecker for being my second supervisor and Susan Seeber for being the third member of my thesis and examination committee. I gratefully acknowledge financial support from the German Federal Ministry of Education and Research under grant number 01PW11004.

I would like to thank my co-authors Kamila Danilowicz-Gösele, Anna-Lena Hoffmann, Johannes Meya, and Robert Schwager for fruitful discussions and wonderful collaboration. Furthermore, I am grateful to all former and recent members at the Chair of Public Economics for the great working environment. I would like to thank my friends and companions for a wonderful time at and around the Oeconomicum. Talks and coffee sweetened my daily work and, in particular, helped me through stressful times.

I am especially grateful to my family, first and foremost my parents, for accompanying and supporting me not only throughout my doctoral studies, but throughout my entire life. Finally, and most importantly, I want to thank my husband, Nils, for his love, support, and patience during all the years. I am grateful for having such a wonderful person at my side. 


\section{Contents}

1 Introduction 1

2 Determinants of Students' Success at University 6

2.1 Introduction . . . . . . . . . . . . . . . . . 6

2.2 Literature . . . . . . . . . . . . . . . . . . . 8

2.3 Data and Approach . . . . . . . . . . . . . . . 10

2.3.1 Variable Description and Institutional Background . . . . 11

2.3.2 Summary Statistics . . . . . . . . . . . . . . . . . . . 13

2.3.3 Empirical Setup . . . . . . . . . . . . . . . . . . 15

2.4 Results . . . . . . . . . . . . . . . . . . 16

2.4.1 University Level . . . . . . . . . . . . . . . . . 16

2.4 .2 Faculties . . . . . . . . . . . . . . . 18

2.5 Discussion and Policy Implications _ . . . . . . . . . . . 27

2.A Appendix I: Coefficients . . . . . . . . . . . . . . . . . . 30

2.B Appendix II: Data Processing . . . . . . . . . . . . . . 33

3 Class Attendance and University Performance 35

3.1 Introduction . . . . . . . . . . . . . . . . . 35

3.2 Institutional Background . . . . . . . . . . . . . . . 38

3.3 Data . . . . . . . . . . . . . . . . . . . . . . 39

3.4 Results . . . . . . . . . . . . . . . . . . 43

3.4.1 Course $1 \ldots \ldots \ldots \ldots 4 \ldots \ldots$

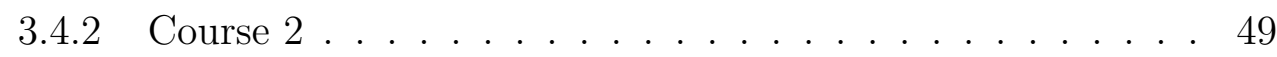

3.4 .3 Discussion ....................... 52

3.5 Conclusion . . . . . . . . . . . . . . . . . 55

3.A Appendix I: Questionnaire . . . . . . . . . . . . . . 57

3.B Appendix II: Data Processing . . . . . . . . . . . . . . . . . . 59 
4 Studying Abroad - Outsmarting the System 61

4.1 Introduction . . . . . . . . . . . . . . 61

4.2 Data Description . . . . . . . . . . . . . . . . 64

4.3 Empirical Framework . . . . . . . . . . . . . . . . 69

4.4 Results . . . . . . . . . . . . . . . . . . 73

4.5 Sensitivity to Unobserved Heterogeneity . . . . . . . . . . . 77

4.6 Conclusion . . . . . . . . . . . . . . . . . . . . . . . . 78

4.A Appendix I: Tables and Figures . . . . . . . . . . . . . . . 80

4.B Appendix II: Data Processing . . . . . . . . . . . . . . . 91

5 The Effect of the Bologna Process on the Duration of Studies 92

5.1 Introduction . . . . . . . . . . . . . . . . 92

5.2 Institutional Background . . . . . . . . . . . . . . . . 95

5.3 Data Description . . . . . . . . . . . . . . . . . . . . . . 96

5.4 Empirical Framework . . . . . . . . . . . . . . . . . . 103

5.5 Results . . . . . . . . . . . . . . . . 105

5.5 .1 Graduation . . . . . . . . . . . . . 106

5.5.2 Dropping Out of University . . . . . . . . . . . . . 108

5.5.3 Robustness Tests . . . . . . . . . . . . . . . . 113

5.6 Discussion and Conclusion . . . . . . . . . . . . . 117

5.A Appendix I: Tables . . . . . . . . . . . . . . . . . . . . . 120

5.B Appendix II: Data Processing . . . . . . . . . . . . . . . . 124

6 Conclusion $\quad 126$

$\begin{array}{lr}\text { Bibliography } & 129\end{array}$ 


\section{List of Tables}

$2.1 \quad$ Summary Statistics . . . . . . . . . . . . . . . . . 14

2.2 University Level . . . . . . . . . . . . . . . . . . . . 17

2.3 Faculties . . . . . . . . . . . . . . . . . . . . . 19

2.4 Graduation by Faculties . . . . . . . . . . . . . . . . . 21

2.5 Predicted Probabilities of Graduation by Faculties . . . . . . . . 23

2.6 Grades by Faculties . . . . . . . . . . . . . . . . . . . . . . . . 24

2.A.1 University Level - Coefficients for Table 2.2 . . . . . . . . . . 30

2.A.2 Faculties - Coefficients for Table 2.3 . . . . . . . . . . . 31

2.A.3 Graduation by Faculties - Coefficients for Table 2.4 . . . . . . . 32

$3.1 \quad$ Summary Statistics . . . . . . . . . . . . . . . . 40

3.2 Probability of Attending Course 1 . . . . . . . . . . . . 45

3.3 Course $1 \ldots \ldots$. . . . . . . . . . . . . . . . . 47

3.4 Course 1 - All Categories . . . . . . . . . . . . . . . . 48

3.5 Probability of Attending Course 2 . . . . . . . . . . . . 50

3.6 Course $2 \ldots \ldots \ldots \ldots \ldots$

3.7 Course 2 - All Categories . . . . . . . . . . . 53

$4.1 \quad$ Summary Statistics . . . . . . . . . . . . . . . . 68

4.2 Final University Grade - OLS Results . . . . . . . . . . . . . 81

4.3 Probability of Studying Abroad . . . . . . . . . . . . . 82

4.4 Final University Grade - Matching Results . . . . . . . . . . . . 83

4.5 Transferring Grades . . . . . . . . . . . . . . . . . 84

4.6 Graduating in Time - Probit Results . . . . . . . . . . . . 85

4.7 Graduating in Time - Matching Results . . . . . . . . . . . . 86

4.8 Sensitivity Analysis . . . . . . . . . . . . . . . . . . . . . 87 
4.A.1 Balancing Table for Nearest Neighbor Matching . . . . . . . . . 88

4.A.2 Determinants of Transferring Grades . . . . . . . . . . . . . . 90

5.1 Summary Statistics . . . . . . . . . . . . . . . 101

5.2 Graduation . . . . . . . . . . . . . . 107

5.3 Dropping Out of University . . . . . . . . . . . . . . 110

5.4 Reduced Sample . . . . . . . . . . . . . . . 111

5.5 New Classification Study Period . . . . . . . . . . . . . 116

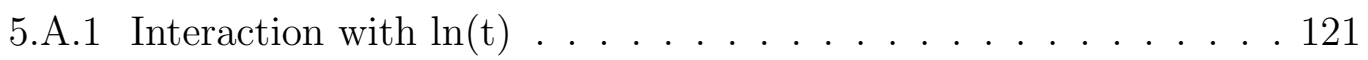

5.A.2 Cohorts $3-5 \ldots \ldots$. . . . . . . . . . . . . . . . . 122

5.A.3 New Definition Study Period . . . . . . . . . . . . . . . . . 123 


\section{List of Figures}

2.1 Grades at Selected Faculties . . . . . . . . . . . . 25

4.A.1 Distribution of the Propensity Score Before and After Matching 89

$5.1 \quad$ Kaplan-Meier Failure Functions . . . . . . . . . . . . . . . 102 


\section{List of Abbreviations}

GPA Grade point average

OLS Ordinary least squares 



\section{Chapter 1}

\section{Introduction}

In the course of the Horizon 2020 strategy, the European Commission emphasizes the crucial role of the higher education system with regard to economic growth and prosperity (European Commission, 2011). In particular, the growing share of knowledge-intensive jobs involves an increasing demand for highly skilled workers. Therefore, the European Council agreed on the Horizon 2020 headline target that, by the year 2020, 40 percent of the 30-34 year old should successfully complete tertiary education or equivalent (General Secretariat of the Council, 2010). To meet this goal, the European Commission proposes to foster participation in higher education and to reduce drop-out rates (European Commission, 2011). In this context, the commission also points out that more effort should be taken to attract students from disadvantaged and vulnerable backgrounds.

For Germany, the Authoring Group Educational Reporting underlines the importance of increasing higher education attainment to meet today's economic and societal challenges. In 2012, the share of the German population aged 30-34 years who successfully completed tertiary education was 32 percent and hence lower than the overall Horizon 2020 target. $^{1}$ In line with the European Commission, the authors point out that more people need to participate in tertiary

\footnotetext{
${ }^{1}$ The national target of 42 percent including an education level ISCED 1997 (International Standard Classification of Education) of 4 (post-secondary non-tertiary education) was met in 2012.
} 
education in order to boost graduation rates and to achieve the stipulated Horizon 2020 objective (Autorengruppe Bildungsberichterstattung, 2014).

The required educational expansion is already taking place in Germany: between 2006 and 2015 the entry rate into tertiary education rose from 35.6 to 58 percent (Statistisches Bundesamt, 2016). However, this sharp increase in participation in tertiary education may not necessarily lead to an equivalently higher share of graduates. Instead, it may pose substantial challenges especially to the universities. First of all, the higher education institutions need to provide enough space as well as scientific and administrative staff in order to ensure a high-quality learning environment. In addition, the educational expansion may lead to a more heterogeneous student population and a higher share of students who need special guidance and support (Autorengruppe Bildungsberichterstattung, 2014). This may be challenging, especially for German universities, as their traditional study concept is characterized by a high degree of individual freedom and self-determination. This still holds true today, even though university education became more structured and scholastic in the course of the Bologna process.

To some extent, the expressed challenges that arise in the course of increasing tertiary education attainment can be met by enhancing the financial situation of higher education institutions. Thereby, politics and society have to decide how much tertiary education is worth to them. Additionally, one may think about institutional reforms, for example concerning examination and study regulations, teaching concepts or student support.

In this context, politics often take it as given that supposed enhancements in the supply, such as an increase in capacity or smaller classes, automatically result in better outcomes, for example more graduates or a lower number of failed examinations. However, little attention is paid to the demand side, the students. Therefore this thesis focuses on the determinants of students' success at university. It identifies individual as well as institutional factors, for example the high school leaving grade, the faculty a student is enrolled at and the decision of attending class, and analyzes their impact on academic performance. Furthermore, it evaluates whether and how students react to organizational features and reforms, such as a study-related visit abroad or restructuring study 
programs in the course of the Bologna process.

The thesis shows that student performance at university is determined by a variety of different factors. In this context, initial ability, measured by the high school leaving grade, is the main driver of academic performance while other individual factors, such as the socio-economic background, seem to play a minor role. Besides, organizational and institutional features are shown to influence student behavior and performance.

The analyses conducted in the course of this thesis are empirical. Chapters 2, 4 and 5 use a unique dataset that contains detailed administrative student data from Göttingen University, Germany. The availability of a variety of individual and study-related variables in the data allows to take a closer look at the determinants of academic performance. Chapter 3 uses survey data that was collected in the course of my co-author's master's thesis at Göttingen University. Based on this data, additional information on student behavior is obtained.

Chapter 2 identifies individual and institutional determinants of students' success at university and evaluates their impact on academic performance. In this context, academic success is measured in three different ways: the probability of obtaining any degree at university, the probability of obtaining a degree within a chosen field of study and the grade of the final university degree. From the analysis, two main results emerge. Firstly, the high school leaving grade is by far the most important individual determinant of students' success at university. In contrast, criteria such as social origin or gender only play a minor role. Secondly, there are substantial differences between faculties implying that institutional factors also influence academic performance. To be precise, there seem to be three different types of faculties with regard to grading and graduation policies. For students enrolled at the first type of faculties, it is more difficult to obtain a degree, but those who graduate can expect rather good grades, for example at the faculty of humanities or social sciences. In contrast, the probability of graduating is higher for students in the second type of faculties whereas grades are more differentiated, such as at the faculty of economic sciences or forest sciences. For students enrolled at the last type of faculties graduation rates are low and it is also difficult to achieve good grades, for example at the faculty of mathematics. 
In Chapter 3, the attention is drawn to student behavior. It evaluates whether attending the lecture and/or tutorial in two basic courses in business administration and economics has an impact on the achieved grade. The two courses under analysis differ with regard to their content and required skills. In addition, they consist of a lecture as well as accompanying tutorials, so that differences between these types of teaching can be assessed. The analysis shows no significant impact of class attendance on student performance in most specifications. This allows the conclusion that going to class and studying on one's own may be substitutes in the given framework. Although it may not be possible to identify a causal effect with the data at hand, the results suggest that the students' educational production functions are more complex than often believed. In particular, more teaching or smaller classes may not necessarily lead to better grades.

Chapters 4 and 5 evaluate the impact of organizational features on student behavior and performance. In this context, Chapter 4 focuses on bachelor students to analyze whether a study-related visit abroad influences university outcomes measured by the final grade of the bachelor degree and the probability of graduating within the standard time period. A propensity score matching strategy is applied to overcome the potential problem of self-selection into studying abroad. The analysis shows that a sojourn improves the final university grade. However, the result seems mainly to be driven by selective transferring of grades. This occurs since most students who study abroad can decide themselves which and how many of the courses taken at the foreign institution shall count towards their degree at home. In addition, bachelor students who do a study-related visit abroad have a lower probability of graduating within the standard time period than their peers who stay at the home university. This suggests that the advantage of selectively transferring grades comes at some costs. Put into a broader perspective, the results indicate that more flexibility concerning the number of courses students are allowed to take and the decision on which of these courses they count towards the degree will lead to better grades and prolonged studies.

Afterwards, Chapter 5 is devoted to the Bologna process which imposed major changes on the German university system. It evaluates the effect of replacing traditional five-year degrees with three year bachelor programs on the duration until graduation and the timing of university drop-out. Competing risks models 
are estimated using a relative time measure that makes information on duration comparable. The analysis shows that the Bologna process reduced the duration until graduation both in absolute and relative terms, so that one of the reform's main objectives was achieved. A possible explanation of this finding is the rearrangement of examination regulations and conditions of study. The more scholastic structure of the bachelor programs helps students to find their way at university and to focus on what is relevant for their studies. However, concerning the timing of university drop-out, the results are less conclusive. Only for the faculty of humanities there is a clear favorable effect of the Bologna process on the probability of dropping out of university.

Finally, Chapter 6 sums up the thesis' main findings and concludes. In addition, it addresses the issue of policy implications and discusses potential future research perspectives. 


\section{Chapter 2}

\section{Determinants of Students' Success at University*}

\subsection{Introduction}

The number of students in higher education worldwide is constantly increasing. Today's students are more heterogeneous than ever before and possess a wide and diverse range of characteristics and abilities. They often differ in educational background, social status, skills, and academic potential, among others. As the diversity of the student population increases, factors predicting students' academic performance become a matter of concern for institutions in the educational sector (see e.g. Burton and Dowling, 2005; Simpson, 2006). For example, knowledge about factors affecting academic success is relevant for universities when selecting the most promising students. At an aggregate level, based on such knowledge, policy can decide to what extent investment in tertiary education should be directed towards those fields where large numbers of students can expect to succeed, or be concentrated in fields which rather cater to a minority of excellent students.

Our study addresses this concern by focusing on the question of whether, and if so to what extent student characteristics can be used for predicting aca-

*This chapter originates from joint work with Kamila Danilowicz-Gösele, Johannes Meya and Robert Schwager (see Danilowicz-Gösele et al., 2014). 
demic success. We find a highly significant and positive effect of the high school leaving grade on academic performance. Additionally, we narrow our view towards differences between fields of study, grouped by faculties. We find that the importance of the high school leaving grade differs strongly between fields. In some faculties graduation is less difficult to achieve, but not necessarily associated with a good final grade. However, in other faculties, graduation seems to be less likely, but among those students who graduate, the final university grade is on average better and less differentiated. This points towards diverging teaching and examination cultures among faculties. Some of them specialize in preparing a positive selection of students to science or demanding employment, whereas others provide an education which is accessible for large numbers of high school graduates with average abilities.

The probability of academic success and the reasons for dropping out of university are subject of the continuously expanding research literature in many areas, notably economics of education, psychology and sociology. These studies provide a consistent picture of previous high school performance as the most prominent predictor of university success (Baron-Boldt, 1989; Betts and Morel, 1999; Cyrenne and Chan, 2012). Furthermore, various other personal characteristics are found to affect students' academic performance, for instance gender (McNabb et al., 2002), age (Hong, 1984) or socio-economic status (Arulampalam et al., 2005). Besides, the type of high school visited is shown to influence both the probability of entering a college (Altonji et al., 2005) as well as the probability of obtaining a good degree (Smith and Naylor, 2005). At university, also the chosen field of study might matter (Achen and Courant, 2009).

Although there is a vast amount of literature on factors predicting academic success, the analysis presented in this chapter differs from previous work in this area in a number of ways. Firstly, to the best of our knowledge, this is the first study that analyzes a comprehensive administrative data set of student population, that aims to be an encompassing analysis of students' characteristics as predictors for academic success at university in Germany. In contrast to much of the earlier work, we can track students' academic careers from the admission day onward. For instance, we observe changes in fields of study. Secondly, we analyze not only one but three dimensions of academic success: graduation from 
the university, graduation within a chosen field of study and the final grade of the university degree. Thirdly, differentiating between faculties allows us to observe different examination cultures.

The remainder of the chapter is structured as follows: In Section 2.2 we present a brief overview of the related literature. In Section 2.3 we describe our dataset, explain the variables used, and lay out the empirical setup. We turn our attention to our empirical results in Section 2.4 and conclude with a discussion of the implications of these results in Section 2.5.

\section{$2.2 \quad$ Literature}

As the universities' selection process is often based on high school performance, almost all literature dealing with students' academic performance examines in the first place whether the high school Grade Point Average (GPA) is a valid predictor for university success. According to the meta-analysis of Robbins et al. (2004), the correlation between secondary school grades and university GPA is on average about 0.41. Trapmann et al. (2007) find a mean corrected validity between 0.26 and 0.53 for high school grades predicting university success by using a meta-analysis approach including studies from Austria, Czech Republic, Germany, Great Britain and Norway. In this sample, the German high school GPA has the highest validity.

However, the predictive effectiveness of secondary school grades on academic performance seems to be different for diverse groups. For instance, Dobson and Skuja (2005) show that high university entrance scores are indeed a good predictor, but not for every field of study. They find a strong correlation between the university entrance scores and students' academic performance in agriculture, engineering and science, and almost no correlation in education and health studies. This corresponds to the results of Trapmann et al. (2007) who find a high predictive power for engineering and natural sciences and a comparatively low validity for psychology.

There is also a large number of contributions showing that students with the same entry grades are often found to perform differently in tertiary education, 
which suggests the importance of other factors when predicting university success. Based on an analysis of about 300 students in a regional equity and access program of Monash University, Australia, Levy and Murray (2005) report that an appropriate coaching program can reduce the impact of discrepancy in university entrance scores. Consequently, the entrance scores themselves may not be able to capture all relevant student characteristics.

In a study by Grebennikov and Skaines (2009) at the University of Western Sydney, data relating to about 9,000 students was analyzed in order to determine a set of variables predicting students' academic performance and retention. They find that the odds of dropping out without applying to other educational institutions are significantly higher for part-time and mature students, who tend to have less time for studying and face stricter financial constraints. Furthermore, the probability of early withdrawal from university is particularly high for students from an English-speaking background and with a low grade point average.

An analysis of academic, psychological, cognitive, and demographic predictors for academic performance can be found in McKenzie and Schweitzer (2001). For this purpose, they examine a group of about 200 first year students and find significant coefficients for the university entry score (accounting for 39 percent of the variance in GPA), student institution integration (accounting for 3 percent of the variance in GPA) and self-efficacy (accounting for 8 percent of the variance in the GPA). When both the measure of integration and the measure of self-efficacy are included in the model, the prediction of GPA at university is improved by 12 percent.

Looking at a data set of the population of newly enrolled students at the University of Brussels, Arias Ortiz and Dehon (2008) examine the probability of succeeding the first year at university by accounting for individual characteristics, prior schooling and socio-economic background. According to their results, socio-economic background, especially the mother's level of education and the father's occupational activity, matters for students' academic success. In addition, they observe differences in academic performance between students coming from different high school programs.

Other factors mentioned in the literature that may help identify students 
at risk of failing include: standardized pre-university tests (Cohn et al., 2004), study skills (Robbins et al., 2004), the ability to adapt to the university environment (McInnis et al., 2000; Peat et al., 2001) or first year experience at the university (Krause et al., 2005). Further studies emphasize the importance of psychosocial variables such as goal and institutional commitment (Tinto, 1975), emotional intelligence (Parker et al., 2004), relationship with the faculty (Girves and Wemmerus, 1988) and social support (Gerdes and Mallinckrodt, 1994).

Altogether it appears to be generally accepted that high school performance is the best predictor for university success. We confirm this result using a new and comprehensive dataset from a German university. Contrary to the mixed results about the link between high school GPA and success in specific fields, we find that such a link is present in all faculties, albeit in different forms. Specifically, by distinguishing between several measures of success, we are able to describe in detail how this relationship varies across fields. Finally, again contrasting with some of the results cited, our data does not support the view that social origin or income have strong additional impact on university success once high school grades are taken into account.

\subsection{Data and Approach}

In our analysis we use an extensive administrative dataset from Göttingen University, Germany, which encompasses detailed, anonymized information on more than 12,000 students. One part of the data is collected when students enroll at university and contains information about the student's high school leaving certificate, her parental address, gender and type of health insurance. The other part includes information about the student's university career, such as the field of study, the reason for her leaving university, whether she obtained a degree and if so, which one.

In addition, we use data on the purchasing power of the German zip-code areas which is provided by GfK, a market research firm. ${ }^{2}$ The index is based on data provided by the German tax offices as well as other relevant statistics, for

\footnotetext{
${ }^{2} G f K$ is one of the biggest companies worldwide in the field of market research and collects information on people's lifestyle and consumption behavior.
} 
instance regarding pensions and unemployment benefits. Detailed information on data filtering and processing can be found in the appendix of this chapter.

\subsubsection{Variable Description and Institutional Background}

We use the following three measures of university success: the probability of finishing studies with a degree, the probability of finishing a chosen field of study with a degree and the grade of the final university degree. For the first two measures, it is necessary to distinguish between students who drop out of university and those who change institution. For this reason, we exclude students who mention that they leave Göttingen University in order to continue studying at another university from the sample.

As one is generally considered to be a successful student if one holds some degree after finishing university, we first examine a binary variable which describes whether the student graduates at all from university. The variable is equal to one for all students who finish their studies with any kind of degree at Göttingen University, and zero otherwise.

However, since in Germany students have to decide on their field of study as soon as they register for university, it is not uncommon that more than one subject is chosen or that the major is changed within the first few years. Therefore, we narrow down the definition of university success by using an additional outcome variable, labeled 'graduation within faculty', measuring success in each program the student enrolled in. This implies that when a student changes her field of study or enrolls in more than one degree program, several observations are generated. Thereby, success or failure are registered individually for every observation dependent on whether the student obtained a degree in this specific field of study or not. For example, for a student who changed her subject of study once during her university career and completed only the second study subject, the dataset will contain two observations. For the first observation, the variable describing success equals zero, and for the second, it is one. However, as study programs within the same faculty are typically quite similar with respect to their content or required abilities, a change of subject is only seen as a failure if it also implies a change of the faculty. 
The third outcome variable is the grade of the university degree. As some students are enrolled in more than one study program or complete two consecutive degree programs, we create individual observations for every final university degree obtained. Furthermore, we transform grades into the U.S. grading scale in order to make results internationally comparable and easier to interpret. In Germany, the grading schedule traditionally ranges from 1.0 to 5.0, with 1.0 being the best grade to achieve and 4.0 the worst grade that is still a pass. This implies that the better the performance, the lower the grade. The outcome variable university GPA, which we use in our analysis, is a transformation of the actual grade achieved. It ranges from 1.0 to 4.0 with 4.0 being the best grade to obtain and 1.0 the worst that is still a pass. ${ }^{3}$

The central exogenous variable used in the analysis is the high school GPA, a transformation of the grade of the high school leaving certificate. Similar to the grade of the university degree, it is converted to the U.S. grading scale with 4.0 being the best and 1.0 the worst passing grade.

The students' socio-economic background is captured by two variables: the type of health insurance and the purchasing power of the parents' zip-code area.

Due to a particular institutional feature of the German health insurance system, the type of health insurance can be used as a proxy for the students' educational and socio-economic background. In order to choose a private instead of the generally compulsory public health insurance, one has to earn more than a certain amount of income (2013: 52,200 Euro gross income per year), be selfemployed or work as civil servant. As most students are insured through their parents, the type of health insurance a student holds contains information about whether her parents satisfy at least one of the above criteria. Specifically, a large group of civil servants are teachers, and many self-employed and high earners hold a university degree. Overall, in 2008, 56.7 percent of the people being privately insured held a degree enabling registration at a university or a university of applied science, 38.0 percent had completed university or university of applied science with a degree or a Ph.D. (Finkenstädt and Keßler, 2012). Within the

\footnotetext{
${ }^{3}$ We transformed the grades into the U.S. grading scale by subtracting the final university grade from five. For legal studies the special grade "vollbefriedigend" is treated as a 2.5.
} 
total German population, these shares were much lower, amounting to 24.4 and 13.0 percent respectively (Statistisches Bundesamt, 2009).

The second socio-economic variable we use is an index of the purchasing power within the zip-code area of the student's home address evaluated in the year 2007. The index, provided by GfK, is measured relative to the German average, and normalized to 100. For example, an index value of 110 means that the purchasing power of this area is 10 percent higher than the German average. Since German zip-code areas are fairly small, with the biggest cities like Hamburg or Berlin encompassing up to 191 different zip-codes, and assuming a certain degree of residential sorting according to income, we are confident that this local measure approximates the students' economic background reasonably well.

As additional covariates we include indicator variables for male students, the sixteen German states and the university's thirteen faculties.

To get a more diversified picture of the determinants of university success, we also divide the data into sub-samples by faculty. At Göttingen University the various fields of study are assigned to thirteen faculties: theology, law, medicine, humanities, mathematics, physics, chemistry, geology/geography, biology, forestry, agriculture, economic sciences, and social sciences. A detailed analysis of individual faculties seems worthwhile since they may differ with regard to scientific approach, organizational structure and general conditions of studying.

\subsubsection{Summary Statistics}

The final dataset contains 12,315 students out of which 48 percent obtained a degree at Göttingen University. The remaining 52 percent left Göttingen University without completing a degree. Taking into account that students might be enrolled in more than one degree program or change fields of study during their university career increases the number of observations to 16,931. For 49 percent of these observations the respective field of study is completed with a degree (Table 2.1).

When taking a look at those students who graduated, we see that a final grade is registered for 8,204 observations. This implies that around one third of 
Table 2.1: Summary Statistics

\begin{tabular}{lccccc}
\hline \hline & & & & & \\
Variable & $\mathrm{N}$ & Mean & Std. Dev. & Min & Max \\
\hline High school GPA & 12315 & 2.50 & 0.63 & 1.10 & 4.00 \\
Graduation (university) & 12315 & 0.48 & 0.50 & 0.00 & 1.00 \\
Graduation (within faculty) & 16931 & 0.49 & 0.50 & 0.00 & 1.00 \\
Final grade & 8204 & 2.97 & 0.59 & 1.00 & 4.00 \\
Male & 12315 & 0.47 & 0.50 & 0.00 & 1.00 \\
Private health insurance & 12315 & 0.22 & 0.42 & 0.00 & 1.00 \\
Purchasing power index & 12315 & 98.50 & 11.79 & 64.72 & 186.99 \\
Theology & 16931 & 0.02 & 0.13 & 0.00 & 1.00 \\
Law & 16931 & 0.07 & 0.26 & 0.00 & 1.00 \\
Medicine & 16931 & 0.09 & 0.28 & 0.00 & 1.00 \\
Humanities & 16931 & 0.20 & 0.40 & 0.00 & 1.00 \\
Mathematics & 16931 & 0.04 & 0.19 & 0.00 & 1.00 \\
Physics & 16931 & 0.03 & 0.18 & 0.00 & 1.00 \\
Chemistry & 16931 & 0.04 & 0.19 & 0.00 & 1.00 \\
Geology/Geography & 16931 & 0.03 & 0.18 & 0.00 & 1.00 \\
Biology & 16931 & 0.08 & 0.28 & 0.00 & 1.00 \\
Forest sciences & 16931 & 0.04 & 0.19 & 0.00 & 1.00 \\
Agriculture & 16931 & 0.09 & 0.29 & 0.00 & 1.00 \\
Economic sciences & 16931 & 0.16 & 0.37 & 0.00 & 1.00 \\
Social sciences & 16931 & 0.11 & 0.31 & 0.00 & 1.00 \\
\hline \hline
\end{tabular}

Grades transformed to 1-4 Scale, with 4 being the best grade and 1 being the worst grade that is still a pass.

the students who finished their studies obtained more than one university degree. The reason for this could be the introduction of the consecutive study programs which by definition leads to more than one degree for many students.

The mean university GPA is 2.97 and hence, higher than the mean high school GPA of all students in the dataset which is 2.50. Furthermore, the standard deviation of the final university grade is smaller than the standard deviation of the high school GPA. This indicates that compared to the grade of the high school leaving certificate, the distribution of the final university grade is compressed and shifted to the upper end of the grading scale. 
With regard to the other covariates, we see that 47 percent of the students are male and 22 percent hold a private health insurance. The mean purchasing power index is 98.50 , meaning that the mean purchasing power in our sample is 1.5 percent lower than the German average.

Taking a look at the distribution of students across faculties, we see that the highest share of students is studying at the faculty of humanities (20 percent). Theology, on the other hand, is the smallest faculty with a share of 2 percent.

\subsubsection{Empirical Setup}

We start by examining the broadest measure of academic success, namely, whether or not a student graduates from university at all. Afterwards, we narrow our view towards graduation within fields, considering a change of field as a failure in the abandoned subject. Finally, we focus on the final grade of the university degree. This grade is a measure of the relative success within the group of successful students completing their studies.

For each of the three outcome variables we start with the GPA achieved at high school as independent variable only and continue by adding the full set of controls. These also include indicator variables for all 16 German states excluding Lower Saxony, the state where Göttingen is located, so as to reflect potential differences between the states concerning schooling systems and grading standards. Afterwards, we allow for differing effects by faculties. The binary outcome, graduation, is analyzed using probit models. For the continuous outcome variable, university grade, we use simple OLS models. In all the regressions we cluster standard errors by administrative district.

In order to interpret the regression results of the probit models right away, we display marginal effects for a benchmark student. ${ }^{4}$ For categorical variables the effects are calculated as discrete changes from the base category. Our benchmark student is characterized by the average high school leaving grade and income, and the mode of categorical variables. Accordingly, the student is female, holds a public health insurance and finished high school in Lower Saxony.

\footnotetext{
${ }^{4}$ The coefficients of the probit regressions can be found in Tables 2.A.1-2.A.3.b in the appendix of this chapter.
} 


\subsection{Results}

There is a strong ex ante expectation that the better the high school leaving grade is, the better the performance at university should be. High income as well as a private health insurance status are expected to have positive effects on academic success. Low family income, proxied by the purchasing power index, might inhibit academic success through channels different from performance in high school. Students from low income families might lack sufficient monetary support and thus have to earn their living expenses outside university, such as working in bars, shops or factories, and thus would have less time to study. They might be less able to buy books that are not (numerous) in the libraries or other auxiliary devices such as software packages. However, payments according to the Federal Training Assistance Act $(B A f \ddot{o} G)$ should at least partly counteract this effect by providing financial support for students from poorer families. ${ }^{5}$ We do not have a clear ex ante expectation about the influence of gender and the different faculties.

\subsubsection{University Level}

Table 2.2 shows the expected highly significant and positive effect of the high school leaving grade on academic success. A marginal improvement of this grade increases the probability of the benchmark student to graduate at all from university by about 21 percentage points per grade, and within fields by about 16 percentage points. An improvement of the high school leaving certificate by one full grade is associated with an improvement of the expected final grade by slightly below 0.4 grades.

The controls are of lesser importance: all else being equal, coming from a family that provides a student with private health insurance increases the estimated probability of the benchmark student of graduating at all or within a faculty by 5 or 4 percentage points respectively. This effect is highly significant

\footnotetext{
${ }^{5}$ These payments are based on the income of the parents and the student. They can amount to up to 670 Euro per month (2010) of which only 50 percent are to be repaid, capped at a maximum amount due of 10,000 Euro. In the winter term 2009/2010 almost 20 percent of all students in Göttingen received payments according to this act.
} 
Table 2.2: University Level

\begin{tabular}{|c|c|c|c|c|c|c|}
\hline & \multicolumn{2}{|c|}{$\begin{array}{c}\text { Graduation } \\
\text {-All Faculties- } \\
\text { Probit }\end{array}$} & \multicolumn{2}{|c|}{$\begin{array}{c}\text { Graduation } \\
\text {-Within Faculty- } \\
\text { Probit }\end{array}$} & \multicolumn{2}{|c|}{$\begin{array}{c}\text { Final Grade } \\
\text { OLS }\end{array}$} \\
\hline & $(1)$ & $(2)$ & $(3)$ & $(4)$ & $(5)$ & $(6)$ \\
\hline High school GPA & $\begin{array}{c}0.210^{* * *} \\
(28.121)\end{array}$ & $\begin{array}{c}0.210^{* * *} \\
(28.444)\end{array}$ & $\begin{array}{c}0.165^{* * *} \\
(21.810)\end{array}$ & $\begin{array}{c}0.161^{* * *} \\
(26.022)\end{array}$ & $\begin{array}{c}0.371^{* * *} \\
(0.010)\end{array}$ & $\begin{array}{c}0.386^{* * *} \\
(0.010)\end{array}$ \\
\hline Male & & $\begin{array}{l}-0.006 \\
(-0.548)\end{array}$ & & $\begin{array}{l}-0.009 \\
(-1.077)\end{array}$ & & $\begin{array}{l}-0.019 \\
(0.014)\end{array}$ \\
\hline $\begin{array}{l}\text { Private health } \\
\text { insurance }\end{array}$ & & $\begin{array}{c}0.053^{* * *} \\
(4.825)\end{array}$ & & $\begin{array}{c}0.036^{* * *} \\
(3.826)\end{array}$ & & $\begin{array}{c}0.014 \\
(0.015)\end{array}$ \\
\hline $\begin{array}{l}\text { Purchasing power } \\
\text { index }\end{array}$ & & $\begin{array}{c}0.001 \\
(0.748)\end{array}$ & & $\begin{array}{c}0.000 \\
(0.423)\end{array}$ & & $\begin{array}{c}0.001 \\
(0.001)\end{array}$ \\
\hline Constant & & & & & $\begin{array}{c}1.986^{* * *} \\
(0.027)\end{array}$ & $\begin{array}{c}1.902^{* * *} \\
(0.070)\end{array}$ \\
\hline States included & No & Yes & No & Yes & No & Yes \\
\hline Pseudo-R ${ }^{2}$ & 0.048 & 0.051 & 0.031 & 0.033 & & \\
\hline $\begin{array}{l}\text { Log Likelihood } \\
\mathrm{R}^{2}\end{array}$ & -8120 & -8093 & -11368 & -11338 & 0.155 & 0.169 \\
\hline Observations & 12315 & 12315 & 16931 & 16931 & 8204 & 8204 \\
\hline
\end{tabular}

Columns 1-4: marginal effects for benchmark student, z-statistic in parentheses; columns 5-6: coefficients, standard errors in parentheses; clustered by counties; ${ }^{*} p<0.05,{ }^{* *} p<0.01,{ }^{* * *} p<0.001$. 
but relatively small: being privately insured raises the graduation probability by as much as having a 0.25 better grade at high school. Conditional on graduating, there is no significant effect of the health insurance on the final grade.

The income variable does not show significant effects in any of the regressions presented in Table 2.2. This might indicate that financial aid, provided according to the Federal Training Assistance Act, is performing well. It could also mean that income alone is not very important for academic success if aspects such as the educational family background, as captured by the health insurance status, are accounted for. Another explanation could be that those who are negatively affected by their low family income have never even started university education in the first place.

Finally, the higher importance of the high school leaving GPA with respect to overall graduation compared to graduation within a field might indicate that being a good (high school) student does not help to find the most preferred field of study right away. Obviously, re-orientation at an early stage of the studies towards a field that fits the student's own preferences or abilities better should not be seen as severe as an overall failure to graduate. This is especially true with respect to international comparisons. For instance in the U.S. a major might be chosen only after trying several fields whereas in Germany students select their field prior to entering university.

\subsubsection{Faculties}

Some students change their field of study while being enrolled. This might reflect some change in their preferences or time needed to search for the perfect match. At the same time it might also reflect differences in the (perceived) degree of difficulty to graduate or to get a good grade. Every now and then a discussion arises in Germany about whether or not some faculties give good grades too easily. The faculties in question will usually defend themselves by pointing out the high ability of their student body (see for instance Krass and Scherf, 2012). In order to address this issue, we allow for differing effects by faculties. Firstly, we add indicator variables for the 13 faculties excluding the base category/faculty, humanities. Afterwards we present separate regressions for each of the faculties. 
Table 2.3: Faculties

\begin{tabular}{|c|c|c|}
\hline & $\begin{array}{c}\text { Graduation } \\
\text { Probit } \\
(1)\end{array}$ & $\begin{array}{c}\text { Final Grade } \\
\text { OLS } \\
(2)\end{array}$ \\
\hline High school GPA & $\begin{array}{c}0.190^{* * *} \\
(25.212)\end{array}$ & $\begin{array}{c}0.373^{* * *} \\
(0.011)\end{array}$ \\
\hline Male & $\begin{array}{l}-0.016^{*} \\
(-2.000)\end{array}$ & $\begin{array}{c}0.049^{* * *} \\
(0.012)\end{array}$ \\
\hline Private health insurance & $\begin{array}{c}0.047^{* * *} \\
(5.040)\end{array}$ & $\begin{array}{l}0.023^{*} \\
(0.011)\end{array}$ \\
\hline Purchasing power index & $\begin{array}{c}0.000 \\
(0.638)\end{array}$ & $\begin{array}{l}0.001^{*} \\
(0.001)\end{array}$ \\
\hline Theology & $\begin{array}{c}-0.073^{* *} \\
(-2.580)\end{array}$ & $\begin{array}{c}-0.648^{* * *} \\
(0.086)\end{array}$ \\
\hline Law & $\begin{array}{c}-0.004 \\
(-0.233)\end{array}$ & $\begin{array}{c}-1.164^{* * *} \\
(0.024)\end{array}$ \\
\hline Medicine & $\begin{array}{c}0.075^{* *} \\
(2.989)\end{array}$ & $\begin{array}{c}-0.267^{* * *} \\
(0.024)\end{array}$ \\
\hline Mathematics & $\begin{array}{c}-0.060^{* * *} \\
(-3.504)\end{array}$ & $\begin{array}{c}-0.123^{* * *} \\
(0.030)\end{array}$ \\
\hline Physics & $\begin{array}{c}-0.059^{* *} \\
(-2.820)\end{array}$ & $\begin{array}{c}0.020 \\
(0.029)\end{array}$ \\
\hline Chemistry & $\begin{array}{c}-0.020 \\
(-0.946)\end{array}$ & $\begin{array}{c}0.042 \\
(0.033)\end{array}$ \\
\hline Geology/Geography & $\begin{array}{c}0.103^{* * *} \\
(4.959)\end{array}$ & $\begin{array}{c}0.073^{*} \\
(0.032)\end{array}$ \\
\hline Biology & $\begin{array}{c}0.119^{* * *} \\
(7.784)\end{array}$ & $\begin{array}{c}0.063^{* * *} \\
(0.019)\end{array}$ \\
\hline Forest sciences & $\begin{array}{c}0.283^{* * *} \\
(13.612)\end{array}$ & $\begin{array}{c}-0.327^{* * *} \\
(0.027)\end{array}$ \\
\hline Agriculture & $\begin{array}{c}0.259^{* * *} \\
(15.286)\end{array}$ & $\begin{array}{c}-0.204^{* * *} \\
(0.021)\end{array}$ \\
\hline Economic sciences & $\begin{array}{c}0.185^{* * *} \\
(12.445)\end{array}$ & $\begin{array}{c}-0.414^{* * *} \\
(0.018)\end{array}$ \\
\hline Social sciences & $\begin{array}{c}0.066^{* * *} \\
(4.541)\end{array}$ & $\begin{array}{c}0.001 \\
(0.019)\end{array}$ \\
\hline Constant & & $\begin{array}{c}2.056^{* * *} \\
(0.065) \\
\end{array}$ \\
\hline States included & Yes & Yes \\
\hline $\begin{array}{l}\text { Pseudo } \mathrm{R}^{2} \\
\text { Log Likelihood } \\
\mathrm{R}^{2}\end{array}$ & $\begin{array}{c}0.062 \\
-11005\end{array}$ & 0.423 \\
\hline Observations & 16931 & 8204 \\
\hline
\end{tabular}

Column 1: marginal effects for benchmark student, z-statistics in parentheses; column 2: coefficients, standard errors in parentheses; clustered by county; ${ }^{*} p<0.05,{ }^{* *} p<0.01,{ }^{* * *} p<0.001$. 
Column (1) of Table 2.3 shows marginal effects for a probit regression, estimating the probability of graduation, for the benchmark student. Column (2) presents corresponding OLS results for the final university grade given graduation.

Many indicator variables of faculties show effects that are significant at the 0.1 percent level. For the benchmark student the predicted probability of graduating, given she started studying at the faculty of humanities, is about 39 percent; given successful graduation, her expected final grade is 3.1. A male student is almost 2 percentage points less likely to graduate within the given faculty compared to the benchmark. Ceteris paribus, if he does, he receives slightly better grades. The private health insurance status is associated with both better grades and a higher probability of graduating.

All else being equal, the predicted probability of graduating at the faculty of economic sciences is about 19 percentage points higher than at the faculty of humanities; at the faculty of mathematics it is 6 percentage points lower than at the base faculty. Given graduation, the faculty of economic sciences awards, ceteris paribus, a final grade that is more than 0.4 grades worse than the respective grade at the faculty of humanities. This difference is greater than the expected change in the degree associated with an improvement of the high school leaving certificate by one full grade. The worst grades are awarded by the faculty of law. ${ }^{6}$

Doing the same regressions separately by faculties, the picture gets more differentiated. Tables 2.4.a and 2.4.b reveal strong differences with respect to how important the high school GPA is for the probability of graduating at the different faculties of Göttingen University. The effect is not significantly different from zero at the faculty of geology and geography, and it is strongest at the medical school and the faculty of chemistry. For the benchmark student at these two faculties, a marginal increase in the GPA earned in high school is associated with an increase in the graduation probability by almost 29 percentage points per grade. At the faculty of social sciences, the effect is only about one third of that size.

\footnotetext{
${ }^{6}$ The faculty of law is traditionally known to only rarely award very good grades. Accordingly, not too much attention should be given to this fact.
} 
2.4.a Graduation by Faculties

\begin{tabular}{lccccccc}
\hline \hline & Theology & Law & Medicine & Humanities & Mathematics & Physics & Chemistry \\
\hline High school GPA & $0.180^{* * *}$ & $0.256^{* * *}$ & $0.285^{* * *}$ & $0.187^{* * *}$ & $0.279^{* * *}$ & $0.209^{* * *}$ & $0.285^{* * *}$ \\
& $(4.558)$ & $(11.171)$ & $(9.357)$ & $(12.378)$ & $(6.412)$ & $(7.185)$ & $(9.016)$ \\
Male & 0.112 & 0.007 & 0.019 & $-0.114^{* * *}$ & 0.060 & $0.110^{*}$ & 0.043 \\
& $(1.789)$ & $(0.231)$ & $(0.685)$ & $(-6.688)$ & $(1.677)$ & $(2.257)$ & $(1.004)$ \\
Private health & $0.184^{*}$ & 0.019 & $0.080^{* *}$ & $0.068^{* * *}$ & $0.131^{*}$ & -0.013 & 0.011 \\
insurance & $(2.507)$ & $(0.611)$ & $(2.923)$ & $(3.541)$ & $(2.464)$ & $(-0.310)$ & $(0.253)$ \\
Purchasing power & 0.002 & -0.000 & -0.001 & 0.002 & -0.001 & -0.000 & 0.001 \\
index & $(0.633)$ & $(-0.031)$ & $(-0.729)$ & $(1.522)$ & $(-0.575)$ & $(-0.246)$ & $(0.349)$ \\
\hline States included & Yes & Yes & Yes & Yes & Yes & Yes & Yes \\
\hline Pseudo R & 0.109 & 0.076 & 0.125 & 0.059 & 0.164 & 0.111 & 0.137 \\
Log Likelihood & -167 & -774 & -896 & -2128 & -367 & -345 & -378 \\
Observations & 284 & 1246 & 1481 & 3342 & 660 & 567 & 644 \\
\hline \hline
\end{tabular}

Marginal effects for benchmark student, z-statistics in parentheses; clustered by county; ${ }^{*} p<0.05,{ }^{* *} p<0.01$, $* * * p<0.001$

\section{4.b Graduation by Faculties}

\begin{tabular}{|c|c|c|c|c|c|c|}
\hline & Geology/Geography & Biology & Forest Sciences & Agriculture & Economic Sciences & Social Sciences \\
\hline High school GPA & $\begin{array}{c}0.069 \\
(1.875)\end{array}$ & $\begin{array}{c}0.176^{* * * *} \\
(8.304)\end{array}$ & $\begin{array}{c}0.152^{* * *} \\
(3.971)\end{array}$ & $\begin{array}{c}0.132^{* * *} \\
(5.451)\end{array}$ & $\begin{array}{c}0.159^{* * *} \\
(8.061)\end{array}$ & $\begin{array}{c}0.086^{* * *} * \\
(4.521)\end{array}$ \\
\hline Male & $\begin{array}{l}-0.127^{*} \\
(-2.151)\end{array}$ & $\begin{array}{l}-0.016 \\
(-0.587)\end{array}$ & $\begin{array}{c}0.031 \\
(0.651)\end{array}$ & $\begin{array}{c}0.049 \\
(1.471)\end{array}$ & $\begin{array}{l}-0.022 \\
(-1.071)\end{array}$ & $\begin{array}{l}-0.027 \\
(-1.225)\end{array}$ \\
\hline $\begin{array}{l}\text { Private health } \\
\text { insurance }\end{array}$ & $\begin{array}{c}0.061 \\
(1.070)\end{array}$ & $\begin{array}{c}0.037 \\
(1.113)\end{array}$ & $\begin{array}{c}0.040 \\
(1.056)\end{array}$ & $\begin{array}{l}-0.038 \\
(-1.071)\end{array}$ & $\begin{array}{c}0.064^{* *} \\
(3.110)\end{array}$ & $\begin{array}{c}0.011 \\
(0.388)\end{array}$ \\
\hline $\begin{array}{l}\text { Purchasing power } \\
\text { index }\end{array}$ & $\begin{array}{c}0.004 \\
(1.436) \\
\end{array}$ & $\begin{array}{l}-0.002 \\
(-1.826)\end{array}$ & $\begin{array}{l}-0.000 \\
(-0.029)\end{array}$ & $\begin{array}{c}-0.002 \\
(-1.390)\end{array}$ & $\begin{array}{c}0.001 \\
(0.553) \\
\end{array}$ & $\begin{array}{c}0.004^{* * *} \\
(3.340) \\
\end{array}$ \\
\hline States included & Yes & Yes & Yes & Yes & Yes & Yes \\
\hline $\begin{array}{l}\text { Pseudo } \mathrm{R}^{2} \\
\text { Log Likelihood } \\
\text { Observations }\end{array}$ & $\begin{array}{c}0.039 \\
-360 \\
542 \\
\end{array}$ & $\begin{array}{l}0.047 \\
-923 \\
1410 \\
\end{array}$ & $\begin{array}{l}0.043 \\
-425 \\
666 \\
\end{array}$ & $\begin{array}{c}0.024 \\
-1004 \\
1546 \\
\end{array}$ & $\begin{array}{c}0.032 \\
-1819 \\
2740 \\
\end{array}$ & $\begin{array}{c}0.019 \\
-1198 \\
1778 \\
\end{array}$ \\
\hline
\end{tabular}

Marginal effects for benchmark student, z-statistics in parentheses; clustered by county; ${ }^{*} p<0.05,{ }^{* *} p<0.01,{ }^{* * *} p<0.001$.

Private health insurance status, which proxies a high socio-economic background, is significant and has a positive sign for about half of the faculties, while being insignificant for the other faculties. Purchasing power is also of little importance for the probability of graduating at the faculty level. It is significant only at the faculty of social sciences.

For illustration and further comparison of faculties, Table 2.5 provides predicted probabilities of graduation based on the estimation results underlying Tables 2.4.a and 2.4.b. The predictions for the benchmark student are presented in the middle column (mean high school GPA). The remaining predictions deviate from the usual benchmark by the high school GPA used. We define low 
and high high school GPA as the mean GPA minus two standard deviations and mean GPA plus two standard deviations respectively.

Although we do not want to put too much emphasis on these predictions, they serve to illustrate the rather large differences between faculties. The predicted probability of graduation for the benchmark student is between roughly 20 and 60 percent. Based on these predictions, a student with a low high school GPA can hardly expect to graduate at some of the faculties, such as mathematics and physics. At other faculties chances to graduate are still relatively high; the predicted probabilities for such a student are 45 and 39 percent at the faculties of agriculture and economic sciences respectively. For an otherwise identical student with a high high school GPA the predictions vary between about 50 and 80 percent.

Tables 2.6.a and 2.6.b show corresponding regression results for final grades at graduation. There is a highly significant positive effect of the high school GPA at every faculty. However, the importance of this GPA differs strongly. It is highest at the faculty of mathematics, where the expected grade at graduation is more than half a grade better for every full grade of the high school leaving certificate. At the faculty of chemistry, where the coefficient of high school GPA is the smallest, the effect is only about half that size. Given graduation, male students can expect slightly better grades than their female fellow students in about half of the faculties. The effects of health insurance status and purchasing power are indistinguishable from zero at most faculties. ${ }^{7}$

Figure 2.1 visualizes the relationship between the GPA earned at university and at high school across selected faculties. The red lines represent fitted values for female students who are publicly insured, come from a zip code area with average purchasing power and finished high school in Lower Saxony. We can notice from the upper two panels of this figure that grades in humanities are generally better than in economic sciences. The lower two panels show that the

\footnotetext{
${ }^{7}$ There is a surprisingly large, highly significant, positive effect of the private health insurance status on the final grade at university at the faculty of theology. Taking this coefficient at face value, a reason for this strong effect could be that children of pastors in Germany are privately insured. However, due to the small sample size of the underlying regression, we refrain from emphasizing this finding.
} 
Table 2.5: Predicted Probabilities of Graduation by Faculties

\begin{tabular}{lccc}
\hline \hline & \multicolumn{3}{c}{ High School GPA } \\
& Low & Mean & High \\
\hline Theology & 0.10 & 0.27 & 0.53 \\
Law & 0.14 & 0.40 & 0.72 \\
Medicine & 0.19 & 0.52 & 0.83 \\
Humanities & 0.21 & 0.42 & 0.66 \\
Mathematics & 0.04 & 0.24 & 0.67 \\
Physics & 0.05 & 0.21 & 0.54 \\
Chemistry & 0.06 & 0.30 & 0.69 \\
Geology/Geography & 0.41 & 0.50 & 0.59 \\
Biology & 0.30 & 0.51 & 0.72 \\
Forest sciences & 0.38 & 0.57 & 0.75 \\
Agriculture & 0.45 & 0.62 & 0.77 \\
Economic sciences & 0.39 & 0.59 & 0.77 \\
Social sciences & 0.34 & 0.45 & 0.56 \\
\hline \hline
\end{tabular}

Predicted probability of graduating at a faculty for female students who are publicly insured, come from a zip code area with average purchasing power, and finished high school in Lower Saxony. Low and high high school GPA are defined as the mean GPA minus two standard deviations and mean GPA plus two standard deviations, respectively. 


\section{6.a Grades by Faculties}

\begin{tabular}{lccccccc}
\hline \hline & Theology & Law & Medicine & Humanities & Mathematics & Physics & Chemistry \\
\hline High school GPA & $0.434^{* *}$ & $0.428^{* * *}$ & $0.279^{* * *}$ & $0.393^{* * *}$ & $0.503^{* * *}$ & $0.291^{* * *}$ & $0.270^{* * *}$ \\
& $(0.157)$ & $(0.030)$ & $(0.044)$ & $(0.019)$ & $(0.043)$ & $(0.051)$ & $(0.052)$ \\
Male & -0.078 & $0.090^{*}$ & -0.066 & $0.080^{* *}$ & $0.150^{*}$ & $0.166^{*}$ & 0.099 \\
& $(0.208)$ & $(0.038)$ & $(0.050)$ & $(0.024)$ & $(0.068)$ & $(0.067)$ & $(0.065)$ \\
Private health & $0.536^{* * *}$ & 0.016 & 0.053 & 0.036 & 0.081 & 0.018 & -0.052 \\
insurance & $(0.146)$ & $(0.052)$ & $(0.049)$ & $(0.023)$ & $(0.062)$ & $(0.059)$ & $(0.059)$ \\
Purchasing power & $-0.019^{*}$ & 0.001 & $0.005^{* *}$ & 0.002 & 0.004 & -0.002 & -0.004 \\
index & $(0.008)$ & $(0.003)$ & $(0.002)$ & $(0.001)$ & $(0.003)$ & $(0.002)$ & $(0.003)$ \\
Constant & $3.125^{* * *}$ & $0.743^{* *}$ & $1.739^{* * *}$ & $1.971^{* * *}$ & $1.177^{* *}$ & $2.551^{* * *}$ & $2.957^{* * *}$ \\
& $(0.797)$ & $(0.278)$ & $(0.210)$ & $(0.128)$ & $(0.371)$ & $(0.287)$ & $(0.312)$ \\
\hline States included & Yes & Yes & Yes & Yes & Yes & Yes & Yes \\
\hline $\mathrm{R}^{2}$ & 0.324 & 0.234 & 0.097 & 0.277 & 0.421 & 0.184 & 0.171 \\
Observations & 86 & 502 & 776 & 1365 & 253 & 249 & 270 \\
\hline \hline
\end{tabular}

Coefficients, standard errors in parentheses; clustered by county; ${ }^{*} p<0.05,{ }^{* *} p<0.01,{ }^{* * *} p<0.001$.

\section{6.b Grades by Faculties}

\begin{tabular}{|c|c|c|c|c|c|c|}
\hline & Geology/Geography & Biology & Forest Sciences & Agriculture & Economic Sciences & Social Sciences \\
\hline High school GPA & $\begin{array}{c}0.293^{* * *} \\
(0.057)\end{array}$ & $\begin{array}{c}0.288^{* * *} \\
(0.029)\end{array}$ & $\begin{array}{c}0.352^{* * *} \\
(0.041)\end{array}$ & $\begin{array}{c}0.386^{* * *} \\
(0.024)\end{array}$ & $\begin{array}{c}0.398^{* * *} \\
(0.019)\end{array}$ & $\begin{array}{c}0.398^{* * *} * \\
(0.026)\end{array}$ \\
\hline Male & $\begin{array}{l}-0.064 \\
(0.051)\end{array}$ & $\begin{array}{l}0.113 * * * \\
(0.033)\end{array}$ & $\begin{array}{c}0.116^{* *} \\
(0.043)\end{array}$ & $\begin{array}{c}0.018 \\
(0.029)\end{array}$ & $\begin{array}{c}0.017 \\
(0.022)\end{array}$ & $\begin{array}{c}0.054 \\
(0.027)\end{array}$ \\
\hline $\begin{array}{l}\text { Private health } \\
\text { insurance }\end{array}$ & $\begin{array}{c}0.011 \\
(0.053)\end{array}$ & $\begin{array}{c}0.013 \\
(0.030)\end{array}$ & $\begin{array}{c}0.041 \\
(0.053)\end{array}$ & $\begin{array}{c}-0.087^{*} \\
(0.037)\end{array}$ & $\begin{array}{c}0.014 \\
(0.035)\end{array}$ & $\begin{array}{c}0.050 \\
(0.035)\end{array}$ \\
\hline $\begin{array}{l}\text { Purchasing power } \\
\text { index }\end{array}$ & $\begin{array}{l}-0.003 \\
(0.003)\end{array}$ & $\begin{array}{c}0.002 \\
(0.001)\end{array}$ & $\begin{array}{c}0.003 \\
(0.002)\end{array}$ & $\begin{array}{l}-0.000 \\
(0.002)\end{array}$ & $\begin{array}{l}0.001 \\
(0.001)\end{array}$ & $\begin{array}{l}0.000 \\
(0.002)\end{array}$ \\
\hline Constant & $\begin{array}{c}2.807 * * * \\
(0.335)\end{array}$ & $\begin{array}{c}2.339^{* * *} \\
(0.159)\end{array}$ & $\begin{array}{c}1.573^{* * *} \\
(0.250)\end{array}$ & $\begin{array}{c}2.030^{* * *} \\
(0.171)\end{array}$ & $\begin{array}{c}1.575^{* * *} \\
(0.129)\end{array}$ & $\begin{array}{c}2.110^{* * *} \\
(0.171)\end{array}$ \\
\hline States included & Yes & Yes & Yes & Yes & Yes & Yes \\
\hline $\begin{array}{l}\mathrm{R}^{2} \\
\text { Observations }\end{array}$ & $\begin{array}{l}0.212 \\
250\end{array}$ & $\begin{array}{l}0.158 \\
784\end{array}$ & $\begin{array}{c}0.184 \\
408\end{array}$ & $\begin{array}{l}0.232 \\
953\end{array}$ & $\begin{array}{l}0.247 \\
1534\end{array}$ & $\begin{array}{l}0.250 \\
774\end{array}$ \\
\hline
\end{tabular}

Coefficients, standard errors in parentheses; clustered by county; ${ }^{*} p<0.05,{ }^{* *} p<0.01,{ }^{* * *} p<0.001$. 
relationship between high school GPA and university grade is much steeper in mathematics than in biology.

Figure 2.1: Grades at Selected Faculties
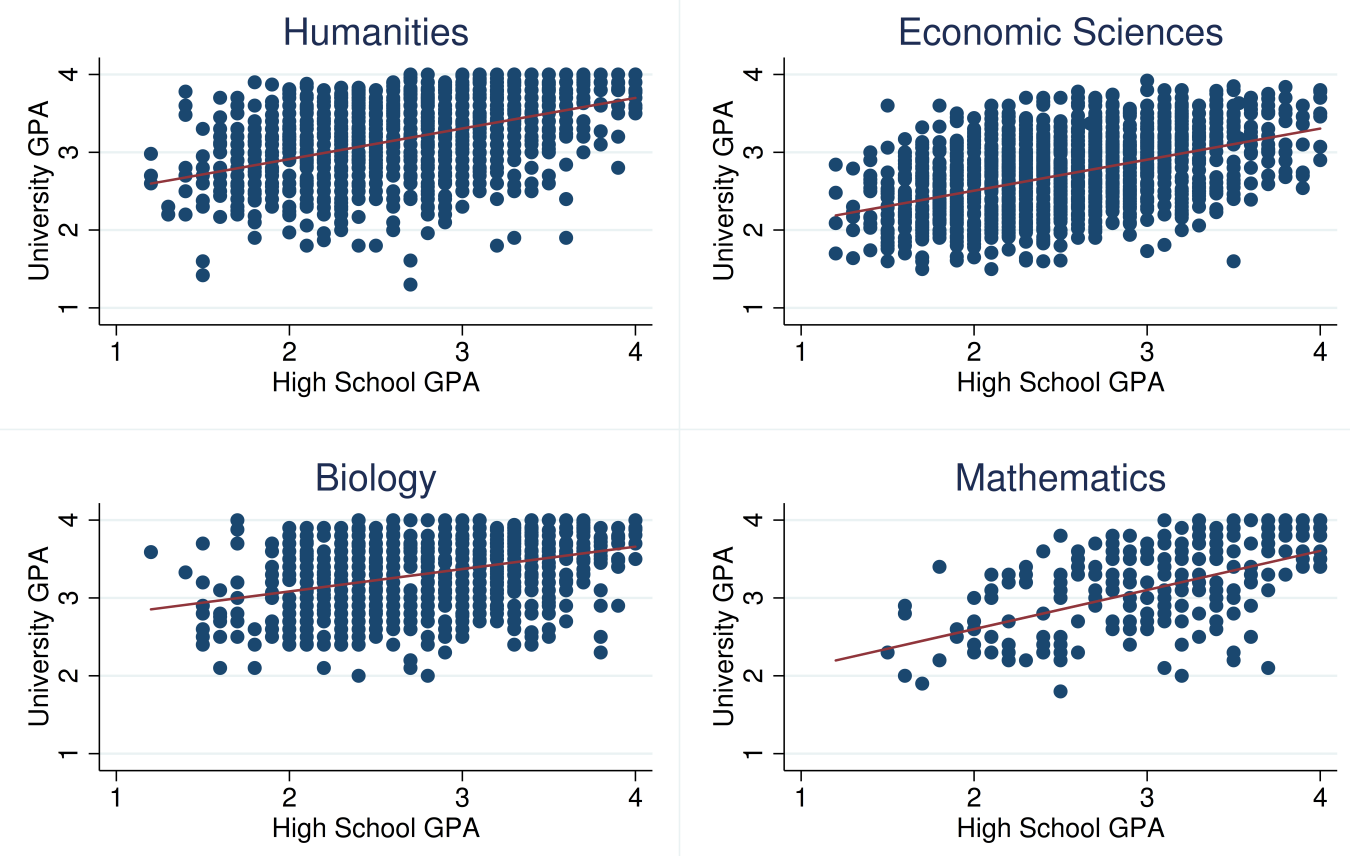

- University GPA $\quad$ fitted values

Dots represent one or several observations. Fitted values are the predicted university GPA for female students who are publicly insured, come from a zip code area with average purchasing power, and finished high school in Lower Saxony.

Comparing the faculties with the highest number of students, humanities and economic sciences, it seems to be easier to graduate in economic sciences whereas the expected grade conditional on graduation is worse. This pattern can also be found for a couple of other faculties and might suggest differences in grading and examination culture between the faculties. It seems that at some faculties it is more difficult to obtain a degree while the grades given differentiate less strongly between students. However, at others achieving a degree is more likely while the grades obtained vary more within the grading scale. 
There are a number of possible mechanisms which might contribute to these faculty-specific results. Firstly, students may self-select into faculties on unobservable characteristics related to the outcome variables. For example, some students may be more motivated to obtain good grades at university than they were in high school. If such students disproportionately choose humanities rather than mathematics or economics, we will find better grades in the former faculty conditional on high school GPA. While we cannot exclude such self-selection with the data at hand, in our view it is not very plausible that students of various faculties should differ precisely in this respect.

Alternatively, and arguably more convincingly, the results may be driven by features of the teaching and grading system in the respective faculties. A first explanation along this line is based on the similarity between curricula in high school and in university. The high school grade is a composite of a comprehensive variety of subjects whereas university studies are more specialized. Since students likely choose subjects which fit their specific abilities, one may expect that in highly specialized fields, university grades are better and less closely associated with high school GPA than in broader subjects. Given that the impact of high school GPA on university grades is largest in mathematics, which is a more specialized field than social science or economics, this explanation, however, does not find much support in the data.

Instead, the differences in grades are likely to reflect different grading cultures. Some faculties may simply be willing to award good grades to most students without differentiating strongly among good and mediocre performance. More subtly, an upward drift of average grades may be built in the structure of some degree programs. When a program grants ample choice among electives, students can avoid difficult or unpleasant courses while still obtaining the degree. Moreover, if students can freely choose courses, teachers might have an incentive to attract students by grading leniently. As a result, grades from such a program will be compressed at the upper end of the scale compared to programs with a more rigid structure of compulsory courses.

Although we have some sympathy for the last explanation, our data do not permit to conclusively distinguish between these mechanisms. Instead, we confine ourselves to pointing out the main result of this chapter: the relationship 
between high school grades and university success varies in a statistically discernible manner among faculties, which hints at some differences in grading, teaching, and examination cultures.

\subsection{Discussion and Policy Implications}

In this chapter, the determinants of studying successfully are analyzed using data from more than 12,000 students from Göttingen University. Two main results are shown. Firstly, the high school leaving grade is by far the best predictor of both the probability of graduating and the final grade obtained at university. Other factors, notably gender or social origin, play only a minor role. Secondly, differences emerge among the various faculties regarding grading and graduation policies. In some faculties, like humanities or social sciences, the rate of graduation is low but those who graduate can expect to obtain quite good grades even when they start from a weaker academic base as measured by the high school GPA. In other faculties, such as economic sciences or forest sciences, the chance of obtaining a degree is relatively high whereas grades are moderate, and strongly linked to high school GPA. Finally, in some faculties such as mathematics, graduation appears to be very difficult and good grades are hard to obtain, especially for weaker students.

These findings carry a number of implications both for the university and for the students individually as well as for education policy in general. Most obviously, our results support the current process of admission to German universities, which is based primarily on high school GPA. Clearly, this practice contributes to improving the academic success of those admitted. We do not find any evidence that adding other information can improve the selection. Specifically, variables capturing income or social background have a comparatively low explanatory power. This suggests that students from disadvantaged social backgrounds do not, on average, have abilities relevant for success at university which are undocumented by high school grades. Consequently, granting privileged access to minorities or providing universities with financial incentives to admit more students from poor districts can be a useful policy to raise equity 
in higher education, but will not enhance the overall quality of the students. It appears that most of the impact of social origin on university achievement is already absorbed in the high school leaving grade. Consequently, policy should start addressing social imbalances in educational outcomes at earlier stages of the academic career.

For prospective students, the faculty specific results, summarized in Table 2.5, may give useful hints about what subject to choose. A student with mean high school GPA has a higher chance of graduating if she chooses agriculture or economic sciences rather than humanities or social sciences. If obtaining some degree irrespective of the field is very important for her, such a student should enroll in the former rather than in the latter faculties. Considering mathematics, physics, or chemistry, the recommendation is even clearer: The average student will graduate in these faculties with a probability of 30 percent or less. For weaker students with high school GPA substantially below the mean this probability falls below 10 percent. This suggests that these three fields are almost unfeasible for students in the bottom half of the ability distribution and that such students are well advised to opt for other fields.

Extending the principle of selection on academic merit to the aggregate level obviously raises a consistency issue: Not every university or field can be restricted to the best students, since the weaker ones also will have to be placed somewhere, or else must be told not to study. This points out a basic choice which education policy must make: Should universities provide an excellent education for the most able individuals at a level defined by the current state of knowledge, or should tertiary education be targeted to large numbers of students and settle for an academic level accessible for these? Related to this, there are competing views on the main purpose of university studies. On the one hand, in Humboldt's tradition, one may see academic studies mainly as a tool of personal intellectual enhancement, where knowledge, understanding and academic debate are rewards in themselves. On the other hand, studies may be seen as an investment in productivity, whose main reward comes in the form of a higher wage. In the former view, graduation and examination grades are of lesser importance. In the latter case, the signaling value of a degree is likely to be essential for employers. As a consequence, the labor market will honor only completed degrees, and a 
wage premium will be paid for good grades as long as these are rare enough so as to convey credible information.

The results presented in this chapter suggest that faculties take different sides in this debate. In humanities, graduation rates are relatively low and individual grades are less differentiated than in other fields. This corresponds to the idea that one does not study for the sake of the examination or for a higher wage, but for intrinsic motivation. Quite possibly these fields specifically attract students with such expectations. In this view, a low completion rate in such subjects should not be seen as a sign of failure. These fields offer students an education tailored to their abilities and preferences and students use this offer to the extent which is individually optimal. On the other end of the scale, examinations in mathematics, physics and chemistry are highly selective. Thereby, these fields cannot cater to large numbers of students, but they prepare those who make it for demanding sections of the labor market. Similarly, economic sciences serve the labor market by awarding differentiated grades while still being accessible for large numbers of weaker students.

These considerations shed some light on the recommendation, repeatedly voiced by the OECD (see for instance OECD, 2013), that Germany should produce more university graduates and the corresponding complaint by employers' organizations that German industry faces a shortage of graduates from mathematics, natural sciences, and engineering (Anger et al., 2013). It is certainly conceivable that reforms in secondary schooling can raise the number of students entering university. It appears far-fetched, however, that a large fraction of those additional students will display academic abilities superior to those of the average current student. Our results show that average or below average students will typically be unable to successfully complete a degree in mathematics, physics or chemistry. Therefore it seems highly unlikely that an increase in university enrollment will produce substantial numbers of additional graduates in the subjects required by industry, at least as long as the concerned faculties are unwilling to lower their academic standards. If this does not occur, any increase in university enrollment will lead to larger numbers of graduates in those fields which cater to the preferences and abilities of the majority of students but not in those fields which firms demand. 


\section{A Appendix I: Coefficients}

Table 2.A.1: University Level - Coefficients for Table 2.2

\begin{tabular}{lcccc}
\hline \hline & \multicolumn{2}{c}{$\begin{array}{c}\text { Graduation } \\
\text {-All Faculties- }\end{array}$} & $\begin{array}{c}\text { Graduation } \\
\text {-Within Faculty- }\end{array}$ \\
& \multicolumn{2}{c}{ Probit } & \multicolumn{2}{c}{ Probit } \\
& $(1)$ & $(2)$ & $(3)$ & $(4)$ \\
\hline High school GPA & $0.528^{* * *}$ & $0.527^{* * *}$ & $0.414^{* * *}$ & $0.405^{* * *}$ \\
Male & $(0.019)$ & $(0.018)$ & $(0.019)$ & $(0.016)$ \\
& & -0.014 & & -0.022 \\
Private health insurance & & $(0.025)$ & & $(0.021)$ \\
& & $0.134^{* * *}$ & & $0.091^{* * *}$ \\
Purchasing power index & & $(0.028)$ & & $(0.024)$ \\
& & 0.002 & & 0.001 \\
Constant & $-1.359^{* * *}$ & $-1.513^{* * *}$ & $-1.076^{* * *}$ & $-1.142^{* * *}$ \\
& $(0.048)$ & $(0.271)$ & $(0.079)$ & $(0.240)$ \\
\hline States included & No & Yes & No & Yes \\
\hline Pseudo-R $\mathrm{R}^{2}$ & 0.048 & 0.051 & 0.031 & 0.033 \\
Log Likelihood & -8120 & -8093 & -11368 & -11338 \\
Observations & 12315 & 12315 & 16931 & 16931 \\
\hline \hline
\end{tabular}

Coefficients, standard errors in parentheses; clustered by counties; ${ }^{*} p<0.05$, ${ }^{* *} p<0.01,{ }^{* * *} p<0.001$. 
Table 2.A.2: Faculties - Coefficients for Table 2.3

\begin{tabular}{|c|c|}
\hline & $\begin{array}{c}\text { Graduation } \\
\text { Probit }\end{array}$ \\
\hline High school GPA & $\begin{array}{c}0.493^{* * *} \\
(0.016)\end{array}$ \\
\hline Male & $\begin{array}{l}-0.040^{*} \\
(0.020)\end{array}$ \\
\hline Private health insurance & $\begin{array}{c}0.119^{* * *} \\
(0.023)\end{array}$ \\
\hline Purchasing power index & $\begin{array}{c}0.001 \\
(0.002)\end{array}$ \\
\hline Theology & $\begin{array}{c}-0.196^{*} \\
(0.080)\end{array}$ \\
\hline Law & $\begin{array}{c}-0.009 \\
(0.039)\end{array}$ \\
\hline Medicine & $\begin{array}{c}0.191^{* *} \\
(0.065)\end{array}$ \\
\hline Humanities & base \\
\hline Mathematics & $\begin{array}{c}-0.160 * * * \\
(0.047)\end{array}$ \\
\hline Physics & $\begin{array}{c}-0.157^{* *} \\
(0.057)\end{array}$ \\
\hline Chemistry & $\begin{array}{l}-0.052 \\
(0.055)\end{array}$ \\
\hline Geology/Geography & $\begin{array}{c}0.261^{* * *} \\
(0.052)\end{array}$ \\
\hline Biology & $\begin{array}{c}0.302^{* * *} \\
(0.039)\end{array}$ \\
\hline Forest sciences & $\begin{array}{c}0.730^{* * * *} \\
(0.058)\end{array}$ \\
\hline Agriculture & $\begin{array}{c}0.663^{* * *} \\
(0.046)\end{array}$ \\
\hline Economic sciences & $\begin{array}{c}0.467^{* * *} \\
(0.038)\end{array}$ \\
\hline Social sciences & $\begin{array}{c}0.167^{* * * *} \\
(0.037)\end{array}$ \\
\hline Constant & $\begin{array}{c}-1.587^{* * *} \\
(0.216) \\
\end{array}$ \\
\hline States included & Yes \\
\hline Pseudo $\mathrm{R}^{2}$ & 0.062 \\
\hline Log Likelihood & -11005 \\
\hline Observations & 16931 \\
\hline
\end{tabular}

Coefficients, standard errors in parentheses: clustered by county; ${ }^{*} p<0.05,{ }^{* *} p<0.01$ $* * p<0.001$ 
2.A.3.a Graduation by Faculties - Coefficients for Table 2.4.a

\begin{tabular}{|c|c|c|c|c|c|c|c|}
\hline & Theology & Law & Medicine & Humanities & Mathematics & Physics & Chemistry \\
\hline High school GPA & $\begin{array}{c}0.539^{* * *} \\
(0.115)\end{array}$ & $\begin{array}{c}0.663 * * * \\
(0.057)\end{array}$ & $\begin{array}{c}0.714^{* * * *} \\
(0.076)\end{array}$ & $\begin{array}{c}0.479^{* * *} \\
(0.038)\end{array}$ & $\begin{array}{c}0.889^{* * *} \\
(0.083)\end{array}$ & $\begin{array}{c}0.717^{* * *} \\
(0.088)\end{array}$ & $\begin{array}{c}0.820^{* * * *} \\
(0.089)\end{array}$ \\
\hline Male & $\begin{array}{c}0.310 \\
(0.167)\end{array}$ & $\begin{array}{c}0.019 \\
(0.084)\end{array}$ & $\begin{array}{c}0.048 \\
(0.070)\end{array}$ & $\begin{array}{l}-0.304^{* * *} \\
(0.047)\end{array}$ & $\begin{array}{c}0.181 \\
(0.112)\end{array}$ & $\begin{array}{l}0.336^{*} \\
(0.150)\end{array}$ & $\begin{array}{c}0.121 \\
(0.120)\end{array}$ \\
\hline $\begin{array}{l}\text { Private health } \\
\text { insurance }\end{array}$ & $\begin{array}{c}0.496^{* *} \\
(0.188)\end{array}$ & $\begin{array}{c}0.048 \\
(0.078)\end{array}$ & $\begin{array}{l}0.204^{* *} \\
(0.071)\end{array}$ & $\begin{array}{c}0.173^{* * *} \\
(0.048)\end{array}$ & $\begin{array}{c}0.373^{* *} \\
(0.139)\end{array}$ & $\begin{array}{l}-0.044 \\
(0.145)\end{array}$ & $\begin{array}{c}0.032 \\
(0.125)\end{array}$ \\
\hline $\begin{array}{l}\text { Purchasing power } \\
\text { index }\end{array}$ & $\begin{array}{c}0.006 \\
(0.009)\end{array}$ & $\begin{array}{l}-0.000 \\
(0.004)\end{array}$ & $\begin{array}{l}-0.003 \\
(0.003)\end{array}$ & $\begin{array}{c}0.005 \\
(0.003)\end{array}$ & $\begin{array}{l}-0.003 \\
(0.006)\end{array}$ & $\begin{array}{l}-0.001 \\
(0.006)\end{array}$ & $\begin{array}{c}0.002 \\
(0.005)\end{array}$ \\
\hline Constant & $\begin{array}{c}-2.518^{* *} \\
(0.953)\end{array}$ & $\begin{array}{c}-1.900^{* * *} \\
(0.419)\end{array}$ & $\begin{array}{c}-1.496 * * * \\
(0.406)\end{array}$ & $\begin{array}{c}-1.848^{* * *} \\
(0.364)\end{array}$ & $\begin{array}{c}-2.571 * * * \\
(0.623)\end{array}$ & $\begin{array}{c}-2.438^{* * *} \\
(0.666)\end{array}$ & $\begin{array}{c}-2.742^{* * *} \\
(0.551)\end{array}$ \\
\hline States included & Yes & Yes & Yes & Yes & Yes & Yes & Yes \\
\hline $\begin{array}{l}\text { Pseudo } \mathrm{R}^{2} \\
\text { Log Likelihood } \\
\text { Observations }\end{array}$ & $\begin{array}{l}0.109 \\
-167 \\
284\end{array}$ & $\begin{array}{l}0.076 \\
-774 \\
1246\end{array}$ & $\begin{array}{l}0.125 \\
-896 \\
1481\end{array}$ & $\begin{array}{c}0.059 \\
-2128 \\
3342\end{array}$ & $\begin{array}{c}0.164 \\
-367 \\
660\end{array}$ & $\begin{array}{c}0.111 \\
-345 \\
567\end{array}$ & $\begin{array}{c}0.137 \\
-378 \\
644\end{array}$ \\
\hline
\end{tabular}

Coefficients, standard errors in parentheses; clustered by county; ${ }^{*} p<0.05,{ }^{* *} p<0.01,{ }^{* * *} p<0.001$.

2.A.3.b Graduation by Faculties - Coefficients for Table 2.4.b

\begin{tabular}{|c|c|c|c|c|c|c|}
\hline & Geology/Geography & Biology & Forest Sciences & Agriculture & Economic Sciences & Social Sciences \\
\hline High school GPA & $\begin{array}{c}0.172 \\
(0.092)\end{array}$ & $\begin{array}{c}0.441 * * * \\
(0.053)\end{array}$ & $\begin{array}{c}0.388^{* * * *} \\
(0.104)\end{array}$ & $\begin{array}{c}0.346^{* * *} \\
(0.068)\end{array}$ & $\begin{array}{c}0.410^{* * *} \\
(0.049)\end{array}$ & $\begin{array}{c}0.218 * * * \\
(0.048)\end{array}$ \\
\hline Male & $\begin{array}{c}-0.325^{*} \\
(0.151)\end{array}$ & $\begin{array}{l}-0.040 \\
(0.069)\end{array}$ & $\begin{array}{c}0.081 \\
(0.123)\end{array}$ & $\begin{array}{c}0.132 \\
(0.090)\end{array}$ & $\begin{array}{l}-0.057 \\
(0.053)\end{array}$ & $\begin{array}{l}-0.069 \\
(0.056)\end{array}$ \\
\hline $\begin{array}{l}\text { Private health } \\
\text { insurance }\end{array}$ & $\begin{array}{c}0.154 \\
(0.145)\end{array}$ & $\begin{array}{c}0.093 \\
(0.083)\end{array}$ & $\begin{array}{c}0.102 \\
(0.097)\end{array}$ & $\begin{array}{l}-0.098 \\
(0.092)\end{array}$ & $\begin{array}{c}0.168 * * \\
(0.055)\end{array}$ & $\begin{array}{c}0.028 \\
(0.072)\end{array}$ \\
\hline $\begin{array}{l}\text { Purchasing power } \\
\text { index }\end{array}$ & $\begin{array}{c}0.010 \\
(0.007)\end{array}$ & $\begin{array}{l}-0.006 \\
(0.003)\end{array}$ & $\begin{array}{l}-0.000 \\
(0.005)\end{array}$ & $\begin{array}{l}-0.005 \\
(0.004)\end{array}$ & $\begin{array}{c}0.002 \\
(0.003)\end{array}$ & $\begin{array}{l}0.009^{* * * *} \\
(0.003)\end{array}$ \\
\hline Constant & $\begin{array}{l}-1.375 \\
(0.715)\end{array}$ & $\begin{array}{l}-0.472 \\
(0.369)\end{array}$ & $\begin{array}{l}-0.772 \\
(0.546)\end{array}$ & $\begin{array}{l}-0.031 \\
(0.423)\end{array}$ & $\begin{array}{c}-0.971^{* *} \\
(0.374)\end{array}$ & $\begin{array}{c}-1.589 * * * \\
(0.308)\end{array}$ \\
\hline States included & Yes & Yes & Yes & Yes & Yes & Yes \\
\hline $\begin{array}{l}\text { Pseudo } \mathrm{R}^{2} \\
\text { Log Likelihood } \\
\text { Observations }\end{array}$ & $\begin{array}{c}0.039 \\
-360 \\
542 \\
\end{array}$ & $\begin{array}{l}0.047 \\
-923 \\
1410 \\
\end{array}$ & $\begin{array}{c}0.043 \\
-425 \\
666 \\
\end{array}$ & $\begin{array}{c}0.024 \\
-1004 \\
1546 \\
\end{array}$ & $\begin{array}{c}0.032 \\
-1819 \\
2740 \\
\end{array}$ & $\begin{array}{c}0.019 \\
-1198 \\
1778 \\
\end{array}$ \\
\hline
\end{tabular}

Coefficients, standard errors in parentheses; clustered by county; ${ }^{*} p<0.05,{ }^{* *} p<0.01,{ }^{* * *} p<0.001$. 


\section{B Appendix II: Data Processing}

We exclude students for whom not all information is available as well as students for whom we observe pure data errors, such as when the grade of the high school leaving certificate is not within the possible interval. Ph.D. students are also dropped from the dataset. The reason for this is that they form a highly selective group and their success may be influenced by other factors than regular students' performance. Furthermore, we only take into account students who either finished university with a degree or dropped out of their study program. Since students are asked to give the reason for dropping out when they leave university, we can distinguish between real drop outs and students who intend to continue their studies at another university. We exclude these students from the sample in order not to register a drop out for the latter group.

As German and foreign high school leaving grades may not be comparable and university success of students with a foreign educational background may be influenced by additional factors such as language skills, we only take into account students who hold a German high school leaving certificate. In addition, we exclude students with a high school leaving grade of 4.0, the worst grade still allowing a student to pass. This is done as in our dataset a high school leaving grade of 4.0 was often found for students, in particular for foreign students, who enrolled in fields of study without admission restriction. This strongly suggests that the grade is sometimes used as a place holder when the real grade seemed not to be important for the admission procedure. However, we are confident that we have only deleted a very small number of students who actually have a high school leaving grade of 4.0 by imposing this restriction.

In addition, students have to provide information about their home address, usually their parents' address, and their semester address, usually the place students live by themselves. Since most students move to Göttingen when starting university, home and semester address should differ. Nonetheless, for some students in our dataset the two zip-codes are identical. As we make use of the parents' address in our analysis it is important that the correct zip-code is used. To deal with this problem, we look at all students for whom the zip-code of their home and semester address are the same. If both zip-codes belong to a 
place outside of Göttingen, it is very likely that this student is still living with her parents. If the zip-codes are identical and from Göttingen, it might be that the student did not provide any information about her parents' home address. Therefore, we take a look at the administrative district the student went to school in. If she graduated from a high school in Göttingen, we have no reason to doubt that her parents also live there. On the other hand, if she went to school outside of Göttingen, it is not entirely clear that the information about the home address really corresponds to the parental address. Consequently, we exclude these students from the sample. 


\section{Chapter 3}

\section{Class Attendance and University Performance*}

\subsection{Introduction}

When it comes to the question of how to enhance students' performance at university, the solution seems often to be more teaching. In particular, the provision of small group tutorials where students apply the methods taught in the lecture, solve problem sets and ask questions is seen as a magic bullet. However, it is not clear whether students who attend lectures or tutorials actually achieve better grades than students who abstain from class. When students have access to the teaching material irrespective of class attendance, or when the content of the lecture can be found in textbooks, going to class and studying on one's own may in fact be substitutes. Since this may especially be true for lectures where students adopt a rather passive role, the gains from attending class may also differ between types of teaching.

This study addresses these issues by evaluating the effect of attending the lecture and/or tutorial on the grade achieved in two basic courses in business administration and economics. The analysis finds no significant impact of going to class on student performance in most specifications, and thereby supports

*This chapter originates from joint work with Anna-Lena Hoffmann (see Hoffmann and Lerche, 2016). 
the idea that attending class and studying on one's own are substitutes. In the given framework, there may simply be no difference between going to class and listening to the lecturer and studying on one's own or with friends.

There already exists literature on the effect of class attendance on student performance. Thereby, many studies identify a positive relationship between going to class and academic performance. Romer (1993) finds that absenteeism has a negative impact on student performance using ordinary least squares regressions. Moreover, looking at descriptive statistics, he shows that students more often attend small classes and classes that focus on mathematical skills. Evaluating the impact on specific examinations in principles of micro- and macroeconomics at a university in the U.S., Marburger $(2001,2006)$ shows that students who were absent a given day have a lower probability of answering correctly to questions concerning material that was covered in this class. Beltz et al. (2011) evaluate the implementation of tutorials at a German university and find a positive effect on the achieved grade. Furthermore, students seem to be more satisfied when a course not only consists of a lecture but also of accompanying tutorials.

In addition to these findings, Cohn and Johnson (2006) as well as Durden and Ellis (1995) point out that the extent of absenteeism matters: excessive absenteeism leads to lower student performance while missing only a few classes has no impact. Arulampalam et al. (2012) also show that the effect of class attendance may not be homogeneous. Using quantile regressions, they find that abstaining from class has a significant negative impact on grades for higherperforming students only.

Some studies use panel data to take unobserved heterogeneity among students into account. Martins and Walker (2006) analyze how attendance, class size, peer group and teacher influence students' performance in undergraduate classes at a major university in the UK. They show that once controlling for student fixed effects, the different class characteristics have no significant impact on the students' grades. In particular, there is no significant effect of class attendance on student achievement. In contrast to these results, Stanca (2006) shows that attending either lecture or classes of an introductory microeconomics course at Milan University has a positive impact on student learning. Similarly, Cohn 
and Johnson (2006) find a positive and significant impact of class attendance on student performance in principles of economics courses at a university in the U.S. also when controlling for individual heterogeneity.

Dobkin et al. (2010) apply a regression discontinuity design in order to evaluate the effect of class attendance on exam performance. To do so, they make use of a regulation stating that students who score below the median on the midterm examination are required to attend class in the second half of the semester. The authors find that students who scored just below the threshold on the midterm examination, and therefore had to attend class, have a better grade on the final examination than students who were just above the median.

We contribute to this literature in two ways: firstly, we look at two basic courses in business administration and economics that differ with regard to their content and required skills. Course 1 focusses on methodological knowledge that is relevant for different following courses at the faculty of economic sciences, while course 2 teaches basics in business administration. Secondly, since both courses consist of a lecture as well as tutorials (small groups), we are able to assess whether the role of class attendance differs between these types of teaching.

Using survey data collected at Göttingen University, Germany, we find that attending a course's lecture, tutorial or both mainly has no significant impact on students' performance in the respective class. Only students who always go to the lecture of course 1 achieve better grades than students who never attend class. We are aware that identifying a causal effect of class attendance on students' performance is not possible with the data at hand. Nevertheless, the analysis shows that the students' educational production functions are more complex and diverse than often believed. Therefore, the results do not contradict the positive link between class attendance and student performance found by other studies on the topic. On the one hand, studies from different countries may not be comparable as the educational system and student body most likely differs. For example, students in our sample are on average older than the students in studies from the U.S. (see e.g. Cohn and Johnson, 2006; Marburger, 2006). Since more mature students may be better in learning on their own this fact can be a reason for the different results. On the other hand, it is likely that differences in teaching concepts play an important role. Students may simply 
benefit to a larger extent from attending classes with a more interactive teaching and learning environment, such as assessed by Beltz et al. (2011). Nevertheless, the argumentation underlines that the idea of enhancing students' performance by simply providing more teaching or reducing class size may be a false conclusion. Instead, the benefits from going to class are likely to depend on a variety of factors.

The chapter is structured as follows: Section 3.2 gives information on the institutional background. Then, Section 3.3 describes the data and presents summary statistics. Section 3.4 shows and interprets our empirical results. Finally, Section 3.5 summarizes the main findings and concludes.

\subsection{Institutional Background}

At the faculty of economic sciences at Göttingen University, bachelor courses of the first and second semester (first study period) have a similar structure. Besides lectures where rather theoretical knowledge is taught, tutorials on a weekly basis are offered, too. The aim of these tutorials is to practice and apply the subject material of the corresponding lecture. For each lecture, there are several accompanying tutorials in order to ensure small groups for each tutorial. The tutorials are held by students who already passed the respective course. As attendance is not mandatory both for the lectures and the tutorials, the students can choose themselves if and how often they want to participate in the learning offer. Furthermore, they can choose the specific tutorial and thus the tutor and size of the tutorial themselves.

For our analysis, we choose two courses of the first study period: course 1 focuses on methodological knowledge that is relevant for different following courses, while course 2 deals with basics in business administration. Besides the thematic difference, a reason for this choice also lies in the different structure of the tutorials. For course 1, the students are supposed to prepare the given exercises themselves, either in advance or during class. Although the final solution is available for all students irrespective of class attendance, the tutorial gives the opportunity to ask the teaching assistant for help with solving the 
exercises. Additionally, problem sets which are difficult to solve for many students are presented by the tutor. In contrast, course 2 offers tutorials where preparation is recommended, but not a precondition for attendance. In class, the tutor presents the approach and solution to every problem set in the manner of a lecture. Moreover, the students have the opportunity to ask questions. For both the lecture and the tutorial of course 1 and 2, the learning material, such as syllabus, textbooks and problem sets, are available for all students irrespective of class attendance.

\subsection{Data}

Data was collected using a standardized paper and pencil-based questionnaire that was given to students of Göttingen University at the beginning of selected classes within business administration and economics. Since these courses were more advanced, it was expected that most students attending them had already passed the two courses under analysis. Besides, the selected courses aim at different student groups, thereby making it possible to address many students from different peer groups. Filling out the two pages questionnaire took approximately ten minutes. The questionnaire contained close-ended as well as half-open-ended questions with the possibility to give either one or several answers.

The questions are grouped into four sequences: sequences one and two deal with the two different courses (one sequence for each) and ask questions on e.g. the semester the student completed the respective course in, the achieved grade and how often she attended class. Sequence three is about individual learning behavior, in particular where and how the students study. Sequence four contains questions on personal details such as the grade of the high school leaving certificate and the mother's level of education. The questionnaire as well as further information on data processing can be found in the appendix of this chapter.

In the analysis, the following dependent and independent variables are used to evaluate the influence of class attendance on student performance. The corresponding summary statistics are shown in Table 3.1. 
Table 3.1: Summary Statistics

\begin{tabular}{lccccc}
\hline \hline Variable & Observations & Mean & Std. Dev. & Min & Max \\
\hline Grade class 1 & 349 & 2.154 & 1.034 & 0 & 4 \\
Lecture 1 never & 349 & 0.092 & 0.289 & 0 & 1 \\
Lecture 1 rarely & 349 & 0.324 & 0.469 & 0 & 1 \\
Lecture 1 frequently & 349 & 0.324 & 0.469 & 0 & 1 \\
Lecture 1 always & 349 & 0.261 & 0.440 & 0 & 1 \\
Lecture 1 & 349 & 0.585 & 0.494 & 0 & 1 \\
Tutorial 1 never & 349 & 0.172 & 0.378 & 0 & 1 \\
Tutorial 1 rarely & 349 & 0.266 & 0.443 & 0 & 1 \\
Tutorial 1 frequently & 349 & 0.203 & 0.403 & 0 & 1 \\
Tutorial 1 always & 349 & 0.358 & 0.480 & 0 & 1 \\
Tutorial 1 & 349 & 0.562 & 0.497 & 0 & 1 \\
Semester 1 class 1 & 349 & 0.003 & 0.054 & 0 & 1 \\
Semester 2 class 1 & 349 & 0.295 & 0.457 & 0 & 1 \\
Semester 3 class 1 & 349 & 0.415 & 0.494 & 0 & 1 \\
Semester 4 class 1 & 349 & 0.117 & 0.322 & 0 & 1 \\
Semester 5 class 1 & 349 & 0.169 & 0.375 & 0 & 1 \\
\hline Grade class 2 & 277 & 2.250 & 0.932 & 0 & 4 \\
Lecture 2 never & 277 & 0.036 & 0.187 & 0 & 1 \\
Lecture 2 rarely & 277 & 0.141 & 0.348 & 0 & 1 \\
Lecture 2 frequently & 277 & 0.350 & 0.478 & 0 & 1 \\
Lecture 2 always & 277 & 0.473 & 0.500 & 0 & 1 \\
Lecture 2 & 277 & 0.823 & 0.382 & 0 & 1 \\
Tutorial 2 never & 277 & 0.051 & 0.219 & 0 & 1 \\
Tutorial 2 rarely & 277 & 0.025 & 0.157 & 0 & 1 \\
Tutorial 2 frequently & 277 & 0.199 & 0.400 & 0 & 1 \\
Tutorial 2 always & 277 & 0.726 & 0.447 & 0 & 1 \\
Tutorial 2 & 277 & 0.924 & 0.265 & 0 & 1 \\
Semester 1 class 2 & 277 & 0.014 & 0.120 & 0 & 1 \\
Semester 2 class 2 & 277 & 0.412 & 0.493 & 0 & 1 \\
Semester 3 class 2 & 277 & 0.274 & 0.447 & 0 & 1 \\
Semester 4 class 2 & 277 & 0.159 & 0.366 & 0 & 1 \\
Semester 5 class 2 & 277 & 0.141 & 0.348 & 0 & 1 \\
\hline High school GPA & 383 & 2.582 & 0.503 & 1.5 & 4 \\
Male & 383 & 0.561 & 0.497 & 0 & 1 \\
Higher education (mother) & 383 & 0.543 & 0.499 & 0 & 1 \\
Age & 383 & 23.282 & 2.666 & 20 & 43 \\
\hline \hline & & & & & \\
\hline
\end{tabular}

Grades transformed to 1-4 Scale, with 4 being the best grade and 1 being the worst grade that is still considered a pass. A grade of 0 means that the student failed the respective course. 
Dependent Variables. As a measure of student performance, we use the grade that the student achieved in course 1 and course 2, respectively. Thereby, all grades were converted into the U.S. grading scheme with 4.0 being the best and 1.0 the worst grade that is still considered a pass. ${ }^{8}$ A grade of 0.0 means that the student failed the respective course. For course 1, the mean-value for a sample of 349 students is 2.154. For course 2, the mean-value for a sample of 277 students is 2.250 and consequently only slightly higher, meaning better, than the mean-value of the first course.

Independent Variables. In the questionnaire, the students were asked how often they attended the lecture and tutorial of course 1 and course 2 . The possible answers were never, rarely, frequently and always. In addition to including these four categories in our analysis, the levels of attendance were grouped by creating an indicator variable that equals one when the student frequently or always went to class and zero otherwise. For course 1, around 9 percent of the students in our sample state that they never, around 32 percent they rarely, around 32 percent they frequently and around 26 percent they always attended the lecture. This means that around 59 percent frequently or always went to the lecture of course 1 (Lecture 1 ). The tutorial of course 1 was never attended by around 17 percent, rarely attended by 27 percent, frequently attended by 20 percent and always attended by 36 percent of the students in our sample. Overall, around 56 percent of the students frequently or always went to the tutorial (Tutorial 1). Compared to this, the attendance rates for course 2 look very different: the lecture of course 2 was never attended by around 3 percent, rarely attended by 14 percent, frequently attended by 35 percent and always attended by 47 percent of the students in our sample. Overall, around 82 percent of the students frequently or always went to the lecture of course 2 (Lecture 2). For the tutorial of course 2, around 5 percent never, 2 percent rarely, 20 percent frequently and 73 always went to the tutorial. This means that approximately 92 percent of the students in our sample frequently or always attended the tutorial of course 2 (Tutorial 2).

\footnotetext{
${ }^{8}$ Grades are transformed into the U. S. grading scheme by subtracting the original grade from five.
} 
The summary statistics show that there is a higher attendance rate both for the lecture and the tutorial of course 2 compared to course 1 . Possible explanations for these differences concerning class attendance can be derived from the different topics and teaching concepts. Basics of course 1 were already treated in high school, while basic knowledge of course 2 can only be expected from students who have previous business experience, e.g. because they did an apprenticeship before starting university. Thus, on the one hand, students may think that course 1 is easier to study on one's own as part of the learning content is already known. On the other hand, it may be that students with a lower high school grade have more difficulties to follow the lecture and the tutorial of course 1 because the treated content is based on knowledge obtained in high school. As a result, they may either feel discouraged because they do not understand the taught material or decide to study on their own and review previous content when needed.

Another possible explanation for the diverse attendance rates are the tutorials' different teaching concepts. The tutorials of course 1 give the students the opportunity to ask for help if they cannot solve the given problem sets or did not understand what was taught in the lecture. This implies that class attendance is only helpful when the students regularly prepare the exercises in advance or during class. If the students have no questions as they can solve the exercises on their own, going to the tutorial is not necessary either. This is different for course 2 where the tutor presents the approach and the solution to every problem set during class. As a result, attending class is helpful for all students irrespective of whether or not they prepared the exercises by themselves.

The additional control variables are listed at the bottom of Table 3.1. The high school grade is used to control for general ability and motivation. In this context, the literature has shown that the grade of the high school leaving certificate is a strong predictor for university success in general (Betts and Morel, 1999; Cyrenne and Chan, 2012; Danilowicz-Gösele et al., 2014). Similar to the grades achieved in course 1 and 2, the high school grades are converted to the U.S. grading scheme. In our sample the mean-value is approximately 2.6 which is higher, meaning better, than the mean of the grades obtained in course 1 and 2 , respectively. This can be explained by the fact that a grade of 0.0 , mean- 
ing failed, is not possible for the high school leaving certificate. Administrative data on bachelor students enrolled at the faculty of economic sciences at Göttingen university between the winter term 2005 and the winter term 2011 reveal a mean high school GPA of 2.43. Assuming some kind of consistency of high school grades over the years, this indicates that the students in our sample on average have a slightly higher academic ability than the overall student body at the faculty.

We account for gender differences by using an indicator variable that equals one if the student is male and zero otherwise. The summary statistics show that 56 percent of the students in our sample are male. This number is slightly lower than the average share of male students at the faculty of economic sciences, which was 61 percent for students who enrolled between the winter term 2005 and the winter term 2011. Furthermore, the student's socio-economic background is controlled for by including the mother's highest level of academic qualification. The indicator variable equals one if the mother obtained a high school leaving certificate that permits access to tertiary education or finished university with a degree or a Ph.D., and zero otherwise. Around 54 percent of the students' mothers either achieved a high school leaving certificate that permits access to tertiary education or finished university with a degree or a Ph.D. Furthermore, we control for age by using a variable that subtracts the student's year of birth from the year of our survey (2013). Finally, the semester the student took the respective course in is taken into account. This is particularly important as the lecturer of course 2 changed during the time under analysis.

\subsection{Results}

In the analysis, we first look at the factors that determine the probability of attending the lecture and tutorial of course 1 and 2. To do so, a probit model is estimated. Afterwards, OLS regressions are applied to analyze the effect of attending the lecture, the tutorial or both on the grade obtained in the respective class. Thereby, indicator variables that distinguish between never or rarely and frequently or always attending the lecture or the tutorial are used. Finally, we 
include all levels of attendance - never, rarely, frequently and always - in order to get a more diversified picture of how class attendance influences students' success. In all regressions, standard errors are clustered by semester.

\subsubsection{Course 1}

We start by taking a look at the factors that determine the probability of always or frequently attending the lecture or tutorial of course 1 , which teaches methodological skills. The results of the probit estimation can be found in Table 3.2. Columns 2 and 4 show marginal effects for a benchmark student, and columns 1 and 3 the corresponding coefficients. The benchmark student is female, never or rarely attends class, has a mother with a lower educational background, took course 1 in the winter term 2011/12 and is average with regard to all continuous variables.

The regressions show that students who always or frequently attend the lecture have a higher probability of also attending the tutorial, and vice versa. This suggests some kind of general willingness to attend class. Furthermore, we find that students with a better high school leaving grade have a higher probability of going to the lecture while the effect is insignificant for the probability of attending the tutorial. An explanation for this may be that in the lecture of course 1, the subject matter is taught in a more general and theoretical way. In contrast to the tutorial, the students do not apply the explained methods themselves. Students with lower academic ability might have more difficulties to understand what is taught, and therefore abstain from going to class.

The insignificant effect of the high school leaving grade on attending the tutorial is more surprising. In the tutorial, the students have the opportunity to ask for help if they do not know how to solve the provided problem sets. Therefore, one might expect that students with lower academic ability are more likely to attend class. However, it may be that the problem sets also contain questions that are challenging for high-ability students. Moreover, students may see the tutorial as a fixed time in the week where they repeat and apply the learned material. This may be true for all students. 
Table 3.2: Probability of Attending Course 1

\begin{tabular}{lcccc}
\hline \hline \multirow{2}{*}{ Dependent variable: } & \multicolumn{2}{c}{ lecture 1} & \multicolumn{2}{c}{ tutorial 1} \\
& $(1)$ & $(2)$ & $(3)$ & $(4)$ \\
\hline Lecture 1 & & & $0.732^{* * *}$ & $0.285^{* * *}$ \\
& & & $(0.17)$ & $(0.06)$ \\
Tutorial 1 & $\left(0.126^{* * *}\right.$ & $0.260^{* * *}$ & & \\
& $0.542^{* * *}$ & $0.216^{* * *}$ & 0.143 & 0.052 \\
High school GPA & $(0.14)$ & $(0.06)$ & $(0.10)$ & $(0.03)$ \\
& $0.278^{*}$ & $0.109^{*}$ & -0.130 & -0.045 \\
Male & $(0.14)$ & $(0.06)$ & $(0.08)$ & $(0.03)$ \\
& $-0.380^{* * *}$ & $-0.149^{* * *}$ & -0.067 & -0.024 \\
Higher education (mother) & $(0.11)$ & $(0.04)$ & $(0.09)$ & $(0.03)$ \\
& 0.035 & 0.014 & -0.017 & -0.006 \\
Age & $(0.03)$ & $(0.01)$ & $(0.02)$ & $(0.01)$ \\
Constant & $-2.146^{*}$ & & -0.417 & \\
& $(0.93)$ & & $(0.56)$ & \\
\hline Semester included & yes & yes & yes & yes \\
\hline Pseudo R ${ }^{2}$ & 0.112 & 0.112 & 0.086 & 0.086 \\
Log Likelihood & -210.4 & -210.4 & -218.7 & -218.7 \\
Observations & 349 & 349 & 349 & 349 \\
\hline \hline
\end{tabular}

Probit estimation; column (1), (3): coefficients; column (2), (4): marginal effects for benchmark student (female, never or rarely attends the tutorial/lecture, mother has a lower educational background, took the course in the winter term 2011/12 and is average with regard to all continuous variables); standard errors in parentheses; clustered by semester; levels of significance for marginal effects refer to p-values of the underlying coefficients; ${ }^{*} p<0.05,{ }^{* *} p<0.01,{ }^{* * *} p<0.001$. 
Besides the high school leaving grade, the student's socio-economic background also has a significant impact on the probability of attending the lecture of course 1 . The coefficient has a minus sign implying that students with a higher socio-economic background are less likely to frequently or always attend the lecture.

In a second step, the effect of always or frequently attending the lecture and/or tutorial on the grade achieved in course 1 is estimated. The results are shown in Table 3.3. In the full specification, always or frequently attending the lecture, the tutorial or both has no significant impact on the obtained grade. This means that being present in class does not influence the achieved grade. When using indicator variables for all categories of class attendance in Table 3.4, we find a significant effect of always attending the lecture. This suggests that students who always go to the lecture achieve a higher, meaning better grade in this course than students who never attend class. In contrast, frequently or rarely going to the lecture has no significant impact on the grade achieved in this course. For the tutorial, all categories of class attendance are insignificant.

With regard to the other controls, we find a positive and highly significant coefficient of the high school leaving grade in the regressions shown in Table 3.3 and Table 3.4. The higher the high school leaving grade, the better the grade the student achieves in course 1 . This is in line with what the literature finds for the impact of the high school leaving grade on university success in general (Betts and Morel, 1999; Cyrenne and Chan, 2012; Danilowicz-Gösele et al., 2014). The comparably big size of the coefficient may be explained by the fact that the content taught in this course is based on skills and methods already learned in high school. Since contents may overlap or build on one another, the course may simply be easier for students who already achieved a good grade in high school.

In Table 3.3, we find a significant effect for male, but the coefficient turns slightly insignificant at the 5\%-level when using all categories of attendance in the regression in Table 3.4. The socio-economic variable, education of the student's mother, does not show a significant effect in all specifications. This is in line with the findings presented in Chapter 2 suggesting that socio-economic factors only have a minor effect on university performance, if at all. Moreover, the coefficient of the student's age is also insignificant in all specifications. 
Table 3.3: Course 1

Dependent variable: grade class 1

(1)

(2)

\begin{tabular}{lcc}
\hline Lecture 1 & $0.395^{* *}$ & 0.253 \\
& $(0.07)$ & $(0.13)$ \\
Tutorial 1 & 0.054 & 0.038 \\
& $(0.09)$ & $(0.05)$ \\
Lecture 1 \# Tutorial 1 & -0.104 & -0.081 \\
& $(0.12)$ & $(0.11)$ \\
High school GPA & & $0.724^{* *}$ \\
& & $(0.10)$ \\
Male & & $0.176^{*}$ \\
& & $(0.06)$ \\
Higher education (Mother) & & 0.081 \\
& & $(0.09)$ \\
Age & & -0.021 \\
& & $(0.01)$ \\
Constant & $1.934^{* * *}$ & 0.591 \\
& $(0.13)$ & $(0.33)$ \\
\hline Semester included & yes & yes \\
\hline R ${ }^{2}$ & 0.027 & 0.181 \\
Observations & 349 & 349 \\
\hline \hline
\end{tabular}

OLS, standard errors in parentheses; clustered by semester; ${ }^{*} p<0.05$, $* * p<0.01, * * * p<0.001$. 
Table 3.4: Course 1 - All Categories

\begin{tabular}{lc}
\hline \hline Dependent variable: grade class 1 & \\
\hline Lecture 1 always & $0.217^{*}$ \\
Lecture 1 frequently & $(0.06)$ \\
& 0.164 \\
Lecture 1 rarely & $(0.12)$ \\
& -0.015 \\
Tutorial 1 always & $(0.13)$ \\
& -0.046 \\
Tutorial 1 frequently & $(0.14)$ \\
& -0.191 \\
Tutorial 1 rarely & $(0.07)$ \\
& -0.152 \\
High school GPA & $(0.12)$ \\
& $0.707^{* *}$ \\
Male & $(0.10)$ \\
Higher education (mother) & 0.160 \\
& $(0.07)$ \\
Age & 0.087 \\
& $(0.10)$ \\
Constant & -0.019 \\
& $(0.01)$ \\
Semester included & 0.727 \\
Observations & $(0.45)$ \\
\hline \hline
\end{tabular}

OLS, standard errors in parentheses; clustered by semester; base categories: lecture 1 never, tutorial 1 never; ${ }^{*} p<0.05$, ${ }^{* *} p<0.01,{ }^{* * *} p<0.001$. 


\subsubsection{Course 2}

Table 3.5 presents the results for the probit estimation of frequently or always attending the lecture or the tutorial of course 2, which focuses on basics in business administration. Columns 2 and 4 show marginal effects for a benchmark student, and columns 1 and 3 the corresponding coefficients. For this course, the benchmark student is female, never or rarely attends class, has a mother with a lower educational background, took course 2 in the summer term 2012 and is average with regard to all continuous variables.

We find that frequently or always going to the tutorial has a positive impact on the probability of attending the lecture, but not vice versa. The effect of the high school leaving grade is significant for both types of teaching. However, the coefficient has a plus sign for the lecture and a minus sign for the tutorial. This means that the higher, implying better, the high school leaving grade, the higher the probability of attending the lecture and the lower the probability of attending the tutorial. The effect we find for the probability of going to the lecture is in line with the results for course 1 . Students with lower academic ability abstain from going to the lecture where the content is presented in a more general and theoretical way. On the other hand, in the tutorial, students are taught how to solve problem sets that are similar to what is asked in the later examination. Therefore, one would expect that all students attend the tutorial in order to be prepared for the examination. However, students may copy each other's notes and take turns in going to class. Since students with higher academic ability may not have as many questions about the taught learning content, they may prefer to learn on their own and abstain from attending the tutorial.

The effect of age on the probability of attending the tutorial of course 2 is negative and significant. A reason for this may be that students who start university at a later point in time, and therefore are older than their peers, often did an apprenticeship after finishing high school. If they worked in a company or bank, they achieved commercial skills which are relevant for course 2 . These students may simply be able to solve the provided problem sets on their own, and therefore do not go to class.

Moreover, for course 2, the effect of attending the lecture, tutorial or both on 
Table 3.5: Probability of Attending Course 2

\begin{tabular}{lcccc}
\hline \hline \multirow{2}{*}{ Dependent variable: } & \multicolumn{2}{c}{ lecture 2} & \multicolumn{2}{c}{ tutorial 2} \\
& $(1)$ & $(2)$ & $(3)$ & $(4)$ \\
\hline Lecture 2 & & & 0.710 & 0.159 \\
& & & $(0.47)$ & $(0.18)$ \\
Tutorial 2 & $\left(0.479^{*}\right.$ & $0.189^{*}$ & & \\
& $0.353^{* *}$ & $0.112^{* *}$ & $-0.299^{*}$ & $-0.092^{*}$ \\
High school GPA & $(0.12)$ & $(0.05)$ & $(0.12)$ & $(0.08)$ \\
& -0.178 & -0.060 & -0.307 & -0.104 \\
Male & $(0.11)$ & $(0.04)$ & $(0.29)$ & $(0.07)$ \\
& -0.124 & -0.041 & 0.407 & 0.106 \\
Higher education (mother) & $(0.11)$ & $(0.04)$ & $(0.44)$ & $(0.16)$ \\
& -0.048 & -0.015 & $-0.103^{* *}$ & $-0.032^{* *}$ \\
Age & $(0.06)$ & $(0.02)$ & $(0.04)$ & $(0.01)$ \\
Constant & 0.895 & & $3.883^{* *}$ & \\
& $(1.79)$ & & $(1.41)$ & \\
\hline Semester included & yes & yes & yes & yes \\
\hline Pseudo R & 0.108 & 0.108 & 0.177 & 0.177 \\
Log Likelihood & -115.3 & -115.3 & -61.2 & -61.2 \\
Observations & 277 & 277 & 277 & 277 \\
\hline \hline
\end{tabular}

Probit estimation; column (1), (3): coefficients; column (2), (4): marginal effects for benchmark student (female, never or rarely attends the tutorial/lecture, mother has a lower educational background, took the course in the summer term 2012 and is average with regard to all continuous variables); standard errors in parentheses; clustered by semester; levels of significance for marginal effects refer to p-values of the underlying coefficients; ${ }^{*} p<0.05,{ }^{* *} p<0.01,{ }^{* * *} p<0.001$. 
Table 3.6: Course 2

Dependent variable: grade class 2

(1)

(2)

\begin{tabular}{lcc}
\hline Lecture 2 & 0.147 & 0.302 \\
& $(0.18)$ & $(0.37)$ \\
Tutorial 2 & -0.127 & 0.235 \\
& $(0.21)$ & $(0.13)$ \\
Lecture 2 \# Tutorial 2 & -0.126 & -0.387 \\
& $(0.24)$ & $(0.22)$ \\
High school GPA & & $0.644^{*}$ \\
& & $(0.15)$ \\
Male & & -0.065 \\
& & $(0.10)$ \\
Higher education (mother) & & -0.142 \\
& & $(0.10)$ \\
Age & & $0.028^{* *}$ \\
& & $(0.01)$ \\
Constant & & -0.050 \\
& $2.344^{* * *}$ & $(0.15)$ \\
\hline Semester included & yes & yes \\
\hline R ${ }^{2}$ & 0.004 & 0.149 \\
Observations & 277 & 277 \\
\hline \hline
\end{tabular}

OLS, standard errors in parentheses; clustered by semester; ${ }^{*} p<0.05$, $* * p<0.01, * * * p<0.001$. 
the achieved grade is estimated. The results of the OLS regressions are presented in Table 3.6. In the shown specification, the indicator variables for the lecture and the tutorial distinguish between never or rarely and frequently or always attending class. Neither for the lecture, for the tutorial or for the interaction term, we find a significant effect on the grade achieved in this course. This holds true for the specification that includes all categories of attendance in Table 3.7.

Similar to the results of course 1, we find a highly significant effect of the high school leaving grade, implying that the better the grade of the high school leaving certificate, the better the grade achieved in course 2. Although the size of the coefficient is smaller than for course 1, it is still comparatively large.

The effect of age is positive and significant in the full specification in Table 3.6, suggesting that more mature students achieve a higher grade in this course. This result can be explained in the same way as the lower probability of older students to attend the tutorial. They may have completed an apprenticeship before going to university, for example in a bank or a company, and thereby achieved commercial skills that are relevant for course 2. However, the coefficient turns slightly insignificant at the 5\%-level when including all categories of attendance. The students' gender and socio-economic background have no significant impact on the achieved grade in all specifications.

\subsubsection{Discussion}

Besides the impact of always attending the lecture of course 1, we do not find any significant effect of class attendance on the grade achieved in the respective course. A reason for this sobering result may be that, especially in case of the lecture, it is comparatively easy to study on one's own: the learning content can be found in textbooks and the syllabus, as well as other study material is available for all students irrespective of class attendance. Given that in the lecture, students do not apply the taught learning material themselves but adopt a rather passive role, attending class and reading a textbook may be substitutes. Consequently, there may simply be no difference between attending class and listening to the lecturer or staying at home or going to the library and reading the argumentation on one's own. 
Table 3.7: Course 2 - All Categories

\begin{tabular}{lc}
\hline \hline Dependent variable: grade class 2 & \\
\hline Lecture 2 always & 0.387 \\
& $(0.44)$ \\
Lecture 2 frequently & 0.211 \\
& $(0.41)$ \\
Lecture 2 rarely & 0.455 \\
& $(0.41)$ \\
Tutorial 2 always & -0.020 \\
& $(0.27)$ \\
Tutorial 2 frequently & -0.202 \\
& $(0.35)$ \\
Tutorial 2 rarely & 0.007 \\
& $(0.58)$ \\
High school GPA & $0.604^{*}$ \\
& $(0.16)$ \\
Male & -0.043 \\
& $(0.09)$ \\
Higher education (mother) & -0.120 \\
& $(0.10)$ \\
Age & 0.021 \\
Constant & $(0.01)$ \\
& 0.075 \\
Semester included & $(0.76)$ \\
\hline \hline
\end{tabular}

OLS, standard errors in parentheses; clustered by semester; base categories: lecture 2 never, tutorial 2 never; ${ }^{*} p<0.05$, ${ }^{* *} p<0.01, * * * p<0.001$. 
In the tutorials, the students apply the methods themselves, learn how to solve problem sets that are similar to the examinations and have the opportunity to ask questions. Therefore, the non-significant effect is more surprising. In the tutorial of course 1, the teaching assistant does not show how to solve the problem sets, but helps when students have questions. However, the final solution to every exercise is provided to all students. Consequently, abstaining from class and trying to figure out the approach by oneself or with friends may be just as effective as asking the teaching assistant.

In the tutorial of course 2, the teaching assistants show and explain how to solve the provided question sets. This means that students who attend class get a perfect solution to the respective problem, and additionally, have the opportunity to ask questions. Nevertheless, some students may prefer to copy a friend's notes and study on their own. Students may also form study groups where they take turns in going to class, and afterwards discuss the learning material with each other. In particular, when students do not take an active role in class, but only listen to the teaching assistant and take down notes, the difference between a lecture and a tutorial turns out to be rather small.

Nevertheless, the insignificant effect of class attendance may also appear due to identification problems. If, for example, students who do not go to class are systematically more motivated than their peers who attend the lecture or tutorial and motivation is not fully captured by controlling for the high school leaving grade, our results would be biased due to a negative self-selection into class attendance. However, it is not obvious why more motivated students should abstain from going to class, especially under the assumption that motivation and academic ability are only partially correlated.

In this context, it is also possible that students who do not attend the lecture or tutorial spend more time studying in total and hence show more effort. However, spending more time studying may not necessarily be an indicator for higher motivation in general, but may simply be the result of self-studying being more time-consuming than going to the lecture or tutorial. If the latter is the case, it is conceivable that students would change their behavior as soon as they start going to class. Consequently, the argumentation is in line with our interpretation that going to class and studying on one's own are substitutes. Although 
students may spend more time studying in total when abstaining from class, it is still possible to independently learn the subject matter and achieve equally good grades as students who attend the lecture or tutorial.

\subsection{Conclusion}

In this chapter, we estimate the effect of class attendance on academic performance by using survey data collected at Göttingen University, Germany. We look at two basic courses in business and economics education that differ with regard to their content and required skills. In addition, we distinguish between two types of teaching: lecture and tutorial.

We find a positive and significant impact of always attending class on the achieved grade only for the lecture of course 1. All other categories of attendance are insignificant for the lecture and the tutorial of both course 1 and course 2 . We are aware that we may not be able to identify a causal effect with the data at hand. Nevertheless, the findings show that the students' educational production functions are more complex than often believed. In particular, more input may not lead to more output by implication.

The non-significant effect of attending the lecture may be explained by the courses' structure. Since attending a lecture usually means to listen to the professor and take notes, students adopt a rather passive role. Furthermore, the learning content can be found in textbooks, and the syllabus and other study materials are provided to all students irrespective of class attendance. Consequently, there may be no difference between going to class and listening to the lecturer and studying on one's own or with friends. In contrast, in the tutorials, students have the opportunity to ask questions and get a better understanding of the learning matter. However, if the solutions to the problem sets are available to everyone or students copy each other's notes, going to class and studying on one's own may again be substitutes.

The argumentation underlines that teaching concepts may play a crucial role when analyzing the effect of class attendance on university performance. It is conceivable that a positive link between going to class and student performance 
can be found when the teaching and learning environment is more interactive and encourages students to discuss and develop own solutions. For example, Beltz et al. (2011) analyze the effect of attending small group tutorials that accompany a basic lecture in business administration at a German university. In contrast to the tutorials that we assess, the students need to take a more active role in class. They have to present homework, solve question sets in groups and discuss the results afterwards. In addition, they have the possibility to take voluntary tests in the course of the semester. Contrary to our study, Beltz et al. (2011) find a positive link between class attendance and student performance. However, this does not contradict our results due to the differences in teaching concepts. In fact, the different results underline the complexity of the students' educational production function where simply providing more teaching or reducing class size may not lead to more output by implication. Instead, a variety of class specific factors such as teaching concepts should be taken into account when analyzing the effect of attendance on student performance. 


\section{A Appendix I: Questionnaire ${ }^{9}$}

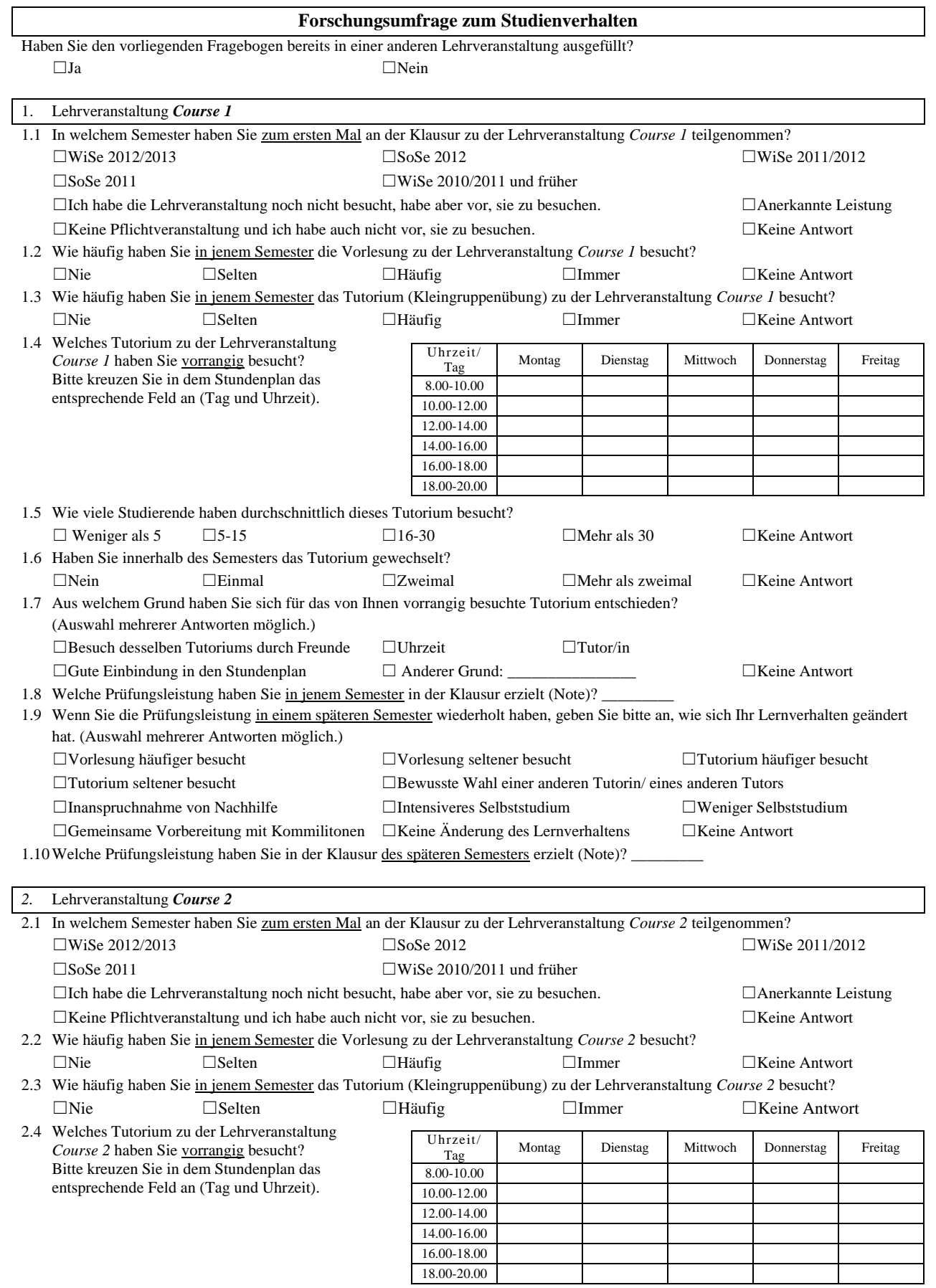

${ }^{9}$ The presented questionnaire is an anonymized version of the original questionnaire. 
2.5 Wie viele Studierende haben durchschnittlich dieses Tutorium besucht?
$\square$ Weniger als 5
$\square 5-15$
$\square 16-30$
$\square$ Mehr als 30
$\square$ Keine Antwort
2.6 Haben Sie innerhalb des Semesters das Tutorium gewechselt?
$\square$ Nein
$\square$ Einmal
$\square$ Zweimal
$\square$ Mehr als zweimal
$\square$ Keine Antwort

2.7 Aus welchem Grund haben Sie sich für das von Ihnen vorrangig besuchte Tutorium entschieden?

(Auswahl mehrerer Antworten möglich.)

$\square$ Besuch desselben Tutoriums durch Freunde $\quad \square$ Uhrzeit $\quad \square$ Tutor/in

$\square$ Gute Einbindung in den Stundenplan $\quad \square$ Anderer Grund:

Welche Prüfungsleistung haben Sie in jenem Semester in der Klausur erzielt (Note)?

2.9 Wenn Sie die Prüfungsleistung in einem späteren Semester wiederholt haben, geben Sie bitte an, wie sich Ihr Lernverhalten geändert hat. (Auswahl mehrerer Antworten möglich.)

$\square$ Vorlesung häufiger besucht

$\square$ Vorlesung seltener besucht

$\square$ Tutorium häufiger besucht

$\square$ Tutorium seltener besuch

$\square$ Bewusste Wahl einer anderen Tutorin/ eines anderen Tutors

$\square$ Inanspruchnahme von Nachhilfe

$\square$ Intensiveres Selbststudium

$\square$ Weniger Selbststudium

$\square$ Gemeinsame Vorbereitung mit Kommilitonen

$\square$ Keine Änderung des Lernverhalten

$\square$ Keine Antwort

2.10 Welche Prüfungsleistung haben Sie in der Klausur des späteren Semesters erzielt (Note)?

3. Individuelles Lernverhalten

Wenn Sie lernen,...

3.1 ...wie oft nutzen Sie die Lernräume (inkl. Bibliotheken) der Universität?

$\square \mathrm{Nie} \quad \square$ Selten $\quad \square$ Häufig $\quad \square$ Immer $\quad \square$ Keine Antwort

3.2 ...wie oft lernen Sie zuhause?
$\square \mathrm{Nie}$
$\square$ Selten
$\square$ Häufig
$\square$ Immer
$\square$ Keine Antwort

3.3 ...wie oft lernen Sie alleine?

$\square$ Nie $\quad \square$ Selten

$\square$ Häufig $\quad \square$ Immer

$\square$ Keine Antwort

3.4 ...wie oft lernen Sie mit einer anderen Person zusammen?

$\square \mathrm{Nie} \quad \square$ Selten $\quad \square$ Häufig

$\square$ Immer

$\square$ Keine Antwort

3.5 ...wie oft lernen Sie in einer Gruppe mit mehr als einer anderen Person?
$\square \mathrm{Nie}$
$\square$ Selten
$\square$ Häufig
$\square$ Immer
$\square$ Keine Antwort

4. Persönliche Angaben

4.1 Wie lautet Ihr Geschlecht?

$\square$ Weiblich

$\square$ Männlich

$\square$ Keine Antwort

4.2 Wie lautet Ihr Geburtsjahr?

4.3 Wie lautet die Postleitzahl Ihrer Heimatanschrift? (Wenn Sie die Postleitzahl nicht kennen, geben Sie bitte den Ort an.)

4.4 Seit welchem Semester studieren Sie an der Georg-August-Universität Göttingen?

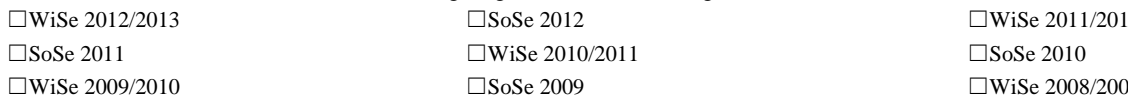

$\square$ WiSe $2009 / 2010-\square$ SoSe 2009

$\square$ SoSe 2008

$\square$ WiSe 2007/2008 und früher $\quad \square$ Keine Antwort

4.5 In welchem Studiengang sind Sie immatrikuliert?

$\square$ Betriebswirtschaftslehre

$\square$ Wirtschaftspädagogik

$\square$ Volkswirtschaftslehre

$\square$ Wirtschaftsinformatik

$\square$ anderer Studiengang:

$\square$ Volkswirtschaftslehre im Rahmen eines Zwei-Fach-Bachelor-Studiengangs

$\square$ Keine Antwort

4.6 Wenn Sie Volkswirtschaftslehre im Rahmen eines Zwei-Fach-Bachelor-Studiengangs studieren, geben Sie bitte Ihr zweites Fach an:

4.7 Wie lautet die Note Ihrer Hochschulzugangsberechtigung (meist Abitur)?

4.8 Welches ist der höchste Bildungsabschluss Ihrer Mutter?
$\square$ Kein Abschluss
$\square$ Volks-/Hauptschulabschluss
$\square$ Realschulabschluss
$\square$ Fachhochschulreife
$\square$ Allgemeine Hochschulreife
$\square$ Hochschulabschluss
$\square$ Keine Antwort

$\square$ Promotion 


\section{B Appendix II: Data Processing}

Since students may attend several of the courses where the questionnaires were distributed, it was important to avoid that they filled out more than one copy. To do so, a question asking whether the students had already filled out the questionnaire was included. All questionnaires with a tick for "yes", meaning that it had been filled out before, were not considered in the analyses.

In some cases, decisions on how to handle specific answers given by the students had to be made in order to ensure standardization. In general, the option "no answer" was transferred into a missing value. The same was done for grades that do not correspond to the German grading scheme as well as the answer "Abitur" (name of the German high school leaving certificate) instead of a grade.

Concerning the mother's level of education, a student filled in the name of a certificate which does not exist in Germany any longer. In this case, a corresponding level of qualification was registered. Furthermore, the answer "I do not know" to the question on the mother's academic qualification was coded as missing value. In the case where more than one answer was given to a specific question, all answers were taken into account. Only questionnaires containing contradictory answers were dropped.

Students are allowed to repeat the examination either because they failed or in order to improve the obtained grade. For this reason, the questionnaire asked if the student repeated the examination and if so, which grade she achieved. In the analysis, only the grade of the first examination is used to measure student performance.

Students with missing data concerning course 1 (course 2) were excluded from the analysis of the respective course only. The same was done for students who had not yet taken the examination or did not take the respective course at all, as well as for those who took the respective course at a different university. Students with missing data regarding personal information, such as the grade of the high school leaving certificate, were removed from the overall sample. Furthermore, we excluded students who stated that their home address is outside of Germany. This is done as the provided grade of the high school leaving certificate may not be transformed into the German grading scheme, and hence 
not comparable. Moreover, foreign students may face additional challenges with regard to language and culture that influence their university performance.

In total, there were 613 questionnaires out of which 383 were used for the final analyses. 349 questionnaires included all information relevant to evaluate course 1; 277 questionnaires were used to analyze course 2. 


\section{Chapter 4}

\section{Studying Abroad - Outsmarting the System*}

\subsection{Introduction}

Globalization and internationalization do not only influence business and political decisions, but also affect university education. According to OECD figures (OECD, 2012) the number of students studying abroad increased by about 400 percent between 1975 and 2010. In 2010 more than 4.1 million students in higher education attended universities outside their home country (OECD, 2012). A similar pattern can be observed in Germany: until the year 2000 the share of university students going abroad increased to one third and stayed at this level since then (DAAD and HIS, 2013). Some of these students obtain their whole degree in a foreign country, while others do an internship or a language course. However, it is noted that the most popular reason for going abroad for German students is a temporary study-related visit abroad. More than half of the German students who decide to go abroad choose to study at a foreign university for one or two semesters (DAAD and HIS, 2013). The popularity of such a sojourn raises the question of what gains can be expected from being internationally mobile during university education.

*This chapter originates from joint work with Johannes Meya (see Meya and Suntheim, 2014). 
The most prominent benefit from studying in a foreign country is arguably personal development. Study-related visits abroad are seen to have a positive impact on students' personality and cross-cultural skills. Students who went abroad report to be more independent, approachable and agreeable than before their stay. Furthermore, they are more open to foreign cultures and ways of working (Clarke et al., 2009; DAAD and HIS, 2013; Zimmermann and Neyer, 2013).

International experience seems to affect job market opportunities and decisions: Parey and Waldinger (2011) point out that studying in a foreign country influences the probability of working abroad later in life for German university graduates. Using an instrumental variables approach, they find that internationally mobile students are 15 percentage points more likely to work abroad after graduation than their counterparts who stayed at home. As possible reasons they emphasize the importance of factors such as having a partner from another country or interest in different cultures. Following the identification strategy applied by Parey and Waldinger (2011), Di Pietro (2012b) finds similar results for Italian graduates. His findings suggest that students who take a sojourn during university studies are 18 to 24 percentage points more likely to also work abroad. These results are supported by Teichler (2011) who analyzes the impact of international experience gained during or shortly after graduation on later employment. Additionally, he finds that even if graduates with international experience work in their home country, they are more likely to have a job that requires cross-cultural skills in particular. Furthermore, Oosterbeek and Webbink (2011) show that studying abroad has a positive impact on the likelihood of living in a foreign country in the beginning of one's professional career. Moreover, in their study regarding the relationship between studying abroad and later migration, Dreher and Poutvaara (2011) find that an increase in the number of foreign students studying in the United States also leads to higher immigration later on.

More directly looking at the success in the job market, Di Pietro (2015) finds that a study-related visit abroad increases the probability of being employed three years after graduation. In contrast, Messer and Wolter (2007) do not find a causal effect of a study-related visit abroad on the first job salary and the 
probability of starting a Ph.D. once they instrument for studying abroad. They suggest that differences in later job market success and academic careers may be due to internationally mobile students generally being more capable rather than due to the visit abroad.

Our study contributes to the literature on the effects of international student mobility by focusing on the impact of a sojourn on academic performance. Drawing on a rich dataset collected at Göttingen University, Germany, we analyze if and how studying one or two semesters at a foreign institution influences the final university grade achieved and the time needed to finish the degree program. We apply a propensity score matching strategy in order to overcome a potential problem of self-selection into studying abroad. This is possible due to the unique dataset at hand containing a variety of individual information on more than 2500 students who successfully completed their bachelor studies.

We find that a temporary study-related visit abroad on average improves the final university grade by $0.095-0.17$ grades. This effect seems to arise as a consequence of students strategically deciding which grades count towards their degree. Since most students who study abroad can decide themselves which and how many of the courses taken at the foreign university shall count towards their degree, they have an edge over their peers who stay at home. With regard to students who studied abroad, we note that the final university grade is 0.2 grades better for those who count the grades obtained at the foreign university towards their degree in contrast to those who do not transfer any grades. Furthermore, we find that students who go abroad have a lower probability of finishing their bachelor studies within the standard time period. This further supports our interpretation that students selectively transfer grades achieved abroad which are better than the average grade obtained at the home university. Moreover, it implies that selective transferring of grades comes at a cost. Although being a case study, these results can be placed into a broader perspective. The chapter shows that giving students more flexibility with regard to the number of courses they take and which of these courses they count towards the degree leads to better final university grades and longer times spend at university.

This chapter is structured as follows: Section 4.2 describes the dataset and presents summary statistics. Section 4.3 gives an overview of the empirical 
framework used in the analysis. Section 4.4 presents and interprets our empirical results. Section 4.5 tests the robustness of our results. Finally, Section 4.6 summarizes the main findings and concludes.

\subsection{Data Description}

For our analysis we use a unique dataset consisting of administrative student data collected at Göttingen University, Germany. It contains detailed, anonymous information about more than 2500 students who successfully completed their bachelor studies between 2006 and 2011, such as the students' university and high school degree and grade, subjects studied, their gender, type of health insurance and the zip-code of their address during semester as well as that of their parents' residence. Information on study-related visits abroad is provided by the international office of Göttingen University which collects data concerning students who take part in international mobility programs such as the European Union student mobility program, ERASMUS. We also use information about exams taken at a foreign university provided by the examination office in order to register stays abroad for students who did not take part in such a program but still studied at a foreign university. ${ }^{10}$

We restrict our sample to bachelor students who started their university studies at Göttingen University. ${ }^{11}$ The reason for this is that we can then observe all examinations relevant for the degree for these students. Furthermore, for all bachelor programs at Göttingen University some common rules apply, among them, a regular length of study of six semesters including thesis. As we have detailed information on the students' course of study, we are able to take into account only semesters of the field of study the respective student achieved her bachelor degree in. We restrict our attention to students who hold a German high school certificate as we use the grade received to control for pre-university ability.

\footnotetext{
${ }^{10}$ Further information on data processing is provided in the appendix of this chapter.

${ }^{11}$ Students of the faculties of theology and law are not part of the analysis, as they are only in extremely rare cases enrolled in bachelor programs.
} 
Since we examine the impact of a study-related visit to a foreign university (usually one or two study terms) on academic performance, we are only interested in study-related stays during which the student could take courses counting towards her degree at Göttingen University. Students who took part in mobility programs that also support other kinds of stays, such as internships, short term field excursions and language courses, are dropped. Furthermore, in some unusual cases, students are enrolled in more than one bachelor program at the same time. In this case it cannot clearly be identified which courses taken abroad were transferred to the respective degree. Therefore, we exclude these students from the analysis.

We distinguish between students who stayed abroad and counted all or some of the grades obtained towards their bachelor degree at Göttingen University and students who stayed abroad, but did not transfer any of the grades achieved at the foreign university. Although most students taking part in an international mobility program are obliged to take courses at the foreign university, these courses taken abroad might not necessarily be part of the home curriculum, and therefore cannot be counted towards the degree at the home institution. For the courses taken abroad to be part of the final university grade, the grades need to be converted into the German grading scheme. Therefore, we require a student who transferred grades, that is count grades she achieved at a foreign university towards her degree at Göttingen University, to have at least one grade from the foreign university that is within the German grading interval. For students with no grade corresponding to the German grading scheme from courses taken abroad or who did not register their grades from the foreign university, the respective indicator variable is zero.

Dependent Variables. Firstly, we analyze the effect of a sojourn on the final university grade. German university grades range from 1 to 4 with 1 being the best and 4 the worst grade still allowing students to pass. We convert them into the U.S. grading scheme with 4 being the best and 1 the worst grade that is still a pass in order to make results internationally comparable. ${ }^{12}$

\footnotetext{
${ }^{12}$ We converted the grades into the US grading scale by subtracting the final university grade from five.
} 
Secondly, we examine whether a study-related visit abroad affects the probability of finishing the bachelor studies in time, i.e. within the standard time period of six semesters. To do so, we create an indicator variable that is equal to one if the student finished within six semesters, and equal to zero if she took longer to complete her degree.

Independent Variables. We control for the student's pre-university ability by using the grade of the high school leaving certificate. Similar to the university grades, the grades of the high school leaving certificate are converted into the U.S. grading scheme.

To account for the students' socio-economic background, we use the type of health insurance a student holds and the purchasing power index related to the zip-code area her parents live in. The health insurance status can be used in this context due to the features of the German health care system, distinguishing between private and public health insurance. One has to fulfill certain criteria concerning income or employment status in order to select a private instead of the generally compulsory public health insurance. Therefore, compared to the overall German population, a disproportionately high number of people who hold a high school certificate enabling them to register at a university or a university of applied sciences and people who finished university or university of applied sciences with a degree or even a Ph.D. are privately insured. ${ }^{13}$ Taking into consideration that students in Germany are normally insured through their parents, their health insurance contains information about their socio-economic background.

The purchasing power index is provided by the market research firm GfK and measures the purchasing power within a zip-code area relative to the German average in 2007. ${ }^{14}$ As the German zip-code areas are relatively small - for

\footnotetext{
${ }^{13}$ In 2008, 56.7 percent of the privately insured held a high school degree that enables enrollment at a university or a university of applied sciences, 38.0 percent finished university or university of applied sciences with a degree or a Ph.D. (Finkenstädt and Keßler, 2012). The corresponding numbers for the whole German population are 24.4 percent and 13.0 percent respectively (Statistisches Bundesamt, 2009).

${ }^{14} \mathrm{GfK}$ is one of the biggest companies worldwide in the field of market research. It collects information on people's consumption behavior and lifestyle. The purchasing power index used in the analysis is based on data provided by the German tax offices as well as other relevant statistics concerning e.g. pensions and unemployment benefits.
} 
instance there are about 190 different zip-codes in Berlin - we are confident to apply a well-founded measure of the students' socio-economic background.

We include the distance between the students' home town and Göttingen into our analysis in order to account for prior mobility decisions. ${ }^{15}$ Furthermore, we control for gender, the university's faculties offering bachelor programs and the student's cohort.

Summary Statistics. Summary statistics are shown in Table 4.1. Our final dataset contains 2624 observations, out of which 12 percent spent part of their studies at a university in a foreign country. The mean university grade point average (GPA) of these students is slightly higher, i.e. better, than the mean university GPA of their counterparts who stay at home. A t-test shows that this difference is significant at the one percent level. The same results hold for the GPA earned at high school.

In our sample, there are slightly more female than male students and it seems that a disproportionately high number of female students go abroad. Students who go on a study-related visit abroad appear to have a higher socio-economic background, accounted for by the private health insurance and the purchasing power index. Moreover, these students seem to be generally more mobile as the mean distance between their parents' home and Göttingen is greater than for students who take all their courses at Göttingen University. These findings are in line with surveys focusing on German students in general (DAAD and HIS, 2013).

Furthermore, it can be seen that 80 percent of the students in our sample who go on a study-related visit abroad also count grades from the foreign university towards their degree. When taking a look at the time needed to finish a degree, summary statistics show that only 36 percent of the students studying abroad graduate in time, i.e. within six semesters, in comparison to 62 percent of their counterparts who stay at home.

The faculties having the highest shares of students studying abroad are the faculty of economic sciences (27 percent) and the faculty of humanities (31 percent). For both faculties, this share is disproportionately high compared to their

\footnotetext{
${ }^{15}$ Google Maps standard route planer is used to measure the distance between the parents' zip-code area and Göttingen.
} 
Table 4.1: Summary Statistics

\begin{tabular}{lcccccc}
\hline \hline & \multicolumn{2}{c}{ Total } & \multicolumn{2}{c}{ Study } & Abroad $=1$ & \multicolumn{2}{c}{ Study Abroad $=0$} \\
Variable & Mean & Std. Dev. & Mean & Std. Dev. & Mean & Std. Dev. \\
\hline University GPA & 2.86 & 0.47 & 2.99 & 0.44 & 2.85 & 0.47 \\
Graduate in time & 0.59 & 0.49 & 0.36 & 0.48 & 0.62 & 0.48 \\
Study abroad & 0.12 & 0.32 & 1.00 & 0.00 & 0.00 & 0.00 \\
Transfer grades & 0.09 & 0.29 & 0.80 & 0.40 & 0.00 & 0.00 \\
High school GPA & 2.60 & 0.63 & 2.71 & 0.59 & 2.58 & 0.63 \\
Male & 0.46 & 0.50 & 0.36 & 0.48 & 0.48 & 0.50 \\
Private health insurance & 0.18 & 0.39 & 0.23 & 0.42 & 0.18 & 0.38 \\
Purchasing power index & 97.73 & 11.58 & 99.04 & 10.71 & 97.56 & 11.68 \\
Distance to university & 184.69 & 118.41 & 204.25 & 118.91 & 182.13 & 118.13 \\
Medicine & 0.02 & 0.12 & 0.01 & 0.08 & 0.02 & 0.13 \\
Humanities & 0.20 & 0.40 & 0.31 & 0.46 & 0.18 & 0.39 \\
Mathematics & 0.04 & 0.19 & 0.03 & 0.17 & 0.04 & 0.20 \\
Physics & 0.04 & 0.19 & 0.02 & 0.13 & 0.04 & 0.20 \\
Chemistry & 0.05 & 0.21 & 0.01 & 0.10 & 0.05 & 0.22 \\
Geology/Geography & 0.03 & 0.18 & 0.01 & 0.08 & 0.03 & 0.18 \\
Biology & 0.11 & 0.31 & 0.08 & 0.28 & 0.12 & 0.32 \\
Forest sciences & 0.09 & 0.28 & 0.05 & 0.21 & 0.09 & 0.29 \\
Agriculture & 0.21 & 0.41 & 0.17 & 0.37 & 0.22 & 0.41 \\
Economic sciences & 0.18 & 0.38 & 0.27 & 0.44 & 0.17 & 0.37 \\
Social sciences & 0.05 & 0.21 & 0.06 & 0.24 & 0.05 & 0.21 \\
Cohort 1 & 0.08 & 0.27 & 0.04 & 0.20 & 0.08 & 0.28 \\
Cohort 2 & 0.08 & 0.27 & 0.09 & 0.28 & 0.08 & 0.26 \\
Cohort 3 & 0.18 & 0.38 & 0.22 & 0.42 & 0.17 & 0.38 \\
Cohort 4 & 0.35 & 0.48 & 0.36 & 0.48 & 0.35 & 0.48 \\
Cohort 5 & 0.31 & 0.46 & 0.29 & 0.45 & 0.32 & 0.46 \\
\hline Observations & 2624 & & 304 & & 2320 & \\
\hline \hline & & & & & &
\end{tabular}

Grades converted to 1-4 scale, with 4 being the best and 1 being the worst grade that is still a pass. 
overall share of students (18 percent and 20 percent respectively) in our sample. The faculty of agriculture, on the other hand, has a disproportionately low share of students who decide to go abroad for part of their studies compared to its overall share of students (17 percent and 21 percent respectively). These findings are also in line with results found with regard to all German students (DAAD and HIS, 2013).

\subsection{Empirical Framework}

The summary statistics suggest that students who go abroad during their university studies might be systematically different from students who stay at home. If this is indeed the case, a direct comparison of the two groups and ordinary least squares regressions may lead to biased results.

The best way to overcome this problem of self-selection into studying abroad would be through the design of an experimental framework, where students are randomly assigned to the treatment, i.e. studying abroad. Such a procedure is, however, not feasible for obvious reasons. Since there is no specified threshold at which students become eligible to go abroad also empirical strategies like regression discontinuity designs cannot be applied in our setting. In fact, there exist several different mobility programs and every institute individually allocates the available amount of places on these programs. Thereby, students are not restricted to only applying at the faculty they are studying at. This means that students who want to go abroad have a lot of different possibilities to apply for an international mobility program. Hence, not being accepted for a certain program or at a certain institute does not necessarily imply that the student cannot go abroad at all.

Bearing this in mind, we apply a propensity score matching strategy in order to take self-selection into studying abroad into account as much as possible. The general idea of this matching approach is to compare individuals that have received a certain treatment and individuals of a control group who have not, but who are very similar concerning their pre-treatment characteristics. Since the matched individuals only differ in the treatment, a difference in the outcome can 
be assigned to the treatment (see for instance Becker and Ichino, 2002; Caliendo and Kopeinig, 2008; Heckman et al., 1998). As it might be difficult to find counterparts that are equal with regard to a variety of covariates, Rosenbaum and Rubin (1983) suggest to use a balancing score in order to group treated and untreated individuals. The balancing score they introduce is the propensity score which measures the conditional probability of being exposed to a treatment given a set of pre-treatment covariates (Becker and Ichino, 2002):

$$
p(X)=\operatorname{Pr}(A=1 \mid X)=E(A \mid X)
$$

where $A$ denotes the treatment, which is studying abroad in our case, and $X$ is a set of pre-treatment covariates.

The treated and untreated individuals are grouped by their propensity scores so that within a respective group, the distribution of covariates is identical and independent of the assignment to the treatment, i.e. receiving the treatment is as good as random given the controls. The average treatment effect on the treated, $\tau_{A T T}$, is the difference between the expected outcome when being and not being exposed to the treatment for all individuals who actually received the treatment (Becker and Ichino, 2002):

$$
\tau_{A T T}=E\left[E\left\{Y_{1 i} \mid A_{i}=1, p\left(X_{i}\right)\right\}-E\left\{Y_{0 i} \mid A_{i}=0, p\left(X_{i}\right)\right\} \mid A_{i}=1\right]
$$

with $Y_{1 i}$ and $Y_{0 i}$ being the outcome for individual $i$ in the case that she received and did not receive the treatment respectively.

In our analysis we estimate the propensity score of going abroad for all students in the sample using a probit model with $\Phi$ being the standard normal cumulative distribution function and $h\left(X_{i}\right)$ a function of the individuals' covariates:

$$
\operatorname{Pr}\left(A_{i}=1 \mid X_{i}\right)=\Phi\left\{h\left(X_{i}\right)\right\}
$$

From the summary statistics presented in Section 4.2 as well as the results of other studies on the topic (e.g. DAAD and HIS, 2013), we expect the high school 
leaving grade, gender, socio-economic background, pre-university mobility, field of study and the student's cohort to have an impact on going abroad.

We match treated and untreated individuals based on their propensity scores. Specifically, we first apply nearest neighbor matching. This means that in order to estimate the average treatment effect on the treated, each individual of the treatment group is assigned the counterpart in the control group that is closest with regard to the propensity score. To reduce the risk of bad matches, we require the nearest neighbor to be within a caliper of 0.05. Additionally, we provide estimation results for kernel matching, with an Epanechnikov kernel function and the standard bandwidth of 0.06, and radius matching, with a caliper of 0.05. The latter two algorithms make use of more individuals of the control group at the cost of these additional matches not being as close as the nearest neighbor.

Unconfoundedness and Weak Overlap. A crucial assumption of propensity score matching is unconfoundedness or conditional independence: $Y_{0}, Y_{1} \| A \mid X$, with $\|$ denoting independence. This means that given the characteristics we observe, potential outcomes do not depend on treatment assignment. Nonetheless, if there exist unobserved variables which affect both going abroad and success at university, propensity score matching would lead to biased results.

By using the grade of the high school leaving certificate, we control for the fact that students who go abroad might be generally academically more able than students who stay at their home university. The grade of the high school leaving certificate is shown to be a strong predictor for university success (Betts and Morel, 1999; Cyrenne and Chan, 2012; Danilowicz-Gösele et al., 2014). Furthermore, the grade may be a measure of motivation since students with a very good high school leaving certificate are typically not only smart, but also willing to put a lot of effort into studying.

The fact that studying abroad might be more costly than staying in Germany may lead to students with a higher socio-economic background being more likely to pursue part of their studies in a foreign country. Going to another country might be difficult to finance, especially for students who cannot afford to move away from their parents' residence when starting university. Moreover, highly educated parents might support a sojourn not only financially, but also 
by emphasizing the advantages of getting to know another country, language and culture. Therefore, we address a possible self-selection with regard to socioeconomic characteristics by using the type of health insurance a student holds and the purchasing power of the parents' zip-code area as controls. Furthermore, we include gender in our model in order to account for systematic differences between male and female students regarding their choice of going abroad as well as academic performance.

Another factor that might influence the decision to go abroad as well as success at university is pre-university mobility. Moving away from home when starting university may imply a high level of independence and openness. Students who already once decided to leave their social environment may be more likely to go to a foreign country than their counterparts who decided to study at a university close to their home town. In addition, pre-university mobility might also affect the final university performance. A possible reason for this could be that students who move far away from home when starting university put more effort into finding the perfect match regarding university and field of study. This might lead to a high level of motivation, resulting in better grades. As it seems likely that the impact of pre-university mobility is non-linear with a decreasing marginal effect of distance, we use the natural logarithm of this variable as a control.

We also take into account that the possibility to go abroad as well as university performance may be influenced by the different faculties. Each student is assigned to one of the thirteen faculties at Göttingen university, depending on the field of study. Since a sojourn may be more common and more useful in some fields, such as in foreign language studies, literature and culture, students belonging to those faculties might be more likely to go abroad. At the same time, examination regulations and policies may differ among faculties, and thereby influence the final university grade as well as the time needed to graduate. In Chapter 2, we provide evidence for this assumption by examining determinants of students' success at university.

Finally, we account for cohort effects by controlling for the semester the student started a bachelor program in the field of study she obtained her degree in. Studying abroad might be more promoted in some years than in others and 
cohort size as well as the number of available places may differ in different years. Therefore, cohorts could have an impact on the probability of studying at a foreign university. Further, students within the same cohort are affected by the same study regulations and conditions: they may even take the same courses and examinations. As these cohort effects are probably even stronger within each of the faculties, we include interaction effects.

To sum up, we are confident to observe the relevant characteristics that might impact both assignment to the treatment and the outcome variables. Nevertheless, we are aware that propensity score matching only leads to robust and unbiased results if the assumption of conditional independence holds. We address this issue by testing the sensitivity of our results with regard to unobserved heterogeneity in Section 4.5.

Besides unconfoundedness the assumption of weak overlap also needs to be satisfied in order to get robust and unbiased results: $\operatorname{Pr}(A=1 \mid X)<1$. It means that individuals with a given set of covariates have a positive probability of not being treated. In our analysis, the weak overlap condition is fulfilled.

\subsection{Results}

We start the empirical analysis with a simple OLS model. Table 4.2 shows a positive and highly significant effect of studying abroad on the university GPA in all three regressions. In the full specification, column (3), the estimated effect of studying abroad is 0.08 grade points, which is slightly larger than the estimated effect of an increase in the high school leaving grade by one fifth of a grade. However, as described above, these results may suffer from a bias due to selfselection.

The descriptive analysis has already shown that students who study abroad might be systematically different from those who stay at their home university. Therefore, we expect that spending some time at a foreign university is not necessarily random and take a closer look to characteristics explaining whether or not a student goes abroad. Table 4.3 presents results of the corresponding probit regression. We display marginal effects for a benchmark student and 
the coefficients of the underlying regression. The benchmark student is female, publicly insured, studies at the faculty of humanities and belongs to the last cohort of the sample. She is average with regard to all continuous variables.

Our findings confirm the descriptive results of DAAD and HIS (2013) as they show that a better high school grade increases the probability of going abroad. Also, the private health insurance status, which proxies socio-economic background, shows the expected positive sign and is significant. The finding of Parey and Waldinger (2011) is supported in our analysis as we find that earlier mobility decisions have predictive power for studying abroad: the coefficient of the variable measuring distance of the parental address to Göttingen carries a positive sign and is highly significant. Besides, male students are less likely to go abroad.

Based on this regression, we apply propensity score matching as described in Section 4.3. Table 4.A.1 in the appendix of this chapter shows that the matching applied balances the treatment and the control group with respect to all variables used. ${ }^{16}$ In addition, Figures 4.A.1.a and 4.A.1.b present the distributions of students in the two groups by their propensity score before and after nearest neighbor matching.

Table 4.4 contains corresponding matching results. The estimated effect is between 0.095 and 0.17 grades and highly significant. ${ }^{17}$ This corresponds to between one fifth and one third of a standard deviation of university GPA. Our findings confirm the positive effect on the final university grade from studying abroad. The effect in Table 4.4 is larger than the OLS coefficient of studying abroad in the full specification in Table 4.2.

Concerning the channels through which studying abroad affects the grade of the degree, at least two main strands of interpretation can be thought of: firstly, an argument based on learning and secondly, an argument based on grades.

\footnotetext{
${ }^{16}$ The balancing table presents results for nearest neighbor matching. However, kernel and radius matching also balance the two groups with respect to all variables used. For the sake of brevity, we leave out corresponding tables.

${ }^{17}$ The statistical inference for the treatment effect does not take into account that the propensity score is estimated. However, repeating the nearest neighbor matching with the teffects psmatch routine of Stata 13 shows that this does not alter our findings. The estimated effect is almost identical and the corresponding Abadie-Imbens standard error is even smaller.
} 
Spending some time studying at a foreign university allows students to complement their courses at their home institution. They may take specialized courses that are not available at their home university and are potentially confronted with different styles of teaching, learning and studying. In many cases, the language spoken is different. Furthermore, the cultural experience is considered to contribute to the personal development of students. Therefore, going abroad may improve the student's academic ability.

The second interpretation refers to grades transferred back to the home university: if these grades are on average better than the average grade earned at the home university, the positive effect shown above can be explained. There are several reasons why this could be the case: For instance, the effect could be based on better teaching or studying conditions at the host university, a more lenient grading policy on average at the foreign universities in the sample or selectively better grades given to visiting students. However, in our opinion, the most convincing reason why grades transferred back are better than the average grade earned at home, is that students primarily count the good grades of the sojourn towards their degree and leave out mediocre ones.

To shed light on the question of how important the grades transferred are for the positive effect on the final university grade shown above, we focus on the subsample of students who studied abroad. Since about 20 percent of this group did not transfer grades, we can exploit this variation to analyze the effect of counting grades towards the degree. All students in this subsample studied abroad so that self-selection into going abroad is not an issue. Still, who transfers grades might not be random. However, the data at hand does not support this hypothesis: estimating whether or not students who go abroad transfer grades does not yield any significant effect. Specifically, we do not find evidence that academically stronger students are more likely to transfer grades than weaker students. ${ }^{18}$ Besides, based on theoretical considerations, it is not obvious why some students should systematically be more likely to transfer grades than others. The individual attractiveness of such a transfer should rather depend on how these grades are relative to those that the student earned at the home university.

\footnotetext{
${ }^{18}$ Corresponding estimation results are shown in Table 4.A.2 in the appendix of this chapter.
} 
Table 4.5 presents OLS results for the effect of transferring grades from abroad on the final university grade. The coefficient of interest is highly significant and positive, implying that the grades transferred on average improve the final grade. A descriptive comparison of the individual grades confirms this econometric result: on average, the difference between the grades a student transferred and her final university GPA is about 0.2 grades. ${ }^{19}$ The corresponding median difference is even larger, a quarter of a grade.

Our second measure of academic success is whether bachelor students graduate within the standard period of time of six semesters. Table 4.6 presents results of the corresponding probit estimation. According to these estimates, going abroad decreases the probability of graduating in time, whereas a better high school leaving grade increases it. Both effects are significant at the 0.1 percent level. However, as shown above, the group of students who spent part of their studies abroad is not a random selection. Therefore, we address this issue again by applying propensity score matching. We present results of nearest neighbor, kernel and radius matching in Table 4.7. ${ }^{20}$ The negative effect of going abroad on the probability of graduating within the standard time period is highly significant and robust with regard to the different matching algorithms. ${ }^{21}$ This suggests that students on average are not simply replacing a semester at their home institution with a semester abroad, but extend their overall time spend at university.

Summarizing our empirical results, we show that spending some time at a foreign university during bachelor studies has a positive effect on the final university grade. Taking into account only students who studied abroad, it can be noted that transferring grades significantly improves the bachelor grade. However, a sojourn reduces the probability of finishing a bachelor program within the standard time period. Selective transferring of grades can explain these findings. It seems that students primarily count those grades awarded abroad

\footnotetext{
${ }^{19}$ The corresponding difference in means is significant at the 0.1 percent level.

${ }^{20}$ Since the same three matching algorithms as above are applied, additional balancing analysis is not necessary.

${ }^{21}$ We also replicate the nearest neighbor matching with the teffects psmatch routine of Stata 13 employing Abadie-Imbens standard errors. Treatment effect and standard error remain virtually unchanged.
} 
towards their degree that are better than the average grade they earn at their home institution. Thereby, students can improve the final grade at the cost of extending the time needed to graduate.

\subsection{Sensitivity to Unobserved Heterogeneity}

As discussed in Section 4.3, propensity score matching is based on the assumption that we observe the relevant pre-treatment characteristics that determine whether a student goes abroad. If there are unobserved factors that influence both treatment assignment and the outcome variables, our estimated effects may be biased. We follow the bounding approach proposed by Rosenbaum (2002) in order to test to what extend our results are sensitive to such unobserved heterogeneity. The idea of this approach is to analyze how much an unobserved variable could cause two individuals with the same pre-treatment characteristics to differ in their odds of going abroad without changing the inference of the estimated effects of a sojourn. ${ }^{22}$

Results of the sensitivity analysis for both outcome variables are shown in Table 4.8. Rosenbaum bounds are applied for the final university grade, column (1), and Mantel-Haenszel bounds for the binary outcome, graduating in time, column (2). The values for the variable $\Gamma$ give the differences in the odds of treatment assignment for individuals with the same pre-treatment characteristics that may occur due to unobserved heterogeneity. With regard to the effect of going abroad on the final university grade, we find a positive and significant effect when assuming that there is no hidden bias $(\Gamma=1)$. The effect turns insignificant at a critical value between 1.4 and 1.45. This means that an unobserved variable could cause a difference in the odds of going abroad for two individuals with the same pre-treatment characteristics of more than 40 percent without changing the inference of our result. With relation to the impact of studying abroad on the probability of graduating in time, an unobserved bias could even cause the odds of treatment assignment to differ by more than 60 percent without turning the effect insignificant. This leads us to the conclusion that the results

\footnotetext{
${ }^{22}$ For a detailed description as well as further empirical applications see also Aakvik (2001); Becker and Caliendo (2007); Caliendo et al. (2008); DiPrete and Gangl (2004).
} 
of our propensity score matching estimations are fairly robust to unobserved heterogeneity.

\subsection{Conclusion}

Using a unique dataset from a German university, this chapter empirically investigates the academic gains to expect from a temporary study-related visit to a foreign university. We can apply a propensity score matching strategy due to the variety of individual information in the data. Our results are robust to different matching estimators and unobserved heterogeneity.

The empirical analysis shows that studying abroad on average improves the final university grade achieved at the home institution by 0.095-0.17 grades. Two possible explanations for this result are that studying abroad improves the students' academic ability or that the grades obtained at the foreign university are better than the average grade achieved at the home institution.

To shed light on this question, we examine the importance of counting grades obtained abroad towards the degree at Göttingen University. We find that students who transfer grades from their study-related visit abroad have a significantly better final university grade than their counterparts who do not count any grade awarded abroad towards their degree. Furthermore, descriptive statistics show that on average the grades a student obtained abroad and transferred towards the degree at Göttingen University is 0.2 grades better than the grade of her final university degree. This supports the interpretation that transferring grades is an important channel through which studying abroad affects academic performance.

Finally, it can be seen that a temporary study-related visit abroad decreases the probability of finishing a bachelor program within the standard time period. This finding suggests that students who go abroad do not count enough courses towards their degree at their home university as they would need in order to be in time with their studies. Thereby, it strengthens our interpretation that students primarily transfer classes if the grade obtained at the foreign university is better than the average grade they achieved at home. 
To sum up, the chapter shows that students who study abroad take the opportunity to selectively transfer grades that are better than the average grade they earn at their home institution in order to improve the grade of their final university degree. Although being a case study, this result can be placed into a broader perspective. It allows for the general conclusion that giving students more flexibility concerning the number of courses they can take and which of these courses they want to count towards their degree will most likely lead to better final university grades. However, the results shown also suggest that this flexibility comes at the cost of prolonged studies. Consequently, the results are not only relevant in the context of study-related visits abroad but give guidance to the design of study regulations in general.

The competitive edge given to students who study abroad can be seen as an unintended consequence of the existing regulations. In this case, universities might want to think of alternative arrangements. For instance, students could be required to transfer a certain number of courses or simply to count all courses taken at the foreign university towards their degree at their home institution. On the other hand, the positive effect might be seen as a bonus awarded to those students taking the effort of organizing a study-related visit abroad. If policy makers aim to increase the number of students spending some time at a foreign university, they might appreciate this feature.

For students going abroad for one or two semesters the results shown might also be of importance. These students need to decide whether to take advantage of selectively transferring grades. By doing so, they can improve their final grade, but should take into account that this might come at the cost of prolonged studies. 
4.A Appendix I: Tables and Figures 
Table 4.2: Final University Grade - OLS Results

Dependent variable: university GPA

\begin{tabular}{lccc} 
& $(1)$ & $(2)$ & $(3)$ \\
\hline Study abroad & $0.139^{* * *}$ & $0.087^{* * *}$ & $0.084^{* * *}$ \\
High school GPA & $(0.027)$ & $(0.024)$ & $(0.025)$ \\
& & $0.407^{* * *}$ & $0.379^{* * *}$ \\
Male & & $(0.011)$ & $(0.010)$ \\
& & & $0.060^{* * *}$ \\
Private health insurance & & & $(0.014)$ \\
& & & -0.008 \\
Purchasing power index & & & $(0.014)$ \\
& & & $0.003^{* * *}$ \\
Log distance & & & $0.001)$ \\
& & & $(0.008)$ \\
Constant & $2.848^{* * *}$ & $1.796^{* * *}$ & $1.745^{* * *}$ \\
& $(0.011)$ & $(0.028)$ & $(0.088)$ \\
\hline Faculties included & No & No & Yes \\
Cohorts included & No & No & Yes \\
Faculties \# cohorts included & No & No & Yes \\
\hline $\mathrm{R}^{2}$ & 0.009 & 0.309 & 0.477 \\
Observations & 2624 & 2624 & 2624 \\
\hline \hline
\end{tabular}

OLS; coefficients, standard errors in parentheses; clustered by counties; ${ }^{*} p<0.05,{ }^{* *} p<0.01$, $* * * p<0.001$. 
Table 4.3: Probability of Studying Abroad

Dependent variable: studying abroad

Marginal Effects Coefficients

(1)

(2)

\begin{tabular}{lcc}
\hline High school GPA & $0.049^{* * *}$ & $0.223^{* * *}$ \\
Male & $(0.012)$ & $(0.053)$ \\
& $-0.030^{*}$ & $-0.148^{*}$ \\
Private health insurance & $(0.014)$ & $(0.069)$ \\
& $0.048^{*}$ & $0.197^{*}$ \\
Purchasing power index & $(0.021)$ & $(0.080)$ \\
& 0.001 & 0.004 \\
Log distance & $(0.001)$ & $(0.003)$ \\
& $0.030^{* * *}$ & $0.135^{* * *}$ \\
Constant & $(0.009)$ & $(0.033)$ \\
& & $-2.741^{* * *}$ \\
Faculties included & & $(0.358)$ \\
Cohorts included & Yes & Yes \\
Faculties \# cohorts included & Yes & Yes \\
\hline Pseudo-R & Yes & Yes \\
Log Likelihood & 0.076 & 0.076 \\
Observations & -842 & -842 \\
\hline \hline
\end{tabular}

Probit estimation; column (1) marginal effects for benchmark student, column (2) coefficients; standard errors in parentheses; clustered by county; ${ }^{*} p<0.05,{ }^{* *} p<0.01,{ }^{* * *} p<0.001$. 
Table 4.4: Final University Grade - Matching Results

Dependent variable: university GPA

Propensity Score Matching

Nearest Neighbor Kernel Radius

(1)

$(2)$ (3)

\begin{tabular}{lccc}
\hline Study abroad & $\begin{array}{c}0.170^{* * *} \\
(0.043)\end{array}$ & $\begin{array}{c}0.095^{* * *} \\
(0.028)\end{array}$ & $\begin{array}{c}0.096^{* * *} \\
(0.028)\end{array}$ \\
\hline Treated observations & 302 & 302 & 302 \\
Untreated observations & 2108 & 2108 & 2108 \\
\hline \hline
\end{tabular}

Propensity score matching, average treatment effects on the treated using nearest neighbor matching with caliper 0.05 (column 1), kernel matching with an Epanechnikov kernel function, bandwidth 0.06 (column 2), and radius matching with caliper 0.05 (column 3) calculated using psmatch2 package for Stata by Leuven and Sianesi (2003), Version 4.0.10; only observations on common support are used; standard errors in parentheses; variables used for the estimation and calculation of the propensity score are high school GPA, male, private health insurance, purchasing power index, log distance to university and indicator variables for faculties and cohorts as well as interactions of faculties and cohorts; ${ }^{*} p<0.05,{ }^{* *} p<0.01,{ }^{* * *} p<0.001$. 
Table 4.5: Transferring Grades

Dependent variable: university GPA

\begin{tabular}{lc} 
High school GPA & $0.416^{* * *}$ \\
Transfer grades & $(0.037)$ \\
& $0.213^{* * *}$ \\
Male & $(0.052)$ \\
& 0.082 \\
Private health insurance & $(0.055)$ \\
& 0.046 \\
Purchasing power index & $(0.043)$ \\
& 0.002 \\
Log distance & $(0.002)$ \\
& -0.005 \\
Constant & $(0.024)$ \\
& $1.708^{* * *}$ \\
\hline Faculties included & $(0.273)$ \\
Cohorts included & Yes \\
Faculties \# cohorts included & Yes \\
\hline $\mathrm{R}^{2}$ & Yes \\
Observations & 0.559 \\
\hline \hline
\end{tabular}

OLS; coefficients, standard errors in parentheses; clustered by county; observations of students who studied abroad; ${ }^{*} p<0.05,{ }^{* *} p<0.01,{ }^{* * *} p<0.001$. 
Table 4.6: Graduating in Time - Probit Results

Dependent variable: graduating in time

Marginal Effects Coefficients

(1)

(2)

\begin{tabular}{lcc}
\hline Study abroad & $-0.238^{* * *}$ & $-0.743^{* * *}$ \\
High school GPA & $(0.035)$ & $(0.086)$ \\
& $0.131^{* * *}$ & $0.549^{* * *}$ \\
Male & $(0.021)$ & $(0.053)$ \\
& 0.018 & 0.076 \\
Private health insurance & $(0.016)$ & $(0.066)$ \\
& -0.028 & -0.112 \\
Purchasing power index & $(0.021)$ & $(0.075)$ \\
& 0.001 & 0.004 \\
Log distance & $(0.001)$ & $(0.003)$ \\
& 0.007 & 0.030 \\
Constant & $(0.005)$ & $(0.021)$ \\
& & $-0.949^{* * *}$ \\
\hline Faculties included & & $(0.279)$ \\
Cohorts included & Yes & Yes \\
Faculties \# cohorts included & Yes & Yes \\
\hline Pseudo-R & Yes & Yes \\
Log Likelihood & 0.223 & 0.223 \\
Observations & -1361 & -1361 \\
\hline \hline
\end{tabular}

Probit estimation; column 1: marginal effects for benchmark student; column 2: coefficients, standard errors in parentheses; clustered by county; ${ }^{*} p<0.05,{ }^{* *} p<0.01,{ }^{* * *} p<0.001$. 
Table 4.7: Graduating in Time - Matching Results

Dependent variable: graduating in time

\section{Propensity Score Matching}

Nearest Neighbor Kernel Radius

$(1)$

\begin{tabular}{lccc}
\hline Study abroad & $\begin{array}{c}-0.219^{* * *} \\
(0.043)\end{array}$ & $\begin{array}{c}-0.224^{* * *} \\
(0.030)\end{array}$ & $\begin{array}{c}-0.226^{* * *} \\
(0.030)\end{array}$ \\
\hline Treated observations & 302 & 302 & 302 \\
Untreated observations & 2108 & 2108 & 2108 \\
\hline \hline
\end{tabular}

Propensity score matching, average treatment effects on the treated using nearest neighbor matching with caliper 0.05 (column 1), kernel matching with an Epanechnikov kernel function, bandwidth 0.06 (column 2), and radius matching with caliper 0.05 (column 3) calculated using psmatch2 package for Stata by Leuven and Sianesi (2003), Version 4.0.10; only observations on common support are used; standard errors in parentheses; variables used for the estimation and calculation of the propensity score are high school GPA, male, private health insurance, purchasing power index, log distance to university and indicator variables for faculties and cohorts as well as interactions of faculties and cohorts; ${ }^{*} p<0.05,{ }^{* *} p<0.01,{ }^{* *} p<0.001$. 
Table 4.8: Sensitivity Analysis

\begin{tabular}{lcc}
\hline \hline & Rosenbaum Bounds & \multicolumn{2}{c}{$\begin{array}{c}\text { Mantel-Haenszel Bounds } \\
\Gamma\end{array}$} & $\begin{array}{c}\text { Upper Bound Significance Level } \\
(1)\end{array}$ & $\begin{array}{c}\text { Lower Bound Significance Level } \\
(2)\end{array}$ \\
\hline 1 & $<0.0001$ & $<0.0001$ \\
1.05 & $<0.0001$ & $<0.0001$ \\
1.1 & 0.0001 & $<0.0001$ \\
1.15 & 0.0005 & 0.0002 \\
1.2 & 0.0015 & 0.0004 \\
1.25 & 0.0037 & 0.0009 \\
1.3 & 0.0084 & 0.0020 \\
1.35 & 0.0171 & 0.0039 \\
1.4 & 0.0320 & 0.0071 \\
1.45 & 0.0549 & 0.0123 \\
1.5 & 0.0879 & 0.0201 \\
1.55 & 0.1319 & 0.0314 \\
1.6 & 0.1871 & 0.0468 \\
1.65 & 0.2524 & 0.0670 \\
1.7 & 0.3255 & 0.0924 \\
1.75 & 0.4037 & 0.1234 \\
\hline \hline
\end{tabular}

$\Gamma$ are the odds of differential assignment due to unobserved factors; column (1) calculated using the rbounds package for Stata by Gangl (2004), Version 1.1.6; column (2) calculated using mhbounds package for Stata by Becker and Caliendo (2006), Version 1.1.5 
Table 4.A.1: Balancing Table for Nearest Neighbor Matching

\begin{tabular}{|c|c|c|c|c|c|}
\hline \multirow{2}{*}{ Variable } & \multirow{2}{*}{ Sample } & \multicolumn{2}{|c|}{ Mean } & \multirow{2}{*}{$\operatorname{Bias}(\%)$} & \multirow{2}{*}{ t-Statistic } \\
\hline & & Treated & Control & & \\
\hline \multirow{2}{*}{ High school GPA } & Unmatched & 2.71 & 2.57 & 23.9 & $3.81^{* * *}$ \\
\hline & Matched & 2.71 & 2.70 & 1.1 & 0.14 \\
\hline \multirow{2}{*}{ Male } & Unmatched & 0.36 & 0.47 & -21.7 & $-3.48 * * *$ \\
\hline & Matched & 0.36 & 0.42 & -12.2 & -1.50 \\
\hline \multirow{2}{*}{ Private health insurance } & Unmatched & 0.23 & 0.17 & 15.6 & $2.65^{* *}$ \\
\hline & Matched & 0.23 & 0.23 & -0.8 & -0.10 \\
\hline \multirow{2}{*}{ Purchasing power index } & Unmatched & 99.03 & 97.57 & 13.1 & $2.07^{*}$ \\
\hline & Matched & 99.03 & 100.35 & -11.8 & -1.24 \\
\hline \multirow{2}{*}{ Distance to university } & Unmatched & 5.03 & 4.85 & 17.6 & $2.77^{* *}$ \\
\hline & Matched & 5.03 & 5.01 & 2.4 & 0.31 \\
\hline \multirow{2}{*}{ Medicine } & Unmatched & 0.01 & 0.00 & 5.5 & 1.06 \\
\hline & Matched & 0.01 & 0.01 & -4.8 & -0.45 \\
\hline \multirow{2}{*}{ Humanities } & Unmatched & 0.31 & 0.20 & 25.7 & $4.43^{* * *}$ \\
\hline & Matched & 0.31 & 0.27 & 9.2 & 1.07 \\
\hline \multirow{2}{*}{ Mathematics } & Unmatched & 0.03 & 0.03 & -2.5 & -0.40 \\
\hline & Matched & 0.03 & 0.03 & -1.9 & -0.23 \\
\hline \multirow{2}{*}{ Physics } & Unmatched & 0.01 & 0.02 & -4.6 & -0.70 \\
\hline & Matched & 0.01 & 0.02 & -7.9 & -0.91 \\
\hline \multirow{2}{*}{ Chemistry } & Unmatched & 0.01 & 0.05 & -24.7 & $-3.28 * * *$ \\
\hline & Matched & 0.01 & 0.01 & 0.0 & 0.00 \\
\hline \multirow{2}{*}{ Geology/Geography } & Unmatched & 0.01 & 0.01 & -3.7 & -0.56 \\
\hline & Matched & 0.01 & 0.01 & 0.0 & -0.00 \\
\hline \multirow{2}{*}{ Biology } & Unmatched & 0.08 & 0.12 & -11.7 & -1.81 \\
\hline & Matched & 0.08 & 0.07 & 3.3 & 0.46 \\
\hline \multirow{2}{*}{ Forest sciences } & Unmatched & 0.05 & 0.09 & -17.6 & $-2.59 * *$ \\
\hline & Matched & 0.05 & 0.06 & -5.3 & -0.73 \\
\hline \multirow{2}{*}{ Agriculture } & Unmatched & 0.17 & 0.24 & -17.8 & $-2.77^{* *}$ \\
\hline & Matched & 0.17 & 0.15 & 5.8 & 0.78 \\
\hline \multirow{2}{*}{ Economic sciences } & Unmatched & 0.27 & 0.18 & 20.1 & $3.45^{* * *}$ \\
\hline & Matched & 0.26 & 0.31 & -11.9 & -1.35 \\
\hline \multirow{2}{*}{ Social sciences } & Unmatched & 0.06 & 0.05 & 4.0 & 0.67 \\
\hline & Matched & 0.06 & 0.05 & 2.9 & 0.35 \\
\hline \multirow{2}{*}{ Cohort 1} & Unmatched & 0.04 & 0.07 & -13.3 & $-1.98^{*}$ \\
\hline & Matched & 0.04 & 0.04 & 0.0 & -0.00 \\
\hline \multirow{2}{*}{ Cohort 2} & Unmatched & 0.09 & 0.07 & 4.5 & 0.76 \\
\hline & Matched & 0.09 & 0.09 & -2.4 & -0.28 \\
\hline \multirow{2}{*}{ Cohort 3} & Unmatched & 0.22 & 0.17 & 11.5 & 1.94 \\
\hline & Matched & 0.22 & 0.24 & -4.2 & -0.49 \\
\hline & Unmatched & 0.36 & 0.34 & 4.0 & 0.65 \\
\hline Cohort 4 & Matched & 0.36 & 0.34 & 3.5 & 0.43 \\
\hline Cohort 5 & Unmatched & 0.29 & 0.34 & -9.9 & -1.59 \\
\hline Cohort 5 & Matched & 0.29 & 0.29 & 1.4 & 0.18 \\
\hline
\end{tabular}

Treatment: Study abroad; summary statistics for treated and controls before and after nearest neighbor matching with caliper 0.05; interactions between faculties and cohorts nearest neighbor matching with caliper 0.05 ; interactions between faculties and cohorts
included and balanced after matching; column Bias(\%) displays the standardized bias in included and balanced after matching; column Bias(\%) displays the standardized bias in percent; column t-Statistic shows the statistic of the t-test for equality of means before and after matching; calculated using psmatch2 package for
(2003), Version $4.0 .10 ;{ }^{*} p<0.05,{ }^{* *} p<0.01,{ }^{* * *} p<0.001$. 
Figure 4.A.1: Distribution of the Propensity Score Before and After Matching

Figure 4.A.1.a: Before Matching

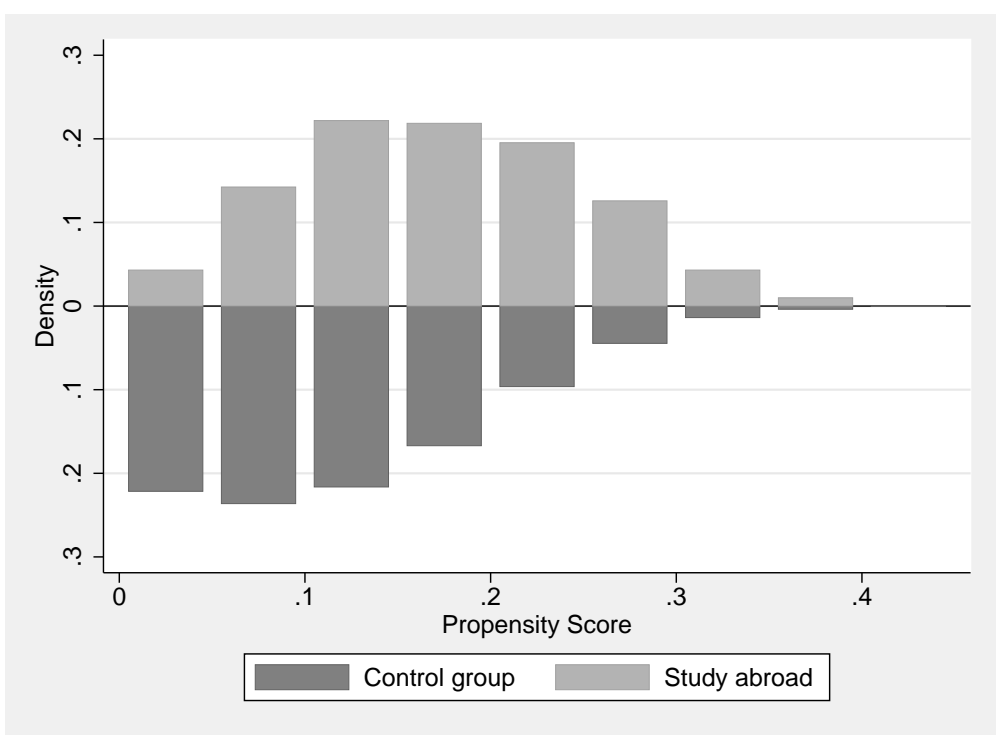

Figure 4.A.1.b: After Nearest Neighbor Matching

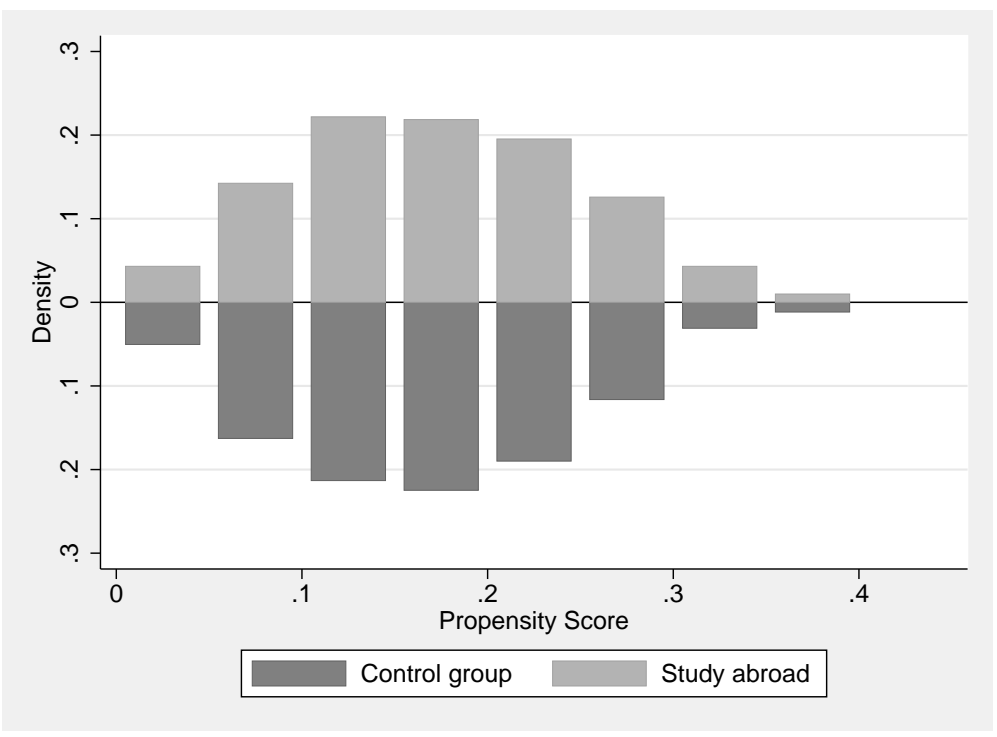

Distribution of the propensity score before and after nearest neighbor matching with caliper 0.05. Calculated using psmatch2 package for Stata by Leuven and Sianesi (2003), Version 4.0.10; only obser the mation and calculation of the propensity score are high school GPA, male, private health insurance, purchasing power index, log distance to university and indicator variables for faculties and cohorts as well as interactions of faculties and cohorts. 
Table 4.A.2: Determinants of Transferring Grades

Dependent variable: transferring grades

Coefficients

\begin{tabular}{lc}
\hline High school GPA & 0.114 \\
Male & $(0.167)$ \\
& -0.296 \\
Private health insurance & $0.202)$ \\
& 0.060 \\
Purchasing power index & $(0.224)$ \\
& -0.005 \\
Log distance & $(0.008)$ \\
& 0.074 \\
Constant & $(0.071)$ \\
& 0.397 \\
& $(1.100)$ \\
\hline Faculties included & Yes \\
Cohorts included & Yes \\
Faculties \# cohorts included & Yes \\
\hline Pseudo-R ${ }^{2}$ & 0.091 \\
Log Likelihood & -124 \\
Observations & 257 \\
\hline \hline
\end{tabular}

Probit estimation; coefficients; standard errors in parentheses; clustered by county; only students who studied abroad; ${ }^{*} p<0.05,{ }^{* *} p<0.01,{ }^{* * *} p<0.001$. 


\section{B Appendix II: Data Processing}

We restrict our attention to students who obtained a German high school leaving certificate, as foreign and German degrees may not be comparable. Furthermore, students with a foreign educational background may face challenges regarding language and culture that may affect their performance at university. In addition, we exclude students with the worst possible high school grade, 4.0, since it is often used as a placeholder when the grade is not important for the admission process.

When students are enrolled in more than one degree program at the same time, a sojourn cannot be assigned. In addition, being enrolled in several study programs may influence the final university grade as well as the time to graduation since students may spend less time on each individual subject. Consequently, these students are removed from the sample. Moreover, we leave out students with missing data or for whom we observe pure data errors, such as a high school leaving grade that is not within the possible interval.

In our analysis, we use the purchasing power of the parental zip-code area to account for the students' socio-economic background. To do so, we use information about the students' home and semester address: the home address usually corresponds to the parents' address and the semester address to the place the students live by themselves. Since most students move to Göttingen when starting university, the two zip-codes should differ. If the zip-codes are identical and from a place outside of Göttingen, it is very likely that the student is still living with her parents. However, if the zip-codes are identical and from Göttingen, it may be that the home address does not correspond to the parents' address. Therefore, we look at the administrative district the student went to school in. When she obtained her high school leaving certificate outside of Göttingen, it is likely that the specified home address does not correspond to the parental address. To this end, we exclude these students from the sample. 


\section{Chapter 5}

\section{The Effect of the Bologna Process on the Duration of Studies*}

\subsection{Introduction}

The Bologna declaration was signed by 29 European countries in 1999 with the aim of establishing a European Higher Education Area. It was, among other things, decided on a homogeneous two-tier university system in order to enhance mobility and to make academic degrees comparable. Therefore, the first degree, the bachelor's degree, is awarded after at least three years of study and should primarily be targeted to the labor market. After the completion of this first cycle, it is then possible to obtain a second, more academic, degree, the master's degree (European Ministers of Education, 1999).

For Germany, the introduction of bachelor and master programs implied a restructuring of part of the degree system. Since the traditional study programs were an example of a one-tier system with a degree awarded after approximately five years of study, the reform involved the implementation of two study cycles, and hence a revision of the existing curricula. Furthermore, examination regulations and conditions of study had to be rearranged. In line with this view,

${ }^{*}$ This chapter originates from Lerche (2016). 
the reform was also seen as an opportunity to evaluate old structures and adapt them to present needs and requirements. In particular, the aim was to reduce the time German graduates need to obtain a degree as well as drop-out rates (Wissenschaftsrat, 2000).

Evaluating the effect of the Bologna process on student behavior and university outcomes is of interest, due to the major changes imposed on the German university system. This chapter addresses this issue by estimating the impact of the reform on the duration until graduation and dropping out of university. The analysis reveals a positive impact of being enrolled in a bachelor program on the time until graduation, indicating that the aim of reducing study duration both in absolute and relative terms was achieved. With regard to university drop-out, however, the results are less conclusive. There is a clear favorable effect of the reform on the probability of dropping out for students at the faculty of humanities. For the other faculties the effect is insignificant or sensitive to different specifications.

The effect of restructuring study programs in the course of the Bologna process has been examined in studies on Germany, Portugal and Italy. Research topics are, among others, university participation and drop-out rates, student behavior and performance as well as labor market implications.

Using administrative data on German students, Horstschräer and Sprietsma (2015) estimate a fixed effects panel model and find no significant impact of the Bologna process neither on enrollment rates nor on university drop-outs for most fields of study. By means of descriptive analysis, Heublein et al. (2009) show that the average duration until university drop out is lower for bachelor students than for students enrolled in one of the old degree systems. Concerning the duration until graduation, further descriptive analysis suggests that the Bologna process resulted in more students graduating within the standard time period (Autorengruppe Bildungsberichterstattung, 2012). Using survey data, Mühlenweg (2010) examines the impact of the reform on student satisfaction. She finds that students enrolled in bachelor programs are slightly more satisfied with their study conditions than their peers who aim at a traditional degree. The author also points out that the reform did not change the composition of the German student population with regard to socio-economic factors. 
For Portugal, Cardoso et al. (2008) and Portela et al. (2009) find that demand increased for most study programs that were restructured in the course of the Bologna process. This result is consistent with findings for Italy: using survey data, Cappellari and Lucifora (2009) show that the restructuring of study programs had a positive impact on university participation. Additionally, they point out that it is mostly students with good high school performance but low socio-economic background who benefit. This is confirmed by Di Pietro (2012a) who finds that university enrollment of Italian students from less advantageous backgrounds increased after the reform. Furthermore, Di Pietro and Cutillo (2008) show that, in contrast to the results obtained by Horstschräer and Sprietsma (2015) for Germany, the introduction of a two-tier system reduced drop-out rates at Italian universities.

Bratti et al. $(2006,2010)$ focus on the impact of the Bologna process on student behavior and performance at an Italian university. They show that students spent less time on courses that had a high workload before the reform. In addition, the probability of failing these courses decreased while the average grade stayed constant. For courses that were already easier in the old system, the authors find no changes in the students' workloads, but evidence of grade inflation (Bratti et al., 2006). When only looking at the faculty of economics (Bratti et al., 2010) the results are similar: the average grades in first-year examinations improved and the number of attempts failed decreased while students reduced their workload.

Finally, Bosio and Leonardi (2011) study the reform's effect on the Italian labor market and find ambiguous results. Except for women living in the south of Italy, there is a positive impact of the Bologna process on the probability of being employed after graduation. However, the wage premium of university compared to high school education is reduced by the reform.

This chapter contributes to the literature on the Bologna process by assessing the effect of replacing traditional German five-year degrees with three-year bachelor programs on the duration until graduation and dropping out of university. To the best of my knowledge, it is the first study that estimates competing risks models to evaluate in detail the time to the occurrence of one of these events in the context of the Bologna process. Thereby, additional information on the 
reform's effects can be obtained, such as whether the aim of reducing study duration was achieved. Since most of the previous literature on Germany is based on descriptive analysis, this study provides more profound results on the impact of the Bologna process.

The remainder of the chapter is structured as follows: Sections 5.2 and 5.3 give an overview of the institutional background and the dataset. Section 5.4 describes the empirical framework. Section 5.5 shows and interprets the results. Finally, Section 5.6 sums up the main findings and concludes.

\subsection{Institutional Background}

The traditional German degree programs were an example of a one-tier system. There were five different types of university degrees: examinations carried out by the state (Staatsexamen) and the church (theologisches Examen), the diploma (Diplom), an old master's (Magister) as well as an old teacher degree, each of them obtained after approximately five years of study. In the teacher program students can choose two to three different subjects that are part of the German high school curriculum. Furthermore, the degree contains pedagogical training that prepares the students for their later teaching profession. In the Magister degree, two to three different subjects, mainly from the faculty of humanities, are combined into one course of study. The Diplom, on the other hand, is obtained when finishing one of the study programs offered by the faculties of biology, mathematics, physics, chemistry, agriculture, economic sciences, social sciences, geology/geography or forestry. Finally, the state and church examinations Staatsexamen and theologisches Examen are achieved in the fields of medicine, law and theology and are characterized by a centralized final examination that is organized by a state authority or the regional subdivision of the church.

Although the state and church examinations are still in existence, the Diplom, Magister and teacher degrees were gradually replaced by the new bachelor and master programs in the course of the Bologna process. Despite only 19 percent of the study programs at German universities and universities of applied sciences 
were bachelor and master programs in the summer term 2004, this number increased to 85.3 percent by the winter term 2011 (Hochschulrektorenkonferenz, 2011). At Göttingen University, the first bachelor programs were introduced in 2001. After the summer term 2006, only a small number of students still enrolled in one of the old degree programs.

The implementation of two study cycles resulted in a reduction of the amount of semesters a student needs to obtain her first university degree. At Göttingen University, the standard time period for bachelor programs is six semesters, while it is nine to ten semesters for the old degree programs.

Besides the outer structure, curricula, examination regulations and conditions of study were adopted in the course of the Bologna process. The old study programs were characterized by a high degree of freedom with regard to which courses to take and when to do the examinations, while the new system is more structured. Especially in the first semesters, there is little flexibility and some faculties introduced stricter rules concerning the time frame when parts of the study program need to be completed. For instance, students enrolled in a bachelor program in agriculture, mathematics or psychology need to successfully complete specific basic courses within the first four semesters of their studies. Furthermore, grades are awarded to nearly all of the courses taken and most of them also count towards the degree. In contrast, the final grades of the teacher and Magister degrees were the result of decentralized final examinations organized by the university's institutes in charge of the respective field. The courses taken during one's studies just had to be passed and sometimes this did not even imply taking an examination. On the other hand, in the Diplom program, grades were awarded to all courses. However, only those achieved in the main study period counted towards the degree.

\subsection{Data Description}

For the analysis, administrative student data collected at Göttingen University, Germany is used. The data contains detailed, anonymized information on more than 9000 students who were enrolled in either a bachelor or a Diplom, Magister 
or teacher program and started university between the winter term 2003 and the summer term 2008. One part of the data is information the students have to provide at the beginning of their studies, for example their high school leaving grade, gender and type of health insurance. The other part covers the students' path at university: for every semester the student is enrolled in, the subjects studied and the target degree are registered. If the student obtained a degree at Göttingen University, the type and grade of the degree as well as the semester are observed.

The sample is restricted to students who started university studies at Göttingen University. The reason for this procedure is that for these students all relevant information from when they first enter the university system until they leave Göttingen University can be observed. Furthermore, I exclude students who change between the old and new system as well as students who are enrolled in more than one study program at the same time. More information on data processing is provided in the appendix of this chapter.

The standard time period for completing a bachelor degree is six semesters while for the old degree programs it is nine to ten semesters. This means that using absolute semesters as time measure is not expedient when analyzing the effect of the Bologna process on the duration until graduation or drop-out. For instance, bachelor students are likely to finish their studies in their sixth semester while most old degree students will not graduate before their ninth semester. Thus, I use a time measure that is relative to the standard time period in the respective field to make information on study duration comparable ${ }^{23}$ : the time variable study period equals one for the first third of the standard time period (semester one and two for bachelor programs, semesters one to three for old degrees), it equals two for the second third of the standard time period, and so on. Hence, students who graduate in the last semester of the standard time period finish their studies in study period three irrespective of the degree program they are enrolled in. The scale continues in the same way so that study period four corresponds to one third above the standard time period, which is semester seven and eight for bachelor programs and semesters ten to twelve for old degrees. As a

\footnotetext{
${ }^{23}$ For all old degree programs a homogeneous standard time period of nine semesters is assumed.
} 
result, this methods allows to assess the duration of studies not only in absolute, but also in relative terms. This is especially interesting for the duration until graduation since bachelor students by definition spend less time at university until they obtain their first degree. However, this does not necessarily imply that the reform reduced the relative time spend at university.

Failure Events. ${ }^{24}$ Each individual has two different possibilities of terminating her studies: graduation and dropping-out of university. Furthermore, students can be censored, which means that it cannot be observed whether they graduate or drop out of university. This is the case for students who either change university or are still studying by the end of the time frame under analysis which is the winter term 2011.

Graduation is registered for all students who achieve a degree at Göttingen University within the observed time frame. Students who neither obtain a degree nor are censored are registered as drop-outs. This includes students who definitely fail their studies as well as students who decide to leave university for whatever reason. In fact, only a small number of students who drop out lose the entitlement to take examinations and are therefore expelled from university.

Independent Variables. The treatment variable bachelor is an indicator variable that equals one if the student is enrolled in a bachelor program and zero if she aims at a Diplom, Magister or old teacher degree. The student's high school leaving grade is used to control for pre-university ability. Additionally, it may be a reasonable measure of general motivation as students with a good high school leaving certificate are probably not only smart but also willing to put a lot of effort into studying. The high school leaving grades are converted into the U. S. grading scheme with 4 being the best and 1 the worst grade still allowing to pass. ${ }^{25}$

In the analysis, the student's socio-economic background is measured by two variables: the purchasing power index related to the zip-code area the student's

\footnotetext{
${ }^{24}$ In the context of survival analysis, the expression failure describes an individual's transition into a different state, e.g. graduation or dropping out of university. This should not be confused with failing in the sense of dropping out of university. Therefore, the term "drop out" is used for students who leave university without a degree.

${ }^{25}$ Grades were converted into the U. S. grading scheme by subtracting the high school grade from five.
} 
parents live in and her health insurance status. The purchasing power index is provided by $G f K$, a market research firm. It quantifies the purchasing power within a zip-code area relative to the German average. ${ }^{26}$ Since zip-code areas in Germany are fairly small, the variable seems to be a reasonable measure of family income.

Additionally, the health insurance status can be used to control for the student's socio-economic background. This is possible due to the German health care system distinguishing between private and public health insurance. In particular, it is only possible to select a private health insurance if one fulfills certain criteria with regard to income or employment status. Therefore, compared to the whole German population, a disproportionately high number of people who are privately insured hold a certificate allowing them to enroll at a university or a university of applied sciences or obtained a degree or even a Ph.D. at a university or a university of applied sciences. ${ }^{27}$ Bearing in mind that students normally are insured through their parents, their health insurance status provides information on their family background. Moreover, I control for the student's gender.

The analysis also takes into account that students who move further away for studying may be different to their peers who decide to study at a place close to their home town. It is conceivable that these students are more independent and put more effort in finding the university that best fits their preferences. This may in turn also influence university outcomes. Since it is likely that the marginal effect of distance is decreasing, I control for the logarithm of the linear distance between the student's home town and Göttingen. ${ }^{28}$

At Göttingen University the faculties are to a large extent responsible for the study and examination regulations and thereby have a direct impact on the

\footnotetext{
${ }^{26} \mathrm{GfK}$ collects information on people's lifestyle and consumption behavior. The purchasing power index used in the analysis is based on data provided by the German tax offices as well as other relevant statistics, such as pensions and unemployment benefits.

${ }^{27}$ In 2008, 56.7 percent of the privately insured held a high school leaving certificate allowing them to register at a university or a university of applied sciences, 38.0 percent finished university or university of applied sciences with a degree or a Ph.D. The corresponding numbers for the overall German population are 24.4 percent and 13.0 percent respectively (Finkenstädt and Keßler, 2012; Statistisches Bundesamt, 2009).

${ }^{28}$ The linear distance is obtained by using geographic coordinates provided by geonames.org. Further information on the calculation is provided in the appendix of this chapter.
} 
study duration. Moreover, there may be differences in the study and learning culture: at some faculties it may for example be more common to take longer until obtaining a degree. With regard to graduation, Chapter 2 shows that it is more difficult to obtain a degree at some faculties than at others. For these reasons, the university's different faculties are controlled for in the analysis.

Furthermore, I control for the student's cohort in order to take changes in study conditions into account. For instance, this includes the introduction of general tuition fees in the winter term 2006. This topic is further discussed in Section 5.5.3.

Summary Statistics. The summary statistics in Table 5.1 show that 54 percent of the students in the sample are enrolled in a bachelor program. Furthermore it can be seen that 25 percent of the students are censored, meaning that they were still studying at Göttingen University by the end of the observed time frame which is the winter term 2011. Nearly half of the students in the sample graduated and 26 percent dropped out of university. Looking at bachelor students and students within one of the old degree programs separately, small differences in these numbers can be observed: graduation rates are higher for bachelor students, while a smaller share drops out of university.

The Kaplan-Meier failure functions for the different events presented in Figure 5.1 give further information. They are defined as one minus the Kaplan-Meier estimate, which is the running product of the conditional probability of surviving beyond a certain point in time (Kaplan and Meier, 1958). Consequently, the functions presented in Figure 5.1 show the unconditional probability of graduating or dropping out of university within a certain study period. The first figure reveals that the probability of graduating is very low in the first two time periods for all degrees and converges towards 0.75 by study period six, which represents semesters 11 and 12 for bachelor students and semesters 16 to 18 for students within the old degree programs. This means that the probability of finishing one's studies before twice the time of the prescribed study duration is nearly 75 percent for the students in the sample. In addition, it can be noted that the probability of graduating within the standard time of study or one third above is higher for bachelor students than for students aiming at one of the old degrees.

In the case of dropping out of university, the Kaplan-Meier failure function 
Table 5.1: Summary Statistics

\begin{tabular}{|c|c|c|c|c|c|c|}
\hline & \multicolumn{2}{|c|}{ Total } & \multicolumn{2}{|c|}{ Bachelor } & \multicolumn{2}{|c|}{ Old Degree } \\
\hline & Mean & Std. Dev. & Mean & Std. Dev. & Mean & Std. Dev. \\
\hline Censored & 0.25 & 0.43 & 0.23 & 0.42 & 0.28 & 0.45 \\
\hline Graduation & 0.49 & 0.50 & 0.54 & 0.50 & 0.44 & 0.50 \\
\hline Drop-out & 0.26 & 0.44 & 0.24 & 0.42 & 0.28 & 0.45 \\
\hline Bachelor & 0.54 & 0.50 & 1.00 & 0.00 & 0.00 & 0.00 \\
\hline High school GPA & 2.46 & 0.62 & 2.46 & 0.62 & 2.47 & 0.61 \\
\hline Female & 0.53 & 0.50 & 0.52 & 0.50 & 0.55 & 0.50 \\
\hline Private health insurance & 0.19 & 0.39 & 0.17 & 0.38 & 0.21 & 0.41 \\
\hline Purchasing power index & 97.60 & 11.49 & 97.63 & 11.41 & 97.57 & 11.59 \\
\hline Log distance & 4.30 & 1.35 & 4.39 & 1.27 & 4.18 & 1.43 \\
\hline Theology & 0.00 & 0.06 & 0.00 & 0.05 & 0.01 & 0.07 \\
\hline Law & 0.00 & 0.04 & 0.00 & 0.05 & 0.00 & 0.02 \\
\hline Medicine & 0.01 & 0.08 & 0.01 & 0.11 & 0.00 & 0.00 \\
\hline Humanities & 0.25 & 0.43 & 0.22 & 0.41 & 0.29 & 0.46 \\
\hline Mathematics & 0.04 & 0.19 & 0.04 & 0.20 & 0.03 & 0.17 \\
\hline Physics & 0.04 & 0.20 & 0.03 & 0.18 & 0.05 & 0.23 \\
\hline Chemistry & 0.05 & 0.22 & 0.04 & 0.21 & 0.05 & 0.23 \\
\hline Geology/geography & 0.03 & 0.18 & 0.03 & 0.17 & 0.04 & 0.19 \\
\hline Biology & 0.11 & 0.31 & 0.10 & 0.30 & 0.12 & 0.32 \\
\hline Forest science & 0.04 & 0.20 & 0.08 & 0.27 & 0.00 & 0.00 \\
\hline Agriculture & 0.09 & 0.29 & 0.17 & 0.37 & 0.00 & 0.00 \\
\hline Economic sciences & 0.18 & 0.39 & 0.20 & 0.40 & 0.16 & 0.36 \\
\hline Social sciences & 0.15 & 0.35 & 0.06 & 0.24 & 0.25 & 0.43 \\
\hline Cohort 1 & 0.23 & 0.42 & 0.06 & 0.24 & 0.43 & 0.49 \\
\hline Cohort 2 & 0.19 & 0.40 & 0.06 & 0.24 & 0.35 & 0.48 \\
\hline Cohort 3 & 0.18 & 0.39 & 0.15 & 0.36 & 0.22 & 0.41 \\
\hline Cohort 4 & 0.17 & 0.37 & 0.31 & 0.46 & 0.00 & 0.02 \\
\hline Cohort 5 & 0.23 & 0.42 & 0.42 & 0.49 & 0.00 & 0.02 \\
\hline Observations & 9167 & & 4984 & & 4183 & \\
\hline
\end{tabular}

Grades transformed to 1-4 Scale, with 4 being the best and 1 being the worst grade still to pass. Faculty is the last faculty the student is enrolled at. 
Figure 5.1: Kaplan-Meier Failure Functions
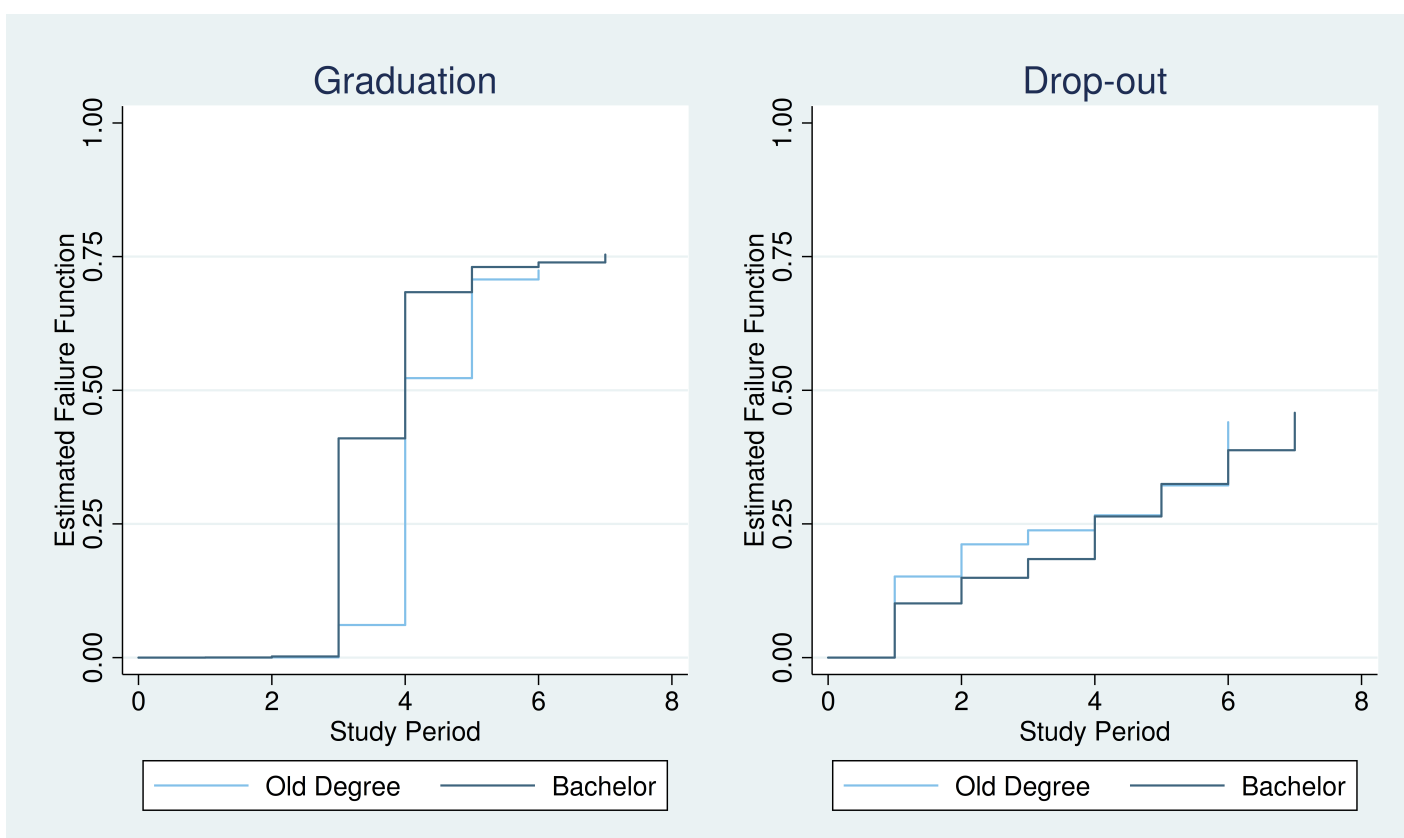

shows that the probability of failure in study period one is around 0.15 for students aiming at one of the old degrees and 0.1 for bachelor students. Afterwards, it increases steadily to around 0.45 for both the treatment and the control group but is lower for bachelor students until study period four.

Summary statistics for the additional control variables (Table 5.1) reveal that the mean high school leaving grade is nearly the same for bachelor and old degree students in the sample. Moreover, the share of female students enrolled in one of the old degree programs is 55 percent and consequently three percentage points higher than within bachelor programs. The purchasing power index is slightly higher for bachelor students, while a lower share of students holds a private health insurance. Concerning the distance to university, the summary statistics show that the average bachelor student's home town is further away than the home town of the average student enrolled in one of the old degree programs.

Looking at the indicator variables for the university's faculties, differences between the share of bachelor and old degree students within the respective 
fields can be observed. For instance, even if 29 percent of the students who aim at one of the old degrees is enrolled at the faculty of humanities the share for bachelor students at this faculty is only 22 percent. On the other hand, for the faculty of economic sciences, the share of bachelor students is higher than the share of students within the old degrees.

Finally, the summary statistics for the different cohorts reflect the introduction of the bachelor programs: only 6 percent of the bachelor students enrolled in the winter term 2003 and summer term 2004 (cohort 1), while 42 percent started studying in the winter term 2007 and summer term 2008 (cohort 5). In comparison, almost all students aiming at one of the old degrees enrolled at university between the winter term 2003 and the summer term 2006 (cohorts $1-3)$.

\subsection{Empirical Framework}

Duration models are generally used to analyze the time until an event occurs, such as the duration until graduating from university. Compared to ordinary least squares regressions, they have the advantage that they do not assume a normal distribution of the residuals. This is important since the assumption implies that, conditional on the covariates, time to an event is normally distributed. However, this assumption does not prove to be realistic for many events (Cleves et al., 2010). For instance, for the event of graduation, one might expect that its rate is close to zero within the first semesters but rises steeply towards the end of the standard time period. ${ }^{29}$

In the context of this chapter, there are two different events, so called failure events, that could cause a student to stop studying: graduation and dropping out of university. Since only one of these events can occur for every student, they represent competing risks. This means that the occurrence of one event prevents the individual from failing due to a different cause of failure: graduation prevents students from dropping out of university and vice versa. Therefore, the likelihood of failing due to one cause, the so called cumulative incidence function, may also

\footnotetext{
${ }^{29}$ For a detailed description of survival analysis see also Cleves et al. (2010).
} 
depend on the probability of failing from a competing risk (Cleves et al., 2010). More precisely, for a given set of covariates, the probability of graduating before a certain point in time also depends on the likelihood of dropping-out of university.

As a result of this correlation between failure events, competing risks need to be treated differently than censoring where a failure is expected to happen at an unobserved point in time. The concept of subhazards proposed by Fine and Gray (1999) is used to take this into account. Thereby, the subhazard for failure event $1, \lambda_{1}$, is defined as follows (Fine and Gray, 1999):

$$
\lambda_{1}(t ; \mathbf{Z})=\lim _{\Delta t \rightarrow 0} \frac{1}{\Delta t} \operatorname{Pr}\{t \leq T \leq t+\Delta t, \varepsilon=1 \mid T \geq t \cup(T \leq t \cap \varepsilon \neq 1), \mathbf{Z}\}
$$

where $t$ denotes time and $\mathbf{Z}$ is a vector of covariates. Furthermore, $T$ is the specific failure time and $\varepsilon$ the cause of failure. Consequently, the subhazard function gives the likelihood of failing from cause 1 at time $T$ given that either no failure or failure from a different cause has occurred.

The model is a counterpart to the traditional Cox regressions. It is semiparametric which means that the effect of the independent variables are assumed to be proportional to an unspecified baseline subhazard $\lambda_{10}(t)$. Thereby, the baseline subhazard is the subhazard for all covariates set to zero (Fine and Gray, 1999):

$$
\lambda_{1}(t ; \mathbf{Z})=\lambda_{10}(t) \exp \left\{\mathbf{Z}^{T} \beta_{0}\right\}
$$

The exponentiated coefficients, $\exp \left\{\mathbf{Z}^{T} \beta_{0}\right\}$, are called subhazard ratios. A positive (negative) coefficient implies a subhazard ratio that is bigger (smaller) than one. Consequently, an increase of the covariate by one unit increases (decreases) the subhazard by the factor of the subhazard ratio. For the binary treatment variable of being in a bachelor program, the subhazard ratio gives the factor by which the likelihood of graduating or dropping out of university differs between the treatment and the control group.

The main characteristic of the subhazard model introduced by Fine and Gray (1999) is that it does not remove subjects who experience competing risks from the sample, but treats them as not having any chance of failing. Therefore, students who drop out of university are not excluded from the risk set, but reduce 
the probability of graduating. Thereby, they are weighted by the likelihood of being otherwise censored, meaning that neither graduation nor drop out is observed. The higher the likelihood of being censored at a given point in time, the lower the weight given to these subjects (Cleves et al., 2010; StataCorp LP, 2013).

Moreover, the model allows the subhazard ratios to vary with duration by interacting the covariates with time. As a result, it is possible to assess whether the impact of the reform changes with duration. In the analysis, I follow this approach and assume linearity in time.

\subsection{Results}

The changes in examination regulations and conditions of study that were implemented in the course of the Bologna process may influence student behavior and performance in different ways. On the one hand, it is likely that the clearer structure of the new study programs helps students to find their way at university and focus on what is relevant for their studies. This may reduce the duration until graduation as well as drop out rates. However, it may also lead to students with low academic ability getting pulled along for some time and dropping out of university at a rather late point of their studies. On the other hand, the stricter examination regulations and the larger number of examinations increase the pressure to perform, especially for students with low academic ability. This may result in higher drop out rates and more drop out at an early stage of one's studies.

To assess the effects of the Bologna process on the duration until graduation and university drop-out, the following analysis estimates competing risks models for the two different possibilities of terminating one's studies. Besides the treatment, I control for the high school leaving grade, the student's socio-economic background, gender, the logarithm of the linear distance between the student's home town and Göttingen, the university's faculties and the student's cohort. The respective tables present the estimated coefficients (columns (1), (3) and (5)) and corresponding subhazard ratios (columns (2), (4) and (6)). The first 
two columns of Table 5.2 and Table 5.3 show the model without time-varying coefficients. In the second model, covariates are interacted with the study period to allow the coefficients to vary with duration. In all regressions, standard errors are clustered by county.

\subsubsection{Graduation}

The results for the competing risks analysis for the event of graduation are shown in Table 5.2. The subhazard ratio for the treatment variable in the model without time-varying coefficients, in column (2), is 1.689. Hence, the model suggests that the subhazard, the probability of graduating at time $T$ given that subjects are not censored or dropped out of university, is 68.9 percent higher for bachelor students than for students within one of the old degree programs in every study period. The model with time-varying coefficients, in columns (3) and (4), confirms the positive impact of being enrolled in a bachelor program on the duration until graduation. However, the negative coefficient of the interaction term in column (3) shows that the size of the effect decreases with study duration. In study period three, the conditional probability of graduating is approximately $250^{30}$ percent higher for bachelor students than for their peers who are enrolled in one of the old programs. This means that bachelor students are more than three times as likely to graduate in the last third of the standard time period as students aiming at one of the old degrees. In study period four (semesters seven and eight for bachelor and semesters 10 to 12 for old degree students), the effect is smaller, but still positive: depending on still studying, bachelor students are 92 percent more likely to graduate one third above the standard time period than students within one of the old degrees.

The findings show that the introduction of the bachelor programs in the course of the Bologna process had a positive impact on the duration until graduation. Consequently, one of the reform's main objectives was achieved. A possible reason for the result is the restructuring of examination regulations and

${ }^{30} e^{\beta_{\text {bachelor }}+\beta_{\text {bachelor }} \cdot t}=e^{\beta_{\text {bachelor }}} \cdot e^{\beta_{\text {bachelor }} \cdot t}=e^{3.017} \cdot e^{(-0.591) \cdot t}=20.432 \cdot 0.554^{3}=3.47$. This means that in study period three, students within the treatment group have a conditional probability of graduating that is 3.47 times, and hence 247 percent, higher than the probability of graduating for students in the control group. 
Table 5.2: Graduation

\begin{tabular}{|c|c|c|c|c|}
\hline Failure: graduation & $(1)$ & $(2)$ & (3) & $(4)$ \\
\hline \multicolumn{5}{|l|}{ Main } \\
\hline Bachelor & $\begin{array}{c}0.524^{* * *} \\
(0.050)\end{array}$ & $\begin{array}{c}1.689^{* * *} \\
(0.084)\end{array}$ & $\begin{array}{c}3.017^{* * *} \\
(0.294)\end{array}$ & $\begin{array}{c}20.432^{* * *} \\
(6.003)\end{array}$ \\
\hline High school GPA & $\begin{array}{c}0.578^{* * *} * \\
(0.028)\end{array}$ & $\begin{array}{c}1.782^{* * *} \\
(0.049)\end{array}$ & $\begin{array}{c}1.062^{* * *} \\
(0.126)\end{array}$ & $\begin{array}{c}2.892^{* * *} \\
(0.363)\end{array}$ \\
\hline Female & $\begin{array}{c}0.084^{* * *} \\
(0.023)\end{array}$ & $\begin{array}{c}1.087^{* * *} \\
(0.025)\end{array}$ & $\begin{array}{c}0.156 \\
(0.152)\end{array}$ & $\begin{array}{c}1.169 \\
(0.178)\end{array}$ \\
\hline Private health insurance & $\begin{array}{c}0.036 \\
(0.028)\end{array}$ & $\begin{array}{c}1.036 \\
(0.029)\end{array}$ & $\begin{array}{l}-0.445^{*} \\
(0.198)\end{array}$ & $\begin{array}{l}0.641^{*} \\
(0.127)\end{array}$ \\
\hline Purchasing power index & $\begin{array}{c}0.002 \\
(0.001)\end{array}$ & $\begin{array}{c}1.002 \\
(0.001)\end{array}$ & $\begin{array}{l}-0.000 \\
(0.005)\end{array}$ & $\begin{array}{l}1.000 \\
(0.005)\end{array}$ \\
\hline Log distance & $\begin{array}{c}0.094^{* * *} \\
(0.013)\end{array}$ & $\begin{array}{c}1.099^{* * *} \\
(0.015)\end{array}$ & $\begin{array}{c}0.097 \\
(0.056)\end{array}$ & $\begin{array}{c}1.102 \\
(0.062)\end{array}$ \\
\hline Cohorts included & yes & yes & yes & yes \\
\hline Faculties included & yes & yes & yes & yes \\
\hline \multicolumn{5}{|c|}{ Time-varying coefficients } \\
\hline Bachelor & & & $\begin{array}{c}-0.591 * * * \\
(0.076)\end{array}$ & $\begin{array}{c}0.554^{* * *} \\
(0.042)\end{array}$ \\
\hline High school GPA & & & $\begin{array}{c}-0.136^{* * *} \\
(0.031)\end{array}$ & $\begin{array}{c}0.873^{* * *} \\
(0.027)\end{array}$ \\
\hline Female & & & $\begin{array}{l}-0.019 \\
(0.040)\end{array}$ & $\begin{array}{c}0.981 \\
(0.040)\end{array}$ \\
\hline Private health insurance & & & $\begin{array}{l}0.127^{*} \\
(0.053)\end{array}$ & $\begin{array}{l}1.136^{*} \\
(0.060)\end{array}$ \\
\hline Purchasing power index & & & $\begin{array}{c}0.001 \\
(0.001)\end{array}$ & $\begin{array}{c}1.001 \\
(0.001)\end{array}$ \\
\hline Log distance & & & $\begin{array}{l}-0.001 \\
(0.013)\end{array}$ & $\begin{array}{c}0.999 \\
(0.013)\end{array}$ \\
\hline Cohorts included & & & yes & yes \\
\hline Faculties included & & & yes & yes \\
\hline Observations & 30063 & 30063 & 30063 & 30063 \\
\hline No. of subjects & 9167 & 9167 & 9167 & 9167 \\
\hline No. failed & 4522 & 4522 & 4522 & 4522 \\
\hline No. competing & 2338 & 2338 & 2338 & 2338 \\
\hline No. censored & 2307 & 2307 & 2307 & 2307 \\
\hline Log Pseudolikelihood & -39081.369 & -39081.369 & -38384.377 & -38384.377 \\
\hline
\end{tabular}

Columns (1) and (3): coefficients, columns (2) and (4) subhazard ratios; standard errors in parentheses; clustered by counties; TVC interacted with t; faculty is the last faculty the student is enrolled at ${ }^{*} p<0.05,{ }^{* *} p<0.01,{ }^{* * *} p<0.001$. 
study conditions which often implied a lower degree of flexibility and stricter rules for the time frame when examinations have to be taken. By giving the study process in itself a clearer structure, the reform helps students to focus on what is relevant for their studies and prevents them from delaying courses. In fact, the German Council of Science and Humanities considered the high degree of freedom within the old study programs to be one of the main causes for the excessive length of studies that was observed before the reform (Wissenschaftsrat, 2000).

However, the negative interaction term in column (3) implies that the effect is decreasing the longer students stay at university. In study period six (semesters 11 and 12 for bachelor and semesters 16 to 18 for students within the old degree programs), bachelor students have even a lower conditional probability of obtaining a degree than their peers within the old degree system. An explanation for this finding lies again in the rearrangement of study regulations. The lower degree of flexibility helps students in focusing on their studies, whereas the stricter examination regulations and time restrictions that were introduced in the course of the Bologna process make it more and more difficult to achieve a degree the longer a student stays at university. In contrast, the high degree of freedom within the old study programs results in longer periods spend at university for most students. Nevertheless, it is more likely to graduate at a very late point in time.

\subsubsection{Dropping Out of University}

Table 5.3 presents the results for the duration until dropping out of university. When not controlling for time-varying coefficients, as shown in columns (1) and (2), the analysis suggests that bachelor students are 14.5 percent less likely to drop out of university in every study period. However, the positive interaction term in column (3) shows that the effect is varying with duration. Conditional on still studying, the probability of dropping out of university is 32 percent lower for bachelor students in study period one and 18 percent lower in study period two. From study period four onward, however, the conditional likelihood of dropping 
out of university is higher for students within a bachelor program and the size of the effect increases over time.

The results suggest that old degree students are more likely to drop out of university at the beginning of their studies while bachelor students have a higher probability of failing at a later point in time. However, further analysis shows that the main effect is driven by the faculty of humanities and the faculty of social sciences. When excluding students who are enrolled at these faculties from the sample, the main coefficient and the interaction term turn insignificant (as shown in Table 5.4, columns (1) and (2)). This result not only holds true for the joint sample, but also when looking at the faculties separately. Besides for the faculty of economic sciences, this could, however, also be due to low numbers of observations. Nevertheless, it indicates that there is no difference between bachelor and old degree students concerning university drop out in most fields of study.

Reducing the sample to students from the faculty of humanities only (represented in Table 5.4, columns (3) and (4)), reveals a negative coefficient of the treatment variable. The interaction term is positive but not significant. Therefore, the results imply that bachelor students who are enrolled at the faculty of humanities are less likely to drop out of university in every study period. Looking at the faculty of social sciences only, reveals a negative main effect and a positive interaction term for students enrolled at this faculty (as shown in Table 5.4, columns (5) and (6)). Both coefficients are significant. Consequently, bachelor students at the faculty of social sciences are less likely to drop out of university in study periods one and two. Afterwards, however, the effect changes. ${ }^{31}$

A possible explanation for the special role of the faculty of humanities is the share of students enrolled in the old Magister and teacher programs. Close to all of the old degree students at the faculty of humanities aim at a Magister or

\footnotetext{
${ }^{31}$ It should be noted that the students' cohort is not controlled for when restricting the sample to a single faculty. Reason for this is a strong correlation between the cohort and the treatment variable. Nevertheless, Section 5.5.3 shows that the results do not change substantially when only looking at students who enrolled at university after the state government's decision to introduce tuition fees. Since this was the main reason for controlling for the students' cohort, I am confident that the shown results are robust.
} 
Table 5.3: Dropping Out of University

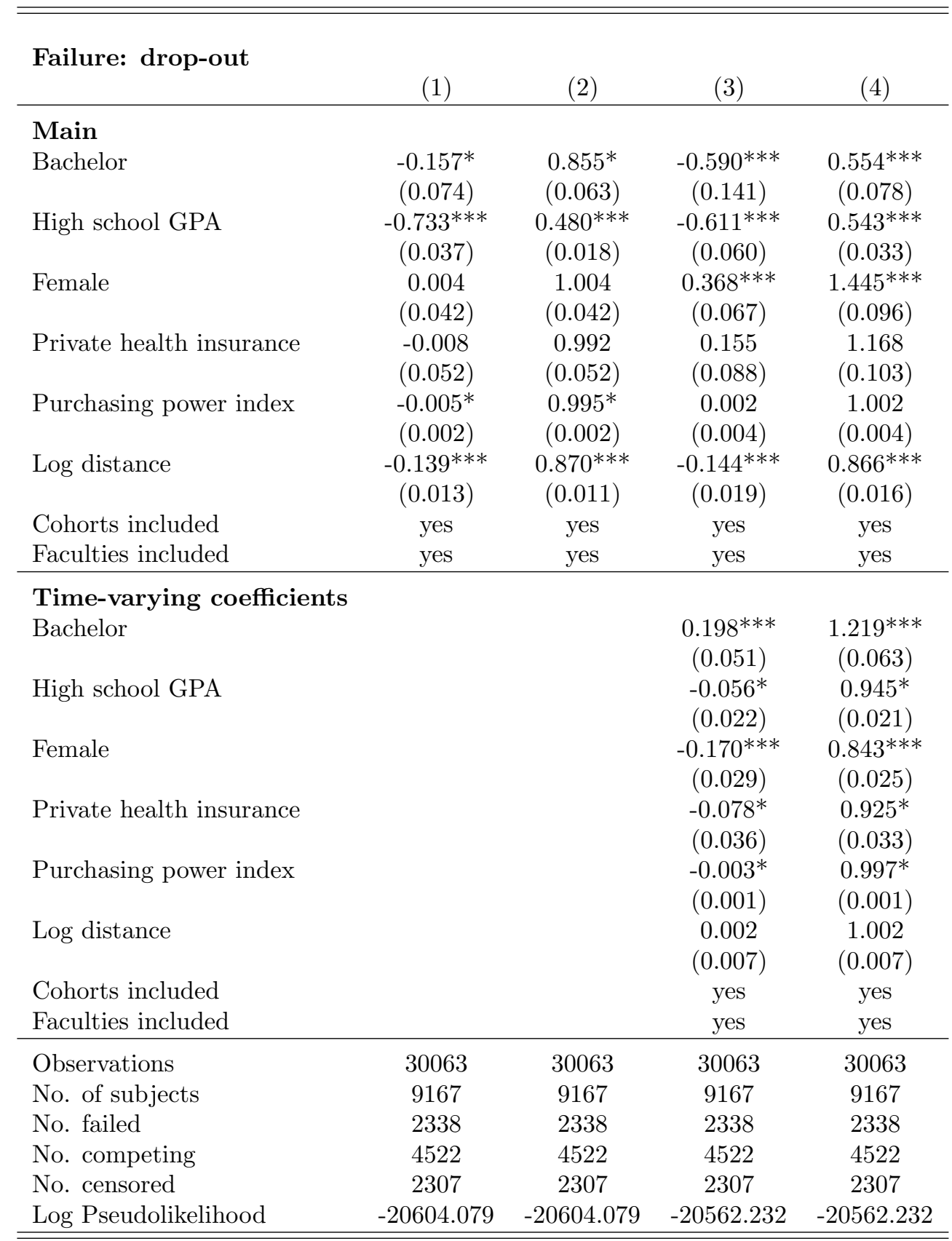

Columns (1) and (3): coefficients, columns (2) and (4) subhazard ratios; standard errors in parentheses; clustered by counties; TVC interacted with t; faculty is the last faculty the student is enrolled at; ${ }^{*} p<0.05,{ }^{* *} p<0.01,{ }^{* * *} p<0.001$. 
Table 5.4: Reduced Sample

\begin{tabular}{|c|c|c|c|c|c|c|}
\hline \multirow[t]{3}{*}{ Drop-out } & \multirow{2}{*}{\multicolumn{2}{|c|}{$\begin{array}{l}\text { Without Humanities } \\
\text { and Social Sciences }\end{array}$}} & \multirow{2}{*}{\multicolumn{2}{|c|}{ Humanities }} & \multirow{2}{*}{\multicolumn{2}{|c|}{ Social Sciences }} \\
\hline & & & & & & \\
\hline & $(1)$ & $(2)$ & $(3)$ & $(4)$ & $(5)$ & $(6)$ \\
\hline \multicolumn{7}{|l|}{ Main } \\
\hline \multirow[t]{2}{*}{ Bachelor } & -0.013 & 0.987 & $-0.773^{* * *}$ & $0.462^{* * *}$ & $-0.715^{* *}$ & $0.489 * *$ \\
\hline & $(0.150)$ & $(0.148)$ & $(0.147)$ & $(0.068)$ & $(0.231)$ & $(0.113)$ \\
\hline \multirow[t]{2}{*}{ High school GPA } & $-0.721^{* * *}$ & $0.486^{* * *}$ & $-0.467^{* * *}$ & $0.627 * * *$ & $-0.383^{*}$ & $0.682^{*}$ \\
\hline & $(0.072)$ & $(0.035)$ & $(0.113)$ & $(0.071)$ & $(0.163)$ & $(0.111)$ \\
\hline \multirow[t]{2}{*}{ Female } & $0.520 * * *$ & $1.682^{* * *}$ & 0.107 & 1.113 & $0.371^{*}$ & $1.449^{*}$ \\
\hline & $(0.094)$ & $(0.158)$ & $(0.142)$ & $(0.158)$ & $(0.152)$ & $(0.220)$ \\
\hline \multirow[t]{2}{*}{ Private health insurance } & 0.216 & 1.241 & 0.002 & 1.002 & 0.153 & 1.165 \\
\hline & $(0.129)$ & $(0.160)$ & $(0.146)$ & $(0.146)$ & $(0.193)$ & $(0.225)$ \\
\hline \multirow[t]{2}{*}{ Purchasing power index } & 0.006 & 1.006 & -0.001 & 0.999 & -0.002 & 0.998 \\
\hline & $(0.005)$ & $(0.005)$ & $(0.007)$ & $(0.007)$ & $(0.008)$ & $(0.008)$ \\
\hline \multirow[t]{2}{*}{ Log distance } & $-0.091^{* * *}$ & $0.913^{* * *}$ & $-0.217^{* * *}$ & $0.805^{* * *}$ & $-0.112^{* *}$ & $0.894^{* *}$ \\
\hline & $(0.020)$ & $(0.018)$ & $(0.030)$ & $(0.024)$ & $(0.041)$ & $(0.037)$ \\
\hline \multirow{2}{*}{$\begin{array}{l}\text { Faculties included } \\
\text { Cohorts included }\end{array}$} & yes & yes & no & no & no & no \\
\hline & yes & yes & no & no & no & no \\
\hline \multicolumn{7}{|l|}{ Time-varying coefficients } \\
\hline \multirow[t]{2}{*}{ Bachelor } & 0.069 & 1.072 & 0.081 & 1.085 & $0.287 * * *$ & $1.333^{* * *}$ \\
\hline & $(0.068)$ & $(0.072)$ & $(0.052)$ & $(0.056)$ & $(0.075)$ & $(0.100)$ \\
\hline \multirow[t]{2}{*}{ High school GPA } & -0.058 & 0.944 & $-0.089^{*}$ & $0.915^{*}$ & -0.010 & 0.990 \\
\hline & $(0.031)$ & $(0.029)$ & $(0.041)$ & $(0.038)$ & $(0.061)$ & $(0.060)$ \\
\hline \multirow[t]{2}{*}{ Female } & $-0.186^{* * *}$ & $0.830 * * *$ & $-0.119^{*}$ & $0.888^{*}$ & $-0.200^{* *}$ & $0.819^{* *}$ \\
\hline & $(0.040)$ & $(0.034)$ & $(0.057)$ & $(0.050)$ & $(0.072)$ & $(0.059)$ \\
\hline \multirow[t]{2}{*}{ Private health insurance } & $-0.118^{*}$ & $0.889^{*}$ & -0.054 & 0.947 & 0.013 & 1.013 \\
\hline & $(0.056)$ & $(0.049)$ & $(0.060)$ & $(0.057)$ & $(0.082)$ & $(0.083)$ \\
\hline \multirow[t]{2}{*}{ Purchasing power index } & $-0.004^{*}$ & $0.996^{*}$ & -0.005 & 0.995 & -0.002 & 0.998 \\
\hline & $(0.002)$ & $(0.002)$ & $(0.003)$ & $(0.003)$ & $(0.003)$ & $(0.003)$ \\
\hline \multirow[t]{2}{*}{ Log distance } & $-0.022^{*}$ & $0.978^{*}$ & $0.041^{* *}$ & $1.042^{* *}$ & -0.013 & 0.987 \\
\hline & $(0.010)$ & $(0.009)$ & $(0.013)$ & $(0.014)$ & $(0.017)$ & $(0.016)$ \\
\hline \multirow{2}{*}{$\begin{array}{l}\text { Faculties included } \\
\text { Cohorts included }\end{array}$} & yes & yes & no & no & no & no \\
\hline & yes & yes & no & no & no & no \\
\hline Observations & 17907 & 17907 & 7481 & 7481 & 4675 & 4675 \\
\hline No. of subjects & 5517 & 5517 & 2305 & 2305 & 1345 & 1345 \\
\hline No. failed & 1303 & 1303 & 669 & 669 & 366 & 366 \\
\hline No. competing & 3099 & 3099 & 858 & 858 & 565 & 565 \\
\hline No. censored & 1115 & 1115 & 778 & 778 & 414 & 414 \\
\hline Log Pseudolikelihood & -10790.484 & -10790.484 & -4919.8897 & -4919.8897 & -2533.2508 & -2533.2508 \\
\hline
\end{tabular}

Columns (1), (3) and (5): coefficients, columns (2), (4) and (6): subhazard ratios; standard errors in parentheses; clustered by counties; TVC interacted with t; faculty is the last faculty the student is enrolled at; ${ }^{*} p<0.05,{ }^{* *} p<0.01, * * * p<0.001$. 
teacher degree while the respective shares are between zero and 50 percent at the other faculties.

Compared to the Diplom, the differences between the Magister and old teacher degree and the new bachelor programs are more substantial. Both programs are characterized by a particularly high level of freedom with regard to which courses to take and when to do the examinations. Sometimes only regular attendance is required to successfully complete a class and most of the grades achieved during one's course of study do not count towards the final degree. Instead, the graduation grade is the result of decentralized final examinations carried out by the university's institutes. The new bachelor programs, on the other hand, have a clear structure and low degree of flexibility. Furthermore, grades are awarded to most of the courses taken and the vast majority also counts towards the degree. These changes in study conditions induce a more scholastic learning environment that helps students in finding their way at university. In addition, the frequent examinations lead to students regularly reflecting their performance and focusing on what is relevant for their studies. Finally, the faculty of humanities did not introduce time restrictions into its examination regulations, which may also explain the special role with regard to university drop out. In particular, it may be a reason for the fact that bachelor students do not have a higher conditional probability of dropping out of university at a rather late point of their studies than students enrolled in one of the old degree programs.

Also at the faculty of social sciences, the share of students enrolled in a Magister or old teacher degree is comparatively high. More than half of the old degree students at this faculty aims at one of the two mentioned degrees. In line with the argumentation for the faculty of humanities, the substantial differences to the new bachelor programs may explain the lower conditional probability of dropping out of university for bachelor students in study period one and two. However, from study period three onward, bachelor students at the faculty of social sciences are more likely to drop out of university than their peers within the old degree system. On the one hand, this finding could be the result of differing effects for students enrolled in Magister programs and the diploma. On the other hand, it may also indicate that students who are at the risk of dropping out get 
pulled along for some time and leave university without a degree at a rather late point of their studies. Although the faculty of social sciences did not introduce time restrictions in the course of the Bologna process, the frequent examinations cause students to regularly reflect their performance. This may not only help them to focus on their studies, but also lead to students with low academic ability getting discouraged the longer they stay at university. Unfortunately, it is not possible to identify the channels which drive the found effects with the data at hand.

\subsubsection{Robustness Tests}

The robustness of the results is tested in three ways. Firstly, the time-varying coefficients are interacted with the logarithm of time, instead of assuming a linear relationship. This implies that the impact of being in a bachelor program is non-linear with a decreasing marginal effect. Secondly, a possible impact of the introduction of general tuition fees on the results is taken into account by reducing the sample to students who enrolled after the state government of Lower Saxony decided to introduce these fees. Thirdly, instead of the relative time measure different definitions of study period are used.

\section{Interaction with $\ln (\mathrm{t})$}

So far, the analysis assumed that there is a linear relationship between the effect of the covariates and time. However, it is also conceivable that the marginal impact of being enrolled in a bachelor program is decreasing with duration. Therefore, Table 5.A.1 shows the results when the covariates are interacted with the logarithm of time instead. The coefficients in column (1) imply that the conditional probability of graduating is approximately 293 percent higher for bachelor students in study period three and 84 percent higher in study period four. In study period six, however, bachelor students are less likely to graduate given that they are still studying. These results are very similar to the findings in Section 5.5.1 where linearity in time is assumed.

Also for the event of dropping out of university, the results are similar to the findings in Section 5.5.2. When looking at all faculties, in column (2), bachelor 
students are less likely to drop out of university in study period one and two. From study period three onward, however, the effect changes. Furthermore, the faculties of humanities and social sciences still play a special role. When looking at students enrolled at the faculty of humanities only, represented in column (4), bachelor students are less likely to drop out of university in all study periods. Also for the faculty of social sciences, interacting the covariates with the logarithm of time, as shown in column (5), leads to similar results than assuming a linear relationship: bachelor students are less likely to drop out of university in study period one. From study period three onward the effect changes.

However, when interacting the covariates with the logarithm of time, the effect for the faculty of economic sciences also turns significant, as shown in column (6). The positive and significant interaction term implies that bachelor students at this faculty have a higher conditional probability of dropping out of university in every study period and the effect is increasing with duration.

Furthermore. excluding students enrolled at the faculty of humanities, the faculty of social sciences and the faculty of economic sciences from the sample, in column (3), leads to insignificant effects for being enrolled in a bachelor program. This is in line with the results in section 5.5.2 which also show insignificant effects for most fields of study.

\section{Tuition Fees}

In July 2005 the state government of Lower Saxony decided to introduce general tuition fees. Students who enrolled at Göttingen University in the winter term 2006 were the first ones who had to pay 500 Euro in addition to the regular administrative fees, all in all resulting in a payment of approximately 700 Euro per semester. From the summer term 2007 onward, every student at Göttingen university had to pay tuition fees, irrespective of when they enrolled at university.

Since most old degree students enrolled at university before the introduction of tuition fees and most bachelor students afterwards, one may argue that the results are affected by this reform. So far, the analysis controls for the student's cohort, which also captures if a student enrolled before or after the introduction 
of general tuition fees. Nevertheless, the sample is reduced to students who enrolled at Göttingen University from the winter term 2005 onward and hence after the state government's decision, cohorts three to five, as a robustness test.

The results for the reduced sample are shown in Table 5.A.2. For the event of graduation, in column (1), the main effect of being enrolled in a bachelor program is still positive and significant while the interaction term turned insignificant. Consequently, when reducing the sample to students who enrolled after the introduction of tuition fees, bachelor students are approximately 246 percent more likely to graduate in every study period. In contrast to the results for the full sample, the effect is not changing with duration.

For the event of dropping out of university the results are similar to those found for the full sample, Section 5.5.2. When looking at students from all faculties, in column (2), bachelor students are less likely to drop out of university in study periods one to three. Afterwards, the effect changes. Furthermore and in line with the findings for the full sample, the effect for being enrolled in a bachelor program turns insignificant when excluding the faculty of humanities and the faculty of social sciences, as shown in column (3). Looking at the faculty of humanities only, in column (4), reveals that bachelor students are still less likely to drop out of university in all study periods. In contrast to the results in Section 5.5.2, however, the size of the effect is decreasing over time. Finally, the results in column (5) show that bachelor students at the faculty of social sciences are less likely to drop out of university in study period one and two. From study period three onward, the conditional probability of dropping out of university is higher for bachelor students than for students enrolled in one of the old degree programs. Similarly, for the faculty of physics and the faculty of mathematics the effect of being enrolled in a bachelor program turns significant. However, these findings have to be dealt with caution due to a low number of observations and are therefore not reported.

The robustness test shows that the results do not change substantially when restricting the sample to students who enrolled after the state government's decision to introduce tuition fees. Therefore, controlling for the student's cohort is an adequate way to take this reform into account. 


\section{Study Period}

So far, the time measure used is relative to the standard time period in the respective field in order to make duration between old and new degree programs comparable. The following analysis uses different classifications to test whether the definition of the study period has an impact on the results. The new classification of the time variable for the events of graduation and university drop-out are shown in Table 5.5.

Table 5.5: New Classification Study Period

\begin{tabular}{ccc|ccc}
\hline \hline \multicolumn{3}{c}{ Graduation } & \multicolumn{4}{c}{$\begin{array}{c}\text { Dropout } \\
\text { Study Period } \\
\text { Semester } \\
\text { Bachelor }\end{array}$} & $\begin{array}{c}\text { Semester } \\
\text { Old Degree }\end{array}$ & Study Period & $\begin{array}{c}\text { Semester } \\
\text { Bachelor }\end{array}$ & $\begin{array}{c}\text { Semester } \\
\text { Old Degree }\end{array}$ \\
\hline 1 & $1-4$ & $1-7$ & 1 & 1 & 1 \\
2 & 5 & 8 & 2 & 2 & 2 \\
3 & 6 & 9 & 3 & 3 & 3 \\
4 & 7 & 10 & 4 & 4 & 4 \\
5 & 8 & 11 & 5 & 5 & 5 \\
6 & 9 & 12 & 6 & 6 & 6 \\
7 & $10-12$ & $13-15$ & 7 & $7-9$ & $7-9$ \\
8 & $\geq 13$ & $\geq 16$ & 8 & $\geq 10$ & $\geq 10$ \\
\hline \hline
\end{tabular}

For the event of graduation the new classification gives a more detailed picture of the time between one semester before and three semesters above the standard time period. The results are shown in Table 5.A.3. The coefficients in column (1) imply that until one third above the standard time period (semester nine for bachelor and semester 12 for old degree students) bachelor students have a higher conditional probability of graduating. Afterwards the effect changes. This is consistent with the findings in Section 5.5.1.

When analyzing the time until dropping out of university it is not only interesting to use a relative time measure, but also to look at the actual semester in which the students leave university. Furthermore, most of the students who drop out of university do so at the beginning of their studies. 75 percent of the bachelor students in the sample who left university without a degree did so between semester one and six, 20 percent dropped out of university between semester seven and nine. The shares for old degree students is 74 percent and 8 percent respectively. Taking these considerations into account, the new time 
classification compares time in absolute terms and is more detailed for the first semesters.

The results in Table 5.A.3 reveal an insignificant effect both for the main coefficient and the interaction term for the full sample, as shown in column (2). For the faculty of humanities, in column (3), the main effect is negative and highly significant. This implies again that bachelor students at this faculty are less likely to drop out of university than their peers enrolled in one of the old study programs. In contrast to the results in Section 5.5.2, the treatment coefficients for the faculty of social sciences, in column (4), turn insignificant when using the new time classification. Furthermore, the results indicate that bachelor students at the faculty of economic sciences have a higher conditional probability of dropping out of university than students who are enrolled in one of the old degree programs, as shown in column (5). Also for the faculty of physics the effect of being enrolled in a bachelor program turns significant. However, this finding should be dealt with caution due to a low number of observations and is therefore not reported.

In a nutshell, the results for the event of graduation are robust to the presented different classifications of the time variable. Concerning the event of dropping out of university, the same holds true for the faculty of humanities. Furthermore, the insignificant effects for the full sample underlines that the reform did not influence university drop-out in most fields of study. The results for the faculty of social sciences and the faculty of economic sciences, however, seem to be sensitive to different time definitions.

\subsection{Discussion and Conclusion}

For Germany, the introduction of bachelor programs in the course of the Bologna process implied a restructuring of part of the degree system. This involved a reduction of the standard time period needed to obtain the first university degree as well as a rearrangement of the existing examination regulations and study conditions. Since the reform may influence students' behavior and performance, this study evaluates its effect on the duration until graduation and dropping out 
of university. An extensive dataset containing detailed administrative data on more than 9000 students allows the application of competing risks models for the two possibilities of terminating one's studies. As the standard time period differs between the old and new study system, a relative time measure is used to make information on study duration comparable.

The analysis shows that the Bologna process had a positive impact on the duration until graduation. This effect is robust to a variety of different specifications. Consequently, one of the reform's main objectives was achieved, namely to reduce the time German graduates need to obtain their first university degree not only in absolute but also in relative terms. In line with this view, the finding also confirms descriptive evidence by the Authoring Group Educational Reporting (Autorengruppe Bildungsberichterstattung, 2012). A possible explanation for the result is the clear structure and low degree of flexibility within the new bachelor programs. Both help students to find their way at university and to focus on what is relevant for their studies.

For the event of dropping out of university, the result is less conclusive. There is no significant effect of the reform on university drop-out for most fields of study. However, the analysis reveals a clear favorable impact of being enrolled in a bachelor program for students at the faculty of humanities. This effect is robust to a variety of different specifications. Furthermore, both results are in line with the study by Horstschräer and Sprietsma (2015) who find, among others, insignificant effects for most fields of study but lower drop-out rates for bachelor students in English and German literature departments.

Furthermore, the analysis shows significant effects on university drop-out for students at the faculty of social sciences and the faculty of economic sciences in some specifications. Thereby, the results suggest, that bachelor students at the faculty of social sciences are less likely to drop out of university in the beginning of their studies, but have a higher conditional probability of leaving university without a degree from study period three onward. At the faculty of economic sciences, bachelor students are, if at all, more likely to drop out of university in all study periods.

These findings differ from the results by Horstschräer and Sprietsma (2015) who find that the reform decreased drop-out rates for students studying business 
administration. Moreover, they show that drop-out rates increase at biology departments. A possible reason for the differing results is that Horstschräer and Sprietsma (2015) are not able do distinguish between students who drop out of university and students who change subject or change to a different institution of higher education. This distinction is made in the present analysis, though. In addition, they look at business administration and economic departments separately while the faculty of economic sciences in this study includes both subjects.

With regard to the timing of university drop-out, the present study does not confirm the descriptive evidence by Heublein et al. (2009). While comparing the average amount of semesters until university drop-out suggests that bachelor students leave university without a degree at an earlier stage of their studies than students aiming at one of the old degrees (Heublein et al., 2009), using survival analysis draws a different picture. Besides the different methodological approach, this may also be due to Heublein et al. (2009) taking into account students from both universities and universities of applied sciences. Furthermore, the group of old degree students also includes students who aim at a state examination in medicine or law. These study programs are, however, special with regard to study and examination regulations.

To sum up, the analysis showed that the restructuring of examination and study regulations in the course of the Bologna process reduced the duration until graduation both in absolute and relative terms. In addition, it had a favorable impact on the probability of dropping out of university for students enrolled at the faculty of humanities. For most of the other faculties the effect of the reform on university drop-out is insignificant. Although being a case study, the assessment of administrative student data allows a broad insight into the timing of graduation and university drop-out. Thereby, the present study obtains additional information and more profound results than the mainly descriptive evidence that so far is available for Germany. However, similar analysis for other German universities are needed in order to assess whether the achieved results can be transferred to a more general level. 
5.A Appendix I: Tables 
Table 5.A.1: Interaction with $\ln (\mathrm{t})$

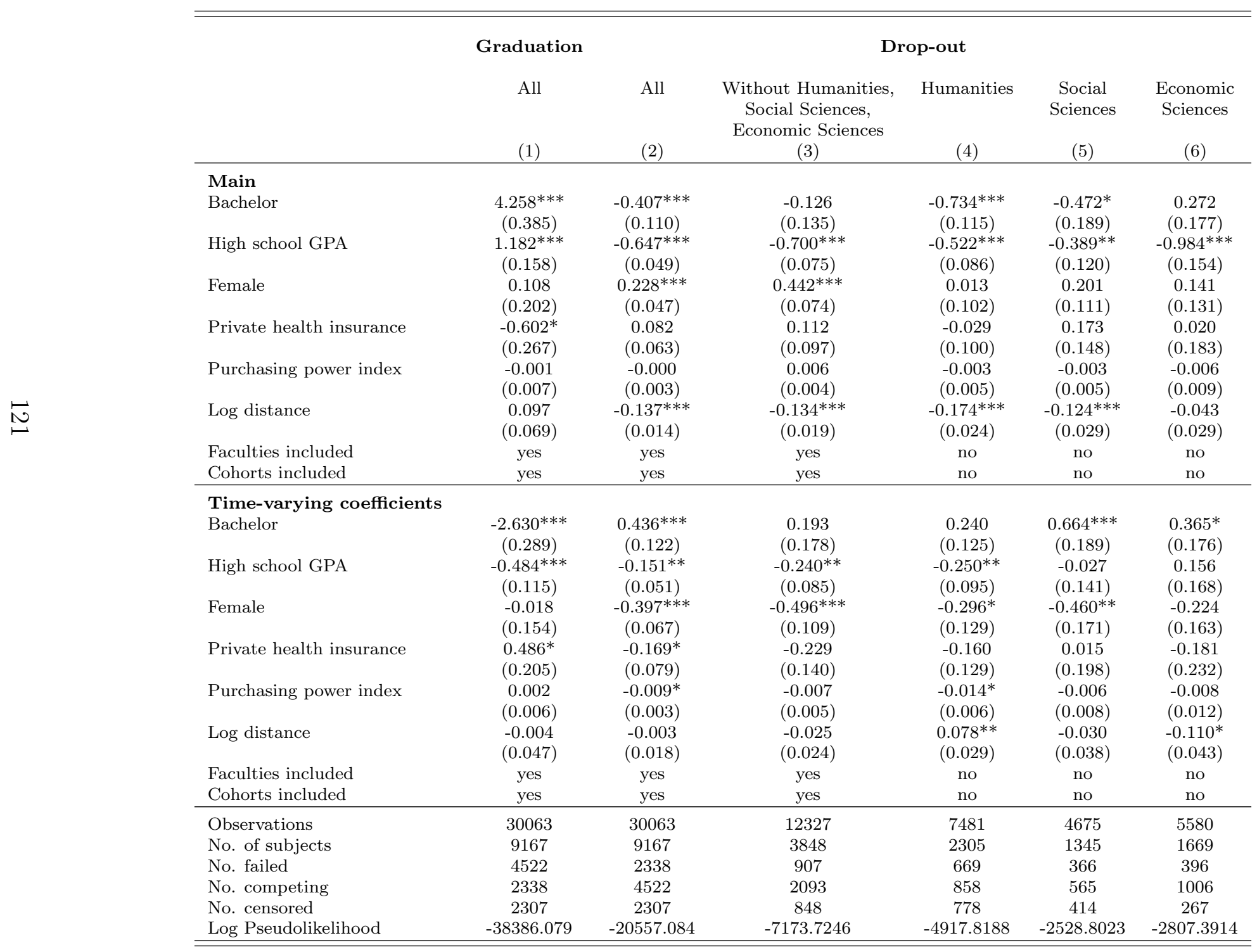

Coefficients; standard errors in parentheses; clustered by counties; TVC interacted with $\ln (\mathrm{t})$; faculty is the last faculty the student is enrolled at; ${ }^{*} p<0.05,{ }^{* *} p<0.01,{ }^{* * *} p<0.001$. 
Table 5.A.2: Cohorts 3-5

\begin{tabular}{|c|c|c|c|c|c|}
\hline & \multirow{2}{*}{$\begin{array}{c}\text { Graduation } \\
\text { All } \\
(1)\end{array}$} & \multicolumn{4}{|c|}{ Drop-out } \\
\hline & & $\begin{array}{l}\text { All } \\
(2)\end{array}$ & $\begin{array}{l}\text { Without Humanities } \\
\text { and Social Sciences } \\
(3)\end{array}$ & $\begin{array}{l}\text { Humanities } \\
\text { (4) }\end{array}$ & $\begin{array}{c}\text { Social Sciences } \\
\qquad(5) \\
\end{array}$ \\
\hline \\
\hline Bachelor & $\begin{array}{c}1.241^{* *} \\
(0.464)\end{array}$ & $\begin{array}{c}-0.923^{* * *} \\
(0.198)\end{array}$ & $\begin{array}{c}0.256 \\
(0.242)\end{array}$ & $\begin{array}{c}-1.160^{* * *} \\
(0.162)\end{array}$ & $\begin{array}{c}-1.367^{* * *} \\
(0.366)\end{array}$ \\
\hline High school GPA & $\begin{array}{c}1.137^{* * *} \\
(0.172)\end{array}$ & $\begin{array}{c}-0.735 * * * \\
(0.086)\end{array}$ & $\begin{array}{c}-0.840^{* * *} \\
(0.110)\end{array}$ & $\begin{array}{c}-0.474^{*} \\
(0.185)\end{array}$ & $\begin{array}{c}-0.698^{*} \\
(0.299)\end{array}$ \\
\hline Female & $\begin{array}{l}-0.290 \\
(0.258)\end{array}$ & $\begin{array}{c}0.281^{* *} \\
(0.102)\end{array}$ & $\begin{array}{c}0.480^{* * *} \\
(0.115)\end{array}$ & $\begin{array}{c}0.010 \\
(0.199)\end{array}$ & $\begin{array}{l}-0.072 \\
(0.231)\end{array}$ \\
\hline Private health insurance & $\begin{array}{l}-0.529 \\
(0.294)\end{array}$ & $\begin{array}{c}0.234 \\
(0.152)\end{array}$ & $\begin{array}{l}0.390^{*} \\
(0.188)\end{array}$ & $\begin{array}{c}0.134 \\
(0.236)\end{array}$ & $\begin{array}{l}-0.362 \\
(0.370)\end{array}$ \\
\hline Purchasing power index & $\begin{array}{c}0.001 \\
(0.008)\end{array}$ & $\begin{array}{l}-0.003 \\
(0.005)\end{array}$ & $\begin{array}{l}-0.003 \\
(0.006)\end{array}$ & $\begin{array}{c}-0.004 \\
(0.011)\end{array}$ & $\begin{array}{l}-0.004 \\
(0.012)\end{array}$ \\
\hline Log distance & $\begin{array}{c}0.038 \\
(0.063)\end{array}$ & $\begin{array}{c}-0.139 * * * \\
(0.026)\end{array}$ & $\begin{array}{c}-0.100 * * * \\
(0.028)\end{array}$ & $\begin{array}{c}-0.172^{* * *} \\
(0.046)\end{array}$ & $\begin{array}{c}-0.216^{* *} \\
(0.070)\end{array}$ \\
\hline Faculties included & yes & yes & yes & no & no \\
\hline Cohorts included & yes & yes & yes & no & no \\
\hline \multicolumn{6}{|c|}{ Time-varying coefficients } \\
\hline Bachelor & $\begin{array}{c}-0.057 \\
(0.126)\end{array}$ & $\begin{array}{c}0.251^{* * * *} \\
(0.075)\end{array}$ & $\begin{array}{l}-0.204 \\
(0.106)\end{array}$ & $\begin{array}{l}0.183^{*} \\
(0.078)\end{array}$ & $\begin{array}{c}0.638^{* * *} \\
(0.172)\end{array}$ \\
\hline High school GPA & $\begin{array}{c}-0.161^{* * *} \\
(0.048)\end{array}$ & $\begin{array}{l}-0.005 \\
(0.029)\end{array}$ & $\begin{array}{c}0.003 \\
(0.037)\end{array}$ & $\begin{array}{l}-0.059 \\
(0.062)\end{array}$ & $\begin{array}{c}0.051 \\
(0.116)\end{array}$ \\
\hline Female & $\begin{array}{c}0.111 \\
(0.073)\end{array}$ & $\begin{array}{c}-0.168^{* * *} \\
(0.043)\end{array}$ & $\begin{array}{c}-0.188 * * * \\
(0.048)\end{array}$ & $\begin{array}{l}-0.131 \\
(0.080)\end{array}$ & $\begin{array}{l}-0.132 \\
(0.102)\end{array}$ \\
\hline Private health insurance & $\begin{array}{c}0.155 \\
(0.084)\end{array}$ & $\begin{array}{c}-0.099 \\
(0.063)\end{array}$ & $\begin{array}{l}-0.179^{*} \\
(0.090)\end{array}$ & $\begin{array}{l}-0.112 \\
(0.090)\end{array}$ & $\begin{array}{c}0.252 \\
(0.148)\end{array}$ \\
\hline Purchasing power index & $\begin{array}{c}0.001 \\
(0.002)\end{array}$ & $\begin{array}{l}-0.001 \\
(0.002)\end{array}$ & $\begin{array}{l}-0.000 \\
(0.002)\end{array}$ & $\begin{array}{l}-0.004 \\
(0.004)\end{array}$ & $\begin{array}{l}-0.002 \\
(0.005)\end{array}$ \\
\hline Log distance & $\begin{array}{c}0.018 \\
(0.016)\end{array}$ & $\begin{array}{c}0.003 \\
(0.011)\end{array}$ & $\begin{array}{l}-0.018 \\
(0.011)\end{array}$ & $\begin{array}{c}0.040 \\
(0.022)\end{array}$ & $\begin{array}{c}0.015 \\
(0.029)\end{array}$ \\
\hline Faculties included & yes & yes & yes & no & no \\
\hline Cohorts included & yes & yes & yes & no & no \\
\hline Observations & 17091 & 17091 & 10642 & 4494 & 1955 \\
\hline No. of subjects & 5296 & 5296 & 3354 & 1362 & 580 \\
\hline No. failed & 2505 & 1306 & 814 & 341 & 151 \\
\hline No. competing & 1306 & 2505 & 1752 & 555 & 198 \\
\hline No. censored & 1485 & 1485 & 788 & 466 & 231 \\
\hline Log Pseudolikelihood & -20153.735 & -10771.417 & -6333.0364 & -2335.5462 & -900.91857 \\
\hline
\end{tabular}

Includes students who enrolled at Göttingen University between the winter term 2005 and the summer term 2008. Coefficients; standard errors in parentheses; clustered by counties; TVC interacted with $\mathrm{t}$; faculty is the last faculty the student is enrolled at; ${ }^{*} p<0.05,{ }^{* *} p<0.01,{ }^{* * *} p<0.001$. 
Table 5.A.3: New Definition Study Period

\begin{tabular}{|c|c|c|c|c|c|}
\hline & \multirow{2}{*}{$\begin{array}{c}\text { Graduation } \\
\text { All } \\
(1) \\
\end{array}$} & \multicolumn{4}{|c|}{ Drop-out } \\
\hline & & $\begin{array}{l}\text { All } \\
(2)\end{array}$ & $\begin{array}{c}\text { Humanities } \\
\text { (3) }\end{array}$ & $\begin{array}{c}\text { Social } \\
\text { Sciences } \\
(4)\end{array}$ & $\begin{array}{c}\text { Economic } \\
\text { Sciences } \\
(5)\end{array}$ \\
\hline \multicolumn{6}{|l|}{ Main } \\
\hline Bachelor & $\begin{array}{c}2.463^{* * *} \\
(0.177)\end{array}$ & $\begin{array}{c}-0.228 \\
(0.167)\end{array}$ & $\begin{array}{c}-0.645^{* * *} \\
(0.164)\end{array}$ & $\begin{array}{l}-0.337 \\
(0.253)\end{array}$ & $\begin{array}{c}0.673^{* * *} \\
(0.198)\end{array}$ \\
\hline High school GPA & $\begin{array}{c}0.832^{* * * *} \\
(0.080)\end{array}$ & $\begin{array}{c}-0.632^{* * *} \\
(0.067)\end{array}$ & $\begin{array}{c}-0.421^{* * *} \\
(0.113)\end{array}$ & $\begin{array}{c}-0.370^{*} \\
(0.163)\end{array}$ & $\begin{array}{c}-1.055^{* * *} \\
(0.216)\end{array}$ \\
\hline Female & $\begin{array}{c}0.112 \\
(0.084)\end{array}$ & $\begin{array}{c}0.390^{* * *} \\
(0.070)\end{array}$ & $\begin{array}{c}0.060 \\
(0.137)\end{array}$ & $\begin{array}{c}0.418^{* *} \\
(0.152)\end{array}$ & $\begin{array}{c}0.251 \\
(0.198)\end{array}$ \\
\hline Private health insurance & $\begin{array}{c}-0.273^{*} \\
(0.107)\end{array}$ & $\begin{array}{c}0.190 \\
(0.098)\end{array}$ & $\begin{array}{c}0.075 \\
(0.153)\end{array}$ & $\begin{array}{c}0.221 \\
(0.209)\end{array}$ & $\begin{array}{c}0.073 \\
(0.267)\end{array}$ \\
\hline Purchasing power index & $\begin{array}{c}0.001 \\
(0.003)\end{array}$ & $\begin{array}{c}0.002 \\
(0.003)\end{array}$ & $\begin{array}{c}0.002 \\
(0.007)\end{array}$ & $\begin{array}{c}0.001 \\
(0.008)\end{array}$ & $\begin{array}{l}-0.005 \\
(0.012)\end{array}$ \\
\hline Log distance & $\begin{array}{l}0.079 * \\
(0.036)\end{array}$ & $\begin{array}{c}-0.153^{* * *} \\
(0.020)\end{array}$ & $\begin{array}{c}-0.238 * * * \\
(0.031)\end{array}$ & $\begin{array}{c}-0.116^{* *} \\
(0.040)\end{array}$ & $\begin{array}{l}-0.002 \\
(0.041)\end{array}$ \\
\hline Faculties included & yes & yes & no & no & no \\
\hline Cohorts included & yes & yes & no & no & no \\
\hline \multicolumn{6}{|c|}{ Time-varying coefficients } \\
\hline Bachelor & $\begin{array}{c}-0.361 * * * \\
(0.041)\end{array}$ & $\begin{array}{c}0.031 \\
(0.033)\end{array}$ & $\begin{array}{c}0.032 \\
(0.032)\end{array}$ & $\begin{array}{c}0.089 \\
(0.048)\end{array}$ & $\begin{array}{l}-0.028 \\
(0.041)\end{array}$ \\
\hline High school GPA & $\begin{array}{c}-0.054^{* * *} \\
(0.016)\end{array}$ & $\begin{array}{c}-0.031^{*} \\
(0.014)\end{array}$ & $\begin{array}{c}-0.066^{* *} \\
(0.023)\end{array}$ & $\begin{array}{l}-0.008 \\
(0.031)\end{array}$ & $\begin{array}{c}0.040 \\
(0.045)\end{array}$ \\
\hline Female & $\begin{array}{l}-0.002 \\
(0.019)\end{array}$ & $\begin{array}{c}-0.100^{* * *} \\
(0.017)\end{array}$ & $\begin{array}{l}-0.055 \\
(0.029)\end{array}$ & $\begin{array}{c}-0.113^{* *} \\
(0.037)\end{array}$ & $\begin{array}{l}-0.043 \\
(0.060)\end{array}$ \\
\hline Private health insurance & $\begin{array}{c}0.070^{* *} \\
(0.025)\end{array}$ & $\begin{array}{l}-0.053^{*} \\
(0.021)\end{array}$ & $\begin{array}{l}-0.050 \\
(0.032)\end{array}$ & $\begin{array}{c}-0.008 \\
(0.044)\end{array}$ & $\begin{array}{l}-0.002 \\
(0.003)\end{array}$ \\
\hline Purchasing power index & $\begin{array}{c}0.000 \\
(0.001)\end{array}$ & $\begin{array}{c}-0.002^{*} \\
(0.001)\end{array}$ & $\begin{array}{l}-0.003^{*} \\
(0.002)\end{array}$ & $\begin{array}{l}-0.002 \\
(0.002)\end{array}$ & $\begin{array}{l}-0.063 \\
(0.046)\end{array}$ \\
\hline Log distance & $\begin{array}{c}0.004 \\
(0.006)\end{array}$ & $\begin{array}{c}0.002 \\
(0.004)\end{array}$ & $\begin{array}{c}0.026^{* * *} \\
(0.007)\end{array}$ & $\begin{array}{l}-0.007 \\
(0.008)\end{array}$ & $\begin{array}{c}-0.029^{* *} \\
(0.011)\end{array}$ \\
\hline Faculties included & yes & yes & no & no & no \\
\hline Cohorts included & yes & yes & no & no & no \\
\hline Observations & 34214 & 53323 & 12846 & 8257 & 10104 \\
\hline No. of subjects & 9167 & 9167 & 2305 & 1345 & 1669 \\
\hline No. failed & 4522 & 2388 & 669 & 366 & 396 \\
\hline No. competing & 2338 & 4522 & 858 & 565 & 1006 \\
\hline No. censored & 2307 & 2307 & 778 & 414 & 267 \\
\hline Log Pseudolikelihood & -37746.136 & -20482.377 & -4885.1514 & -2527.5104 & -2798.5972 \\
\hline
\end{tabular}

Coefficients; standard errors in parentheses; clustered by counties; TVC interacted with t; faculty is the last faculty the student is enrolled at; ${ }^{*} p<0.05,{ }^{* *} p<0.01,{ }^{* * *} p<0.001$. 


\section{B Appendix II: Data Processing ${ }^{32}$}

The sample contains students who obtained a German high school leaving certificate only. Furthermore, students with the worst possible high school grade 4.0 are excluded, as it is often used as a placehoder when the grade is not important for the admission process. Students who died are removed from the sample. Moreover, I leave out students with missing data or for whom I observe pure data errors, such as a high school leaving grade that is not within the possible interval.

In the analysis, the purchasing power of the parental zip-code area is used to control for the students' socio-economic background. This is possible as students have to provide information about their home and semester address when enrolling at university. Thereby, the home address usually corresponds to the parents' address and the semester address to the place the students live by themselves. Since most students move to Göttingen when starting university, the two zip-codes should differ. However, for some students in the sample, the zip-codes of the home and the semester address are identical. If the zip-codes are identical and from a place outside of Göttingen, it is very likely that the student is still living with her parents. However, if the zip-codes are identical and from Göttingen, it may be that the stated home address does not correspond to the parents' address. Therefore, I take the administrative district the student went to school in into account. When she obtained her high school leaving certificate at a school outside of Göttingen, it is likely that the provided home address does not correspond to the parental address. These students are excluded from the sample.

Moreover, the analysis controls for the linear distance between the student's home town and Göttingen. The distance is obtained by using geographic coordinates for the different zip codes that are provided by geonames.org. The distance is calculated by first converting the coordinates from grades to radians (multiplication with $\left.\frac{\pi}{180}\right)$. Afterwards the following formula is used to calculate the linear distance: $\arccos (\sin ($ latitude_home $) * \sin ($ latitude_Goe $)+\cos ($ latitude_home $) *$

\footnotetext{
${ }^{32}$ Due to overlap in the data processing procedure, part of this appendix borrows heavily from Chapter 3.B and the appendix of Danilowicz-Gösele et al. (2014).
} 
$\cos ($ latitude_Goe $) * \cos ($ longitude_Goe - longitude_home $)) * 6367.4445$. In the case where different towns or villages have the same zip code, the mean distance is used in the analysis. To calculate the logarithm one is added to the distance so that the distance for a student coming from Göttingen is zero. 


\section{Chapter 6}

\section{Conclusion}

When politics aim at achieving educational objectives, such as the Horizon 2020 headline target of increasing higher education attainment, it is often taken as given that more input leads to more output. Thereby, input may be a higher rate of first-year students or additional classes, and output a higher share of graduates or better grades. However, little attention is paid to the actual determinants of academic performance. Therefore, this thesis identifies and analyzes individual and institutional factors that influence student performance in higher education, and evaluates the impact of organizational features.

The thesis, and in particular the results presented in Chapter 2, underline that the high school leaving grade is the best predictor for university success while the students' socio-economic background is of less importance. However, Chapter 2 also shows that the impact of the high school leaving grade differs substantially between fields of study.

These results are particularly interesting in the context of the Horizon 2020 strategy where an increase in the number of first-year students is seen as an instrument to boost graduation rates. The thesis' finding suggests that this may not be a winning strategy by implication. The strong link between the high school GPA and students' success at university rather underlines the importance of skills obtained in high school. Especially at some faculties, for example mathematics and physics, graduation appears to be very difficult for students who start from a weaker academic base as measured by the high school leaving 
grade. Consequently, one may either consider reducing academic standards at some faculties or think about special guidance and support for students with low academic ability in order to still increase tertiary education attainment.

The question of how institutional factors influence academic performance is further addressed in Chapter 3. It is shown that simply providing more teaching or reducing class size may not automatically result in better grades. In particular, when students adopt a rather passive role in class and when the learning material is available to everyone irrespective of class attendance, going to class and studying on one's own may be substitutes. Hence, the results do not imply that lectures or tutorials have no impact on student performance per se, but rather suggest that the actual course design matters.

Additionally, Chapters 4 and 5 show that organizational features of study programs influence student behavior and performance. In this context, the results on study-related visits abroad allow the conclusion that more flexibility concerning the decision of how many courses to take and which of these courses to count towards the degree may, on the one hand, lead to better final university grades. On the other hand, this advantage appears to come at the cost of prolonged studies.

The importance of the study organization for academic performance is further supported by the results in Chapter 5 . It is shown that restructuring degree programs in the course of the Bologna process had a positive impact on the duration until graduation. Furthermore, the reform had a favorable effect on the probability of dropping out of university for students enrolled at the faculty of humanities. For the other faculties, however, the effect is insignificant or inconclusive. Both results can be explained by the restructuring of examination and study regulations which induced a more scholastic study organization. Thereby, the result is in line with the findings in Chapter 4 which suggest that more flexibility within study programs leads to prolonged studies. Hence, if policymakers want to maintain the positive effect of the Bologna process on the duration until graduation, they should abstain from increasing the degree of flexibility within bachelor programs.

In conclusion, the thesis shows that student performance at university is determined by a variety of factors. In particular, two main results become apparent: 
firstly, it rather seems to be differences in academic ability than heterogeneity with regard to the students' socio-economic background that imposes challenges to the university system. Therefore, higher education policy and research should take a closer look at students who start from a weaker academic base. In particular, the evaluation of special guidance and support programs seem to be an interesting topic for future research. Additionally, the strong link between the high school leaving grade and academic performance emphasizes the importance of school education in the context of students' success at university. In line with the proverb "you can't teach an old dog new tricks", the aim of increasing tertiary education attainment while maintaining consistent academic quality seems largely to depend on students possessing the necessary basic skills.

Secondly, the thesis underlines the importance of institutional and organizational features for academic performance. Therefore, research on special institutional settings or organizational reforms, for example the use of digital media in teaching or changes in study regulations, is needed to draw a clearer picture of the factors that affect academic performance and to give targeted policy advice. In this context, the implementation of a quality management system at university, as proposed by the German federal government and the state governments in the course of the qualification initiative, seems to be a promising approach (Die Bundesregierung und die Regierungschefs der Länder, 2008). 


\section{Bibliography}

Aakvik, A., 2001. Bounding a matching estimator: The case of a Norwegian training program. Oxford Bulletin of Economics and Statistics 63 (1), 115143.

Achen, A. C., Courant, P. N., 2009. What are grades made of? The Journal of Economic Perspectives: A Journal of the American Economic Association $23(3), 77-92$.

Altonji, J. G., Elder, T. E., Taber, C. R., 2005. Selection on observed and unobserved variables: Assessing the effectiveness of catholic schools. Journal of Political Economy 113 (1), 151-184.

Anger, C., Demary, V., Koppel, O., Pluennecke, A., May 9 2013. Zu wenig Nachwuchs. https://www.iwd.de/artikel/zu-wenig-nachwuchs-111260/, accessed September 17, 2014.

Arias Ortiz, E., Dehon, C., 2008. What are the factors of success at university? A case study in Belgium. CESifo Economic Studies 54 (2), 121-148.

Arulampalam, W., Naylor, R. A., Smith, J., 2012. Am i missing something? The effects of absence from class on student performance. Economics of Education Review 31 (4), 363-375.

Arulampalam, W., Naylor, R. A., Smith, J. P., 2005. Effects of in-class variation and student rank on the probability of withdrawal: Cross-section and timeseries analysis for UK university students. Economics of Education Review $24(3), 251-262$. 
Autorengruppe Bildungsberichterstattung, 2012. Bildung in Deutschland 2012. Eine indikatorengestützter Bericht mit einer Analyse zur kulturellen Bildung im Lebenslauf. W. Bertelsmannverlag GmbH \& Co. KG, Bielefeld.

Autorengruppe Bildungsberichterstattung, 2014. Bildung in Deutschland 2014. Eine indikatorengestützter Bericht mit einer Analyse zur Bildung von Menschen mit Behinderungen. W. Bertelsmannverlag GmbH \& Co. KG, Bielefeld.

Baron-Boldt, J., 1989. Die Validität von Schulabschlussnoten für die Prognose von Ausbildungs- und Studienerfolg: Eine Metaanalyse nach dem Prinzip der Validitätsgeneralisierung. Vol. 280 of Europäische Hochschulschriften, Reihe 6, Psychologie. Lang, Frankfurt/M.

Becker, S. O., Caliendo, M., 2006. Mhbounds: Stata module to perform MantelHaenszel bounds to check sensivity of estimated average treatment effects on the treated, version 1.1.5.

Becker, S. O., Caliendo, M., 2007. Sensitivity analysis for average treatment effects. The Stata Journal 7 (1), 71-83.

Becker, S. O., Ichino, A., 2002. Estimation of average treatment effects based on propensity scores. The Stata Journal 2 (4), 358-377.

Beltz, P., Link, S., Ostermaier, A., 2011. Können Studienbeiträge die Lehre in der BWL verbessern? Eine empirische Analyse der Wirkungen studienbeitragsfinanzierter Tutorien. Zeitschrift für Betriebswirtschaft 81 (11), 1205-1223.

Betts, J. R., Morel, D., 1999. The determinants of undergraduate grade point average: The relative importance of family background, high school resources and peer group effects. Journal of Human Resources 24 (2), 268-293.

Bosio, G., Leonardi, M., 2011. The impact of Bologna process on the graduate market: Demand and supply. IZA Discussion Paper (5789), Bonn.

Bratti, M., Broccolini, C., Staffolani, S., 2010. Higher education reform, student time allocation and academic performance in Italy: Evidence from a faculty 
of economics. Rivista italiana degli economisti: The Journal of the Italian Economic Association 15 (2), 275-304.

Bratti, M., Staffolani, S., Broccolini, C., 2006. Is '3+2'equal to 4? University reform and student academic performance in Italy. Quaderni di Ricera (251), Ancona.

Burton, L. J., Dowling, D., 2005. In search of the key factors that influence student success at university. In: Proceeding at the 28th HERDSA International Conference: Higher Education in a Changing World. pp. 66-78.

Caliendo, M., Hujer, R., Thomsen, S., 2008. The employment effects of job creation schemes in Germany - A microeconometric evaluation. Modelling and Evaluating Treatment Effects in Econometrics 21, 381-428.

Caliendo, M., Kopeinig, S., 2008. Some practical guidance for the implementation of propensity score matching. Journal of Economic Surveys 22 (1), 31-72.

Cappellari, L., Lucifora, C., 2009. The "Bologna process" and college enrollment decisions. Labour Economics 16 (6), 638-647.

Cardoso, A. R., Portela, M., Sá, C., Alexandre, F., 2008. Demand for higher education programs: The impact of the Bologna process. CESifo Economic Studies 54 (2), 229-247.

Clarke, I., Wright, N. D., McMillen, R. M., 2009. Student intercultural proficiency from study abroad programs. Journal of Marketing Education 31 (2), $173-181$.

Cleves, M., Gould, W., Gutierrez, R. G., Marchenko, Y. V., 2010. An Introduction to Survival Analysis Using Stata, 3rd Edition. College Station, Texas.

Cohn, E., Cohn, S., Balch, D. C., Bradley, J., 2004. Determinants of undergraduate GPAs: SAT scores, high-school GPA and high-school rank. Economics of Education Review 23 (6), 577-586.

Cohn, E., Johnson, E., 2006. Class attendance and performance in principles of economics. Education Economics 14 (2), 211-233. 
Cyrenne, P., Chan, A., 2012. High school grades and university performance: A case study. Economics of Education Review 31 (5), 524-542.

DAAD, HIS, 2013. Wissenschaft Weltoffen 2013: Facts and figures on the international nature of studies and research in Germany. Bielefeld.

Danilowicz-Gösele, K., Meya, J., Schwager, R., Suntheim, K., 2014. Determinants of students success at university. Cege Discussion Papers (214), Göttingen.

Di Pietro, G., 2012a. The Bologna process and widening participation in university education: New evidence from Italy. Empirica 39 (3), 357-374.

Di Pietro, G., 2012b. Does studying abroad cause international labor mobility? Evidence from Italy. Economic Letters 117 (3), 232-635.

Di Pietro, G., 2015. Do study abroad programs enhance the employability of graduates? Education, Finance and Policy 10 (2), 223-243.

Di Pietro, G., Cutillo, A., 2008. Degree flexibility and university drop-out: The Italian experience. Economics of Education Review 27 (5), 546-555.

Die Bundesregierung und die Regierungschefs der Länder, 2008. Aufstieg durch Bildung. Die Qualifizierungsinitiative für Deutschland. Dresden.

DiPrete, T. A., Gangl, M., 2004. Assessing bias in the estimation of causal effects: Rosenbaum bounds on matching estimators and instrumental variables estimation with imperfect instruments. Sociological Methodology 34 (1), 271310 .

Dobkin, C., Gil, R., Marion, J., 2010. Skipping class in college and exam performance: Evidence from a regression discontinuity classroom experiment. Economics of Education Review 29 (4), 566-575.

Dobson, I. R., Skuja, E., 2005. Secondary schooling, tertiary entry ranks and university performance. People and Place 13 (1), 53-62. 
Dreher, A., Poutvaara, P., 2011. Foreign students and migration to the United States. World Development 39 (8), 1294-1307.

Durden, G. C., Ellis, L. V., 1995. The effects of attendance on student learning in principles of economics. The American Economic Review Papers and Proceedings 85 (2), 343-346.

European Commission, 2011. Supporting growth and jobs - An agenda for the modernisation of Europe's higher education system. Publication Office of the European Union, Luxembourg.

European Ministers of Education, 1999. The Bologna declaration of 19 June 1999. Joint declaration of the European Ministers of Education. European Union, Brussels.

Fine, J. P., Gray, R. J., 1999. A proportional hazards model for the subdistribution of a competing risk. Journal of the American Statistical Association 94 (446), 496-509.

Finkenstädt, V., Keßler, T., 2012. Die sozioökonomische Struktur der PKVVersicherten-Ergebnisse der Einkommens- und Verbrauchsstichprobe 2008. WIP Discussion Paper (3), Köln.

Gangl, M., 2004. Rbounds: Stata module to perform Rosenbaum sensitivity analysis for average treatment effects on the treated, version 1.1.6. https: //ideas.repec.org/c/boc/bocode/s438301.html.

General Secretariat of the Council, 2010. European Council, 17 June 2010, Conclusions. Brussels.

Gerdes, H., Mallinckrodt, B., 1994. Emotional, social, and academic adjustment of college students: A longitudinal study of retention. Journal of Counseling \& Development 72 (3), 281-288.

Girves, J. E., Wemmerus, V., 1988. Developing models of graduate student degree progress. The Journal of Higher Education 59 (2), 163-189. 
Grebennikov, L., Skaines, I., 2009. University of Western Sydney students at risk: Profile and opportunities for change. Journal of Institutional Research 14 (1), 58-70.

Heckman, J. J., Ichimura, H., Todd, P., 1998. Matching as an econometric evaluation estimator. The Review of Economic Studies 65 (2), 261-294.

Heublein, U., Hutzsch, C., Schreiber, J., Dieter, S., Besuch, G., 2009. Ursachen des Studienabbruchs in Bachelor- und in herkömmlichen Studiengängen. Ergebnisse einer bundesweiten Befragung von Exmatrikulierten des Studienjahres 2007/08. HIS: Projektbericht, Hannover.

Hochschulrektorenkonferenz, 2011. Statistiken zur Hochschulpolitik 2/2011: Statistische Daten zu Bachelor- und Masterstudiengängen. Wintersemester 2011/2012. Bonn.

Hoffmann, A.-L., Lerche, K., 2016. Class attendance and university performance. Cege Discussion Papers (286), Göttingen.

Hong, S.-M., 1984. The age factor in the prediction of tertary academic success. Higher Education Research and Development 3 (1), 61-70.

Horstschräer, J., Sprietsma, M., 2015. The effects of the introduction of bachelor degrees on college enrollment and drop-out rates. Education Economics 23 (3), $296-317$.

Kaplan, E. L., Meier, P., 1958. Nonparametric estimation from incomplete observations. Journal of the American Statistical Association 53, 457-481.

Krass, S., Scherf, M., November 19 2012. Warum die Einser-Inflation nicht überrascht. http://www.sueddeutsche.de/bildung/gute-notenan-hochschulen-warum-die-einser-inflation-nicht-ueberrascht1.1526490, accessed July 14, 2014.

Krause, K.-L., Hartley, R., James, R., McInnis, C., 2005. The First Year Experience in Australian Universities: Findings From a Decade of National Studies. 
Centre for the Study of Higher Education, University of Melbourne, Melbourne.

Lerche, K., 2016. The effect of the Bologna process on the duration of studies. Cege Discussion Papers (287), Göttingen.

Leuven, E., Sianesi, B., 2003. Psmatch2: Stata module to perform full mahalanobis and propensity score matching, common support graphing, and covariate imbalance testing, version 4.0.4. http://ideas.repec.org/c/boc/ bocode/s432001.html.

Levy, S., Murray, J., 2005. Tertiary entrance scores need not determine academic success: An analysis of student performance in an equity and access program. Journal of Higher Education Policy and Management 27 (1), 129-141.

Marburger, D. R., 2001. Absenteeism and undergraduate exam performance. Journal of Economic Education 32 (2), 99-109.

Marburger, D. R., 2006. Does mandatory attendance improve student performance? Journal of Economic Education 37 (2), 248-255.

Martins, P. S., Walker, I., 2006. Student achievement and university classes: Effects of attendance, size, peers, and teachers. IZA Discussion Paper (2490), bonn.

McInnis, C., James, R., Hartley, R., 2000. Trends in the First Year Experience in Australian Universities. Department of Education, Training and Youth Affairs, Canberra.

McKenzie, K., Schweitzer, R., 2001. Who succeeds at university? Factors predicting academic performance in first year Australian university students. Higher Education Research and Development 20 (1), 21-33.

McNabb, R., Pal, S., Sloane, P., 2002. Gender differences in educational attainment: The case of university students in England and Wales. Economica 69 (275), 481-503. 
Messer, D., Wolter, S. C., 2007. Are student exchange programs worth it? Higher Education 54 (5), 647-663.

Meya, J., Suntheim, K., 2014. The second dividend of studying abroad - The impact of international student mobility on academic performance. Cege Discussion Papers (215), Göttingen.

Mühlenweg, A. M., 2010. Teaching, organization, and personal problems - Evidence from reforming tertiary education in Germany. ZEW Discussion Paper (10-040), Mannheim.

OECD, 2012. How many students study abroad and where do they go? OECD Publishing, http://dx.doi.org/10.1787/eag_highlights-2012-9-en.

OECD, 2013. Economic policy reforms 2013: Going for growth. OECD Publishing, http://dx.doi.org/10.1787/growth-2013-en.

Oosterbeek, H., Webbink, D., 2011. Does studying abroad induce a brain drain? Economica 78 (310), 347-366.

Parey, M., Waldinger, F., 2011. Studying abroad and the effect on international labour market mobility: Evidence from the introduction of ERASMUS. The Economic Journal 121, 194-222.

Parker, J. D., Summerfeldt, L. J., Hogan, M. J., Majeski, S. A., 2004. Emotional intelligence and academic success: Examining the transition from high school to university. Personality and Individual Differences 36 (1), 163-172.

Peat, M., Dalziel, J., Grant, A. M., 2001. Enhancing the first year student experience by facilitating the development of peer networks through a oneday workshop. Higher Education Research and Development 20 (2), 199-215.

Portela, M., Sá, C., Alexandre, F., Cardoso, A. R., 2009. Perceptions of the Bologna process: What do students' choices reveal? Higher Education 58 (5), $465-474$. 
Robbins, S. B., Lauver, K., Le, H., Davis, D., Langley, R., Carlstrom, A., 2004. Do psychosocial and study skill factors predict college outcomes? A metaanalysis. Psychological Bulletin 130 (2), 261-288.

Romer, D., 1993. Do students go to class? Should they? The Journal of Economic Perspectives 7 (3), 167-174.

Rosenbaum, P. R., 2002. Observational Studies. Springer, New York, NY.

Rosenbaum, P. R., Rubin, D. B., 1983. The central role of the propensity score in observational studies for causal effects. Biometrika 70 (1), 41-55.

Simpson, O., 2006. Predicting student success in open and distance learning. Open Learning: The Journal of Open and Distance Learning 21 (2), 125-138.

Smith, J., Naylor, R., 2005. Schooling effects on subsequent university performance: Evidence for the UK university population. Economics of Education Review 24 (5), 549-562.

Stanca, L., 2006. The effects of attendance on academic performance: Panel data evidence for introductory microeconomics. The Journal of Economic Education 37 (3), 251-266.

StataCorp LP, 2013. User's Guide. Release 13. Stata Press, College Station, Texas.

Statistisches Bundesamt, 2009. Bildungsstand der Bevölkerung: Ausgabe 2009.

Statistisches Bundesamt, 2016. Entwicklung der Studienanfäengerquote in Deutschland von 2000 bis 2015.

Teichler, U., 2011. International dimensions of higher education and graduate employment. In: Allen, J., van der Velden, R. (Eds.), The Flexible Professional in the Knowledge Society: New Challenges for Higher Education. Springer, Dordrech, pp. 188-220.

Tinto, V., 1975. Dropout from higher education: A theoretical synthesis of recent research. Review of Educational Research 45 (1), 89-125. 
Trapmann, S., Hell, B., Weigand, S., Schuler, H., 2007. Die Validität von Schulnoten zur Vorhersage des Studienerfolgs - Eine Metaanalyse. Zeitschrift für pädagogische Psychologie 21 (1), 11-27.

Wissenschaftsrat, 2000. Empfehlungen zur Einführung neuer Studienstrukturen und -abschlüsse (Bakkalaureus/Bachelor - Magister/Master) in Deutschland. Drs. 4418/00, Berlin.

Zimmermann, J., Neyer, F. J., 2013. Do we become a different person when hitting the road? Personality development of sojourners. Journal of Personality and Social Psychology 105 (3), 515-530. 